\begin{tabular}{|c|c|c|}
\hline $\begin{array}{l}\operatorname{UIV}_{12} 1936 \text { 21ENGINE } \\
\text { Jta., }\end{array}$ & DATA TRANSMITTAL & 1. EDT 158625 \\
\hline $\begin{array}{l}\text { 2. To: (Receiving Organization) } \\
\text { Distribution }\end{array}$ & $\begin{array}{l}\text { 3. From: (originating Organization) } \\
\text { Instrument Systems, } 74 F 40\end{array}$ & $\begin{array}{l}\text { 4. Related EDT No.: } \\
\text { NA }\end{array}$ \\
\hline $\begin{array}{l}\text { 5. Proj./Prog./Dept./Div.: } \\
\text { Safety Programs }\end{array}$ & $\begin{array}{l}\text { 6. Cog. Engr.: } \\
\text { CA ESVELT }\end{array}$ & $\begin{array}{l}\text { 7. Purchase Order No.: } \\
\text { NA }\end{array}$ \\
\hline \multirow{2}{*}{\multicolumn{2}{|c|}{$\begin{array}{l}\text { 8. Originator Remarks: } \\
\text { For approval and realease }\end{array}$}} & $\begin{array}{c}\text { 9. Equip./Component No.: } \\
\text { NA }\end{array}$ \\
\hline & & $\begin{array}{c}\text { 10. System/Bldg./Facility: } \\
200 \mathrm{G}\end{array}$ \\
\hline \multirow{3}{*}{\multicolumn{2}{|c|}{ 11. Receiver Remarks: }} & $\begin{array}{r}\text { 12. Major Assm. Dwg. No.: } \\
H-14-100457 \\
\end{array}$ \\
\hline & & $\begin{array}{l}\text { 13. Permit/Permit Application No.: } \\
\text { NA }\end{array}$ \\
\hline & & $\begin{array}{l}\text { 14. Required Response Date: } \\
6 / 5 / 96\end{array}$ \\
\hline
\end{tabular}

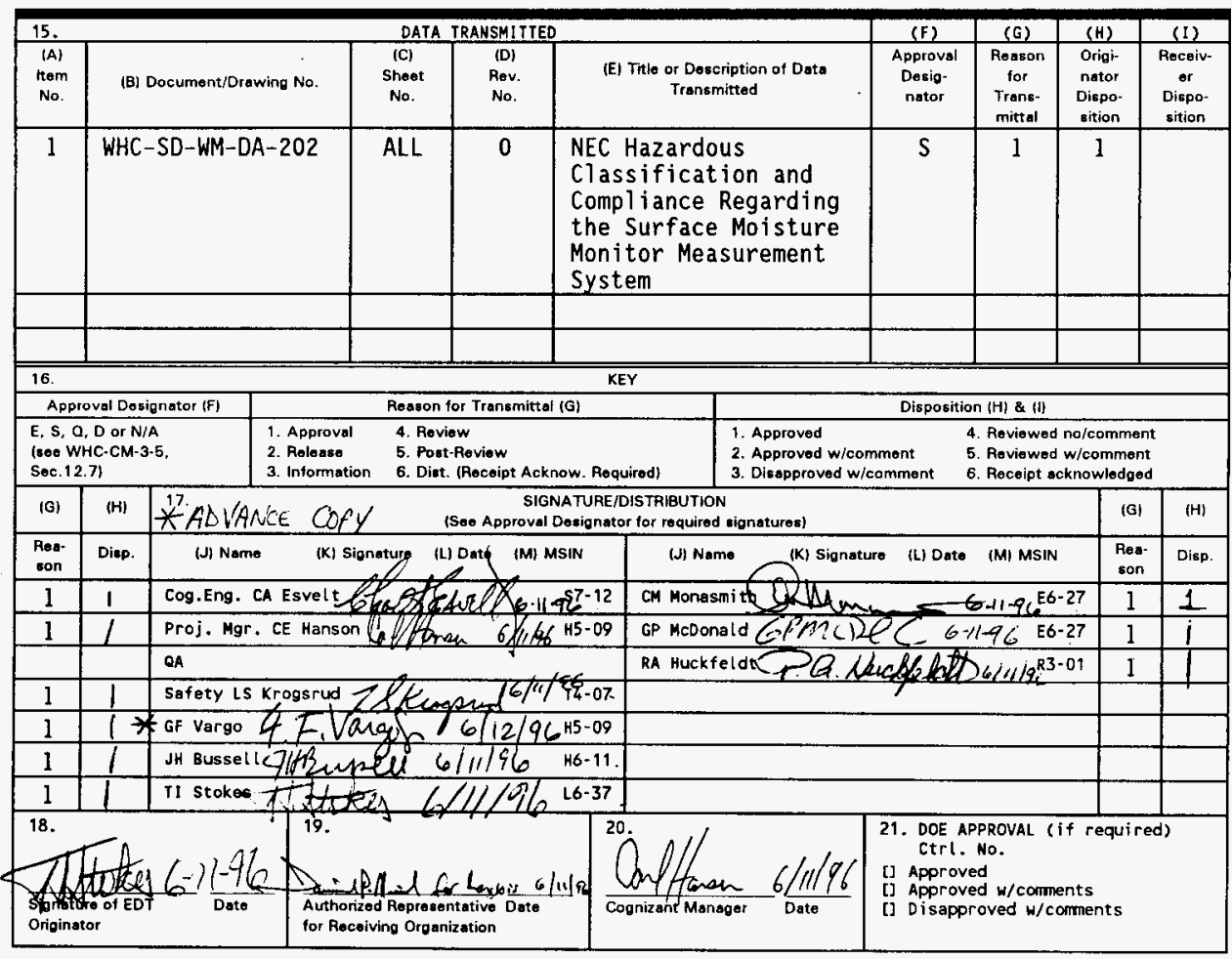

BD-7400-172-2 (04/94) GEF097 


\title{
NEC HAZARDOUS CLASSIFICATION AND COMPLIANCE REGARDING THE SURFACE MOISTURE MONITOR MEASUREMENT SYSTEM
}

\author{
JH Bussell \\ TI Stokes \\ Westinghouse Hanford Company, Richland, WA 99352 \\ U.S. Department of Energy Contract DE-AC06-87RL10930 \\ $\begin{array}{lll}\text { EDT/ECN: } & 158625 & \text { UC: } 2030 \\ \text { Org Code: } & 74 F 40 & \text { Charge Code: } \\ \text { B\&R Code: } & \text { EW3120074 } & \text { Total Pages: } 7.5 \\ & & \end{array}$
}

Key Words: NEC, classified location, intrinsically safe, explosion proof, surface moisture probe, neutron moisture probe, waste tank, SMMS, tank safety

Abstract: The National Electrical Code (NFPA 70) and National Fire Protection Association requirements for use of Surface Moisture Monitor Systems in classified locations are discussed. The design and configuration of the surface moisture monitor are analyzed with respect to how they comply with requirements of the National Electrical Code requirements, articles 500-504.

IRADEMARK DISCLAIMER. Reference herein to any specific conmercial product, process, or service by trade name, tradenark, manufacturer, or otherwise, does not necessarily constitute or imply its endorsement, recommendation, or favoring by the United states Government or any agency thereaf or its contractors or subcontractors.

Printed in the United States of America. To obtain copies of this document, contact: WHC/BCS Document Control Services, P.O. Box 1970, Mailstop H6-08, Richland WA 99352, Phone (509) 372-2420; Fax (509) 376-4989.
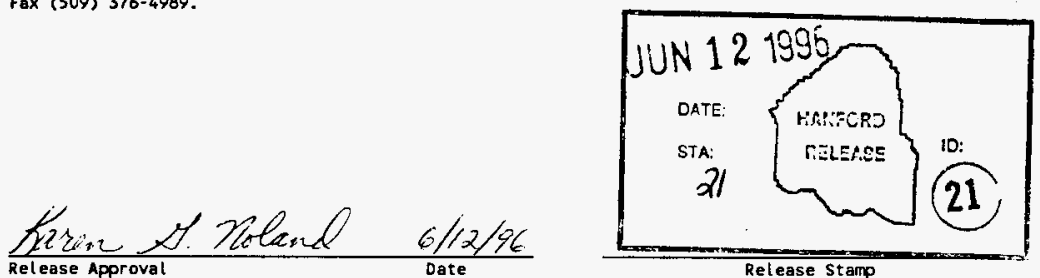

Approved for Public Release 


\section{NEC HAZARDOUS CLASSIFICATIONŞ AND COMPLIANCE REGARDING THE \\ SURFACE MOISTURE MEASUREMENT SYSTEM}

\section{AUTHOR LIST: \\ J.H. BUSSELL \\ T.I. STOKES}

Dated:

5/9/96 
TABLE OF CONTENTS

Page

1.0 Executive Summary 4

2.0 System Overview $\quad 4$

3.0 Hazardous Location Classification 6

4.0 Design Requirements $\quad 7$

4.1 General 7

5.0 Approval Process of Electrical Equipment 9

5.1 Equipment Enclosures

6.0 Hazardous Classification \& Equipment of the SMMS 10

6.1 Deployment Device Upper Enclosure(s) 10

6.2 Deployment Device Mast \&.Arm 10

6.3 Neutron Probe 11

6.4 Miscellaneous Equipment Adjacent to Deployment Device 11

7.0 Equipment Compliance with Hazard Classification 11

7.1 Deployment Device Upper Enclosure(s) 11

7.2 Deployment Device Mast \& Arm 12

7.3 Neutron Probe 12

7.4 Miscellaneous Equipment Adjacent to Deployment Device 12

8.0 References 13

Appendix A Bussell intrinsic safety circuit writeup, inclinometer and probe wiring, barriers regarding neutron probe power in \& zener diode network protected faulted power back from probe.

Appendix B Bussell catalog cut sheets and test reports submitted to $E T L$, explosion proof thing, rest of ETL package.

(Project Files)

Appendix C ETL findings report, Comparison of Probe Housing to UL-1203.

Appendix D SAIC and PNNL Explosion Pressure Calculations. D-1

Appendix E SMMS Structural Evaluations for Normal Operating and Handling Conditions. 


\author{
NEC National Electrical Code \\ NFPA National Fire Protection Association \\ EDT Engineering Data Transmittal \\ ETL Electrical Testing Laboratory \\ AHJ Authority Having Jurisdiction \\ NRTL Nationally Recognized Testing Laboratory \\ HECB Hanford Electrical Codes Board
}




\subsection{Executive Summary}

This document discusses the hazardous classification of the SMMS, and how the SMMS equipment complies with the National Electric Code (NEC) for the worst case hazardous location. Furthermore, the basic approval processes for equipment, in a hazardous location, is discussed.

Signature on this document's EDT indicates concurrence by the technical community and the Hanford Electrical Codes Board (HECB), the Hanford Site "Authority Having Jusidiction" (AHJ), that the SMMS equipment has been found to meet the intent of UL-1203. This system is therefore approved for use in any of Hanford's waste tanks, including those classified as Class I, Division 1, Group B Hazardous locations as defined by the National Fire Protection Association (NFPA).

\subsection{System Overview}

The Surface Moisture Monitor System (SMMS) is designed to measure the moisture in the near surface layers of tank waste. The depth of interrogation depends on the moisture level encountered. The probe must be placed on the surface of the waste to make these measurements. See the SMMS engineering work plan (WHC-SD-WM-WP-200 Rev. 1) for the background of this project.

The SMMS consists of a deployment device, a probe containing a neutron source, decontamination system, and a data acquisition van. Additionally, an overview camera system as required. However, this document does not address the overview camera system. Figure 1 shows the SMMS.

At the top of the deployment device, there is a single large enclosure, divided into two separate enclosed areas. One area contains the manual winches and is open to the tank atmosphere. The other area contains electrical equipment, such as the line driver electronics, intrinsic safety barriers, and the cable terminations and connectors for power and signal connection to the data acquisition van.

A crane picks up the deployment device and lowers it into the tank through a 4" or larger riser. Once the deployment device is seated to the riser, power is connected and the probe electronics are energized. The probe is manually lowered using a worm gear driven winch while simultaneously observing the lowering process via a separate in-tank camera located in an adjacent riser. The probe cable drives a distance encoder (via a rolling wheel on the probe cable) which is used to measure the amount of probe cable deployed. The probe is lowered to the waste surface and a count is obtained from each of the three detectors over a 3 to 6 minute period. The probe is then moved to a different test point location within the work space defined by the geometry of arm. 
WHC-SD-WM-DA-202 REV 0

Page 5 of 13

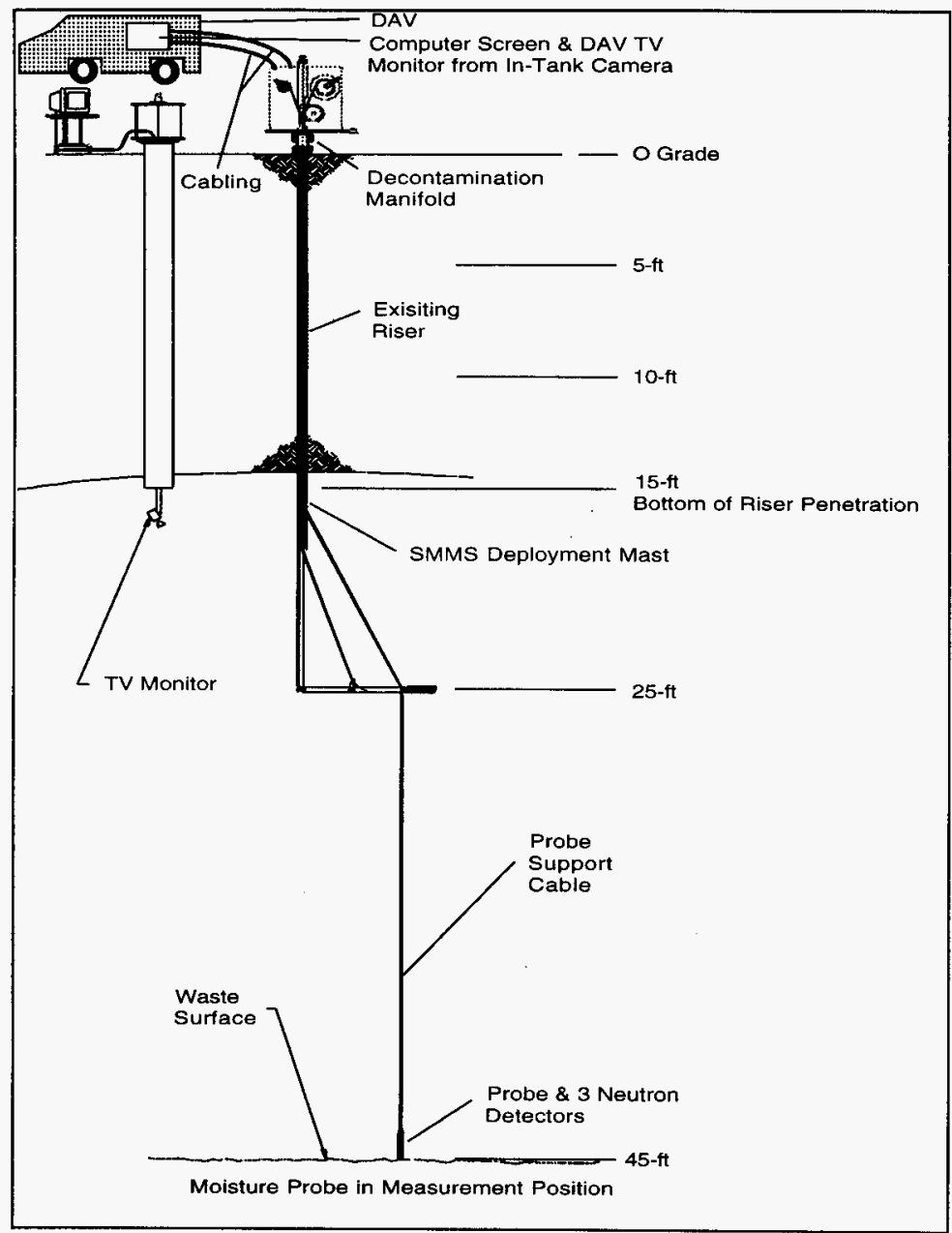

Figure 1 Surface Monitor System Deployed in Waste Tank 


\subsection{Hazardous Location Classification}

The typical classification for the interior of single shell tanks is Class I Division 2 Group B [Reference 1]. The tank classification for the interior SY-101 is Class I Division 2 Group B [Reference 2]. Table 2 lists the common flammable gasses that may be found in the waste tanks. These classification positions are highly disputed, and constantly challenged. Therefore, the SMMS has been designed to be operable in a Class I Division 1 Group B criteria to minimize project risk.

It is considered that the tank dome space or vapor space may have several different flammable gases present during unusual conditions. These gases are; nitrous oxide, ammonia, hydrogen, methane, and non-paraffinic hydrocarbons (kerosene-like or naphtha-like hydrocarbons). The group classification and auto-ignition temperatures per NFPA 497M for these gases is shown below in Table 2 .

The classification of gases may appear to be linked to an order of flammability or explosive pressures. This link should be considered to be coincidental only. The Group designations are based on factors that are unique to the gases in that group. Molecular size, ease of migration, weight relative to normal atmosphere, auto-ignition temperature and pressure expansion on ignition are only some of the factors that determine the grouping of a particular gas. Equipment used in an atmosphere of mixed gases, such as this, must be qualified for all the gases present e.g. equipment to be used in a an atmosphere containing both hydrogen and methane must be approved for Group B (hydrogen) and Group D (methane). A qualification to Group B does not include all Groups alphabetically past that Group, qualification of a group B gas only does not automatically qualify that equipment for a group $\mathrm{C}$ or $\mathrm{D}$ gas also.

\begin{tabular}{|c|c|c||}
\hline \multicolumn{3}{|c|}{$\begin{array}{c}\text { Table 2 } \\
\text { NFPA Group Classification for Common } \\
\text { Found in Waste Tanks }\end{array}$} \\
\hline Gas & NFPA Group & $\begin{array}{c}\text { Auto-ignition } \\
\text { Temperature }\end{array}$ \\
\hline Ammonia & D & $928^{\circ} \mathrm{F}$ \\
\hline Hydrogen & B & $968^{\circ} \mathrm{F}$ \\
\hline Methane & D & $999^{\circ} \mathrm{F}$ \\
\hline Naphtha (NPH) & D & $550^{\circ} \mathrm{F}$ \\
\hline
\end{tabular}




\subsection{Design Requirements and Equipment Description}

\subsection{General}

DOE Orders require electrical equipment to be Listed by a nationally recognized testing laboratory, e.g. Underwriters Laboratory, Factory Mutual, etc. The applications of Listed equipment must be within the parameters of the Listing. The application of Listed intrinsically safe equipment must also consider all associated equipment. Associated equipment is any other equipment or device connected to, or otherwise coupled to the same wiring. Specific apparatus and wiring requirements vary with the Class I and Division 1 or 2 classification for the location specified in the National Electrical Code (NEC) Articles 500 , 501 , and 504.

In the NEC there are two distinct areas in classified locations, Division 1 and Division 2. Division 1 is used for locations where there is a concentration of a flammable gas above the lower flammability limit (LFL) during normal operating conditions. This does not mean there is always flammable concentrations of gases present. In a probability of explosion analysis in Magison [Reference 3] the percentage of time when flammable concentration of gases is set at $10 \%$ for Division 1 classified locations. Division 2 is used when the location has a possibility of flammable gases in concentrations above LFL only in abnormal conditions. In the probability of explosion analysis previously cited, $0.01 \%$ of the time there is a flammable gas concentration above LFL in Division 2 classified locations. The same risk analysis establishes that in non-classified locations $1 \times 10^{-11 \%}$ of the time there is flammable gas concentration above the LFL. The preceding information is provided to give a qualitative meaning between the differences of Division 1 and Division 2 classified locations and the reason for more stringent requirements in Division 1 classified locations as compared to Division 2 classified locations.

\subsubsection{Methods}

The NEC provides for three alternative methods to prevent fire or explosions from electrical equipment operating in a classified hazardous locations. These methods are (simplified interpretations):

\subsubsection{Intrinsically Safe Apparatus}

Intrinsically safe apparatus: the electrical equipment/device does not store and can not provide sufficient energy to ignite a flammable mixture. Intrinsically safe equipment is approved for the flammable vapor group (A to D) and for area classification (Class I Division 1 or Class I Division 2). An intrinsically safe system for a vapor group (such as B), can also be considered intrinsically safe for lesser gas groups $\mathrm{C}$ and D. Figure 2 shows a fault tree illustrating the number of faults of an intrinsically safe apparatus to ignite a flammable mixture. This figure is provided for illustrative purposes and is not meant to convey or represent an accident probability. 


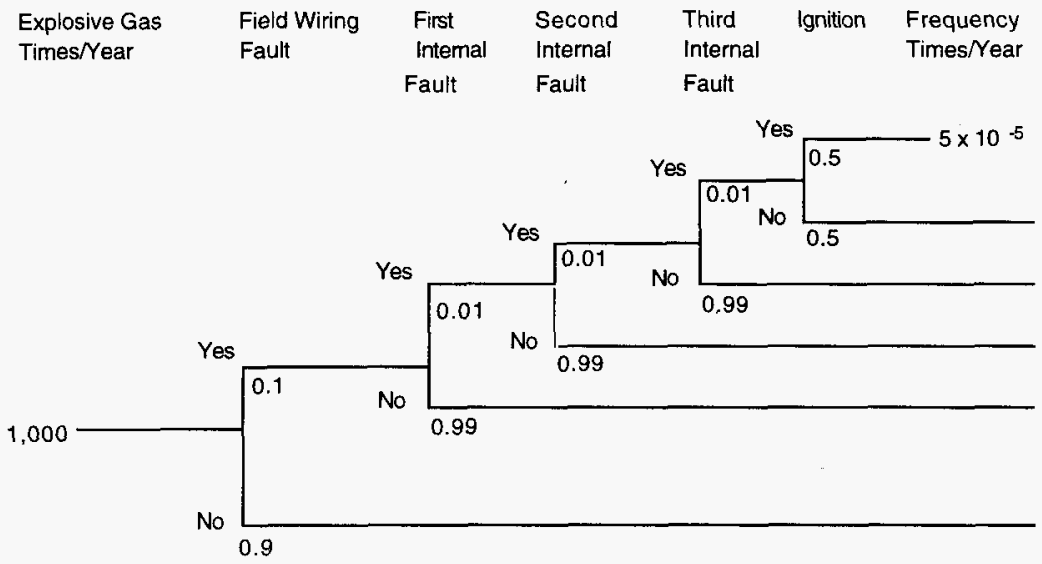

Figure 2. Simple fault tree illustrating faults required for intrinsically safe apparatus to ignite flammable vapor. [Bossert, 1994]

\subsubsection{Purging}

Purging and pressurizing of electrical enclosures: reducing either the fuel or the oxidizer, or both, to a noncombustible level and providing power cutoff switches to the equipment if purge and pressurization control is lost. Three different purging methods are recognized by the NEC, type $X, Y$, and $Z$ the requirements for these purging and pressurizing methods and the appropriate Class and Division for X, Y and Z applications are described in NFPA 496.

\subsubsection{Explosion Proof}

Explosion proof enclosures and wiring methods: housing the electrical device within a qualified enclosure which is capable of containing explosions due to arcing or other possible ignition sources within the enclosure. Combustion gases will not escape from the enclosure with sufficient temperature to ignite combustible gas mixtures that may be present outside of the enciosure. The requirements for explosion proof housing are described in UL-1203.

Enclosures are Listed for Class I Division 1 locations only. Enclosures are not Listed for Class I Division 2 locations. Electrical devices used in a Class I Division 2 location may not produce either sparks or high heat as required by NEC Article 501-3(b)(1). Note that if "arcing/sparking" components must be used in a Class I, Division 2 location, that equipment must be housed in an 
explosion proof housing approved for Class I, Division 1 locations.

\subsection{Approval Process of Electrical Equipment}

The NEC code is typically adopted by a jurisdiction (state, city, county, DOE, etc) and is used to provide binding regulations. Equipment can be considered suitable for use in a hazardous location if it has been listed for that service by a Nationally Recognized Testing Laboratory (NRTL), or if the "Authority Having Jurisdiction" (AHJ) approves its use.

The DOE is the Authority Having Jurisdiction, since it is the DOE that is the governmental body requiring application of the NEC to its electrical installations. DOE-RL has chosen to allow the Hanford Electrical Codes Board (HECB) to provide the approval as required by the NEC. The HECB can only provide permission to use systems or equipment that are code compliant as per their judgement. Use of systems that are prohibited by the NEC can only be granted by DOE-RL.

An NRTL may provide a Listing of equipment that has met the applicable national standard as interpreted by the NRTL for use in a specific area. [For example, an "FM" label on an intrinsic safety barrier having received Factory Mutual approval.] Often the AHJ will accept the Listing of equipment as its approval without further investigation of the equipment.

\subsection{Equipment Enclosures}

Approval by the AHJ of custom built equipment for use in a specific location can be accomplished in several ways. It is considered for this discussion that custom built enclosure equipment is not Listed by a NRTL.

\subsubsection{Approval by NRTL Testing}

AHJ can require an enclosure be tested by a NRTL to prove that it is indeed capable of containing an explosion from within. This involves a destructive test of a sample of the enclosure to be evaluated. The enclosure is filled with the particular gas for the atmosphere requested. i.e. If an enclosure is seeking to be rated for Group B a Group B gas must be used. The enclosure also will contain a spark producing (ignition source) device. The gas filled enclosure will is placed in a Westerbeke Chamber which is also filled with the test gas. A Westerbeke Chamber is a special test chamber that will withstand the explosive pressures that can potentially be involved if the test item fails. When the enclosures internal spark device ignites the gases inside, it must not ignite the same gas mixture inside the Westerbeke Chamber.

This test usually destroys the integrity of the enclosure being tested. The test must be repeated for each Group of gases for which Listing is sought. 


\subsubsection{Approval by AHJ}

AHJ can evaluate the enclosure using the expertise it has available within its own jurisdiction and issue a document approving the specific enclosure for a specific application. The AHJ must have the expertise within its own ranks sufficient to evaluate and qualify a design. The AHJ has evaluated the SMMS neutron probe enclosure against the UL-1203 standard.

\subsection{Design Hazardous Classification \& Equipment of the SMMS}

\subsection{Deployment Device Upper Enclosure(s)}

The enclosures were NEMA 4X rated prior to modification and installation on the top of the deployment device.

\subsubsection{Winch Enclosure}

The winch box space is considered a Class I, Division 1, Group B classified area, because the winch box is open to the waste tank which is also considered a Class I, Division 1, Group B classified area.

\subsubsection{Electrical Enclosure}

This box is considered a non-classified location. Although this box is immediately adjacent to the winch box, it is separated by a sealed metal barrier from the winch box. There are approximately 3 mechanical shafts and one electrical connector running from the winch box into the electrical enclosure box. All the mechanical shafts employ a double lipped seal, [similar to a wheel seal on a car axle] to externally seal leakage paths around the shaft. Two of the shafts are hollow, and serve as conduit passages for wiring. This hollowed area has been potted and sealed with ScotchCast Resin \#8. The electrical connector uses a glass metal seal around the pins, and uses an external bulkhead type O-ring seal, so leakage through the connector is very minimal. In short, plausible leak paths from the winch box to the electrical enlosure box have engineered barriers to greatly minimize, if not entirely prevent, in leakage of gasses from the winch box space.

It should be noted that the winch box will never be at a higher pressure than the electrical box on ventilated tanks. On non-ventilated tanks, the winch box may, at most, be 0.1 inch of water higher pressure higher than the electrical enclosure. The acceptance test of the equipment required pressure and vacuum testing of the winch box and electrical enclosure box to confirm the seal integrity of the boxes.

If the device is left in a tank for extended time periods, it is suggested that the electrical and winch enclosures be checked for presence of combustible gasses prior to energization of electrical equipment.

\subsection{Deployment Device Mast \& Arm}


All areas within and without the deployment mast and arm (the portion in the tank vapor space) are considered a Class I, Division 1, Group B classified area.

\subsection{Neutron Probe}

The area surrounding the neutron probe is considered a Class I, Division 1, Group B location.

\subsection{Miscellaneous Equipment Adjacent to Deployment Device}

This space is considered a non-classified location, once the deployment device is fully installed and the riser bolts have been torqued. Although this space is immediately adjacent to the winch box, it is separated by the sealed NEMA $4 X$ winch box, sealed riser gaskets, and sealed decontamination equipment. Plausible leak paths from the tank space (riser, winch box, etc.) have engineered barriers to greatly minimize, if not entirely prevent, outward leakage of gasses.

It should be noted that the tank space will never be at a higher pressure than the atmospheric pressure on ventilated tanks. On non-ventilated tanks, the winch box pressure will fluctuate with changes in barometric pressure. Depending on the dynamics of barometric pressure swing, the winch box pressure may reach a higher pressure than the non-classified space surrounding the winch box. As noted above, the acceptance test of the equipment requires pressure and vacuum testing of the winch box to confirm the external seal integrity.

\subsection{Equipment Compliance with Hazard Classification}

\subsection{Deployment Device Upper Enclosure(s)}

\subsubsection{Winch Enclosure}

There are no electrical components besides cabling that passes through this space. All electrical cabling passing through this space is intrinsically safe. There had been a camera winch and associated wiring in this space as well, however the winch and cabling have been permanently removed. See Appendix A for confirmation of circuit intrinsic safety. (BUSSELL, TBD Action)

\subsubsection{Electrical Enclosure}

This box is considered a non-classified location. This box contains intrinsic safety barriers for the neutron probe and inclinometer. None of the electrical equipment in this box must comply with requirements of any classified location.

For information only, this box also contains a line driver board, electronic compass, circulation fan motor, and an open frame thermostat. Also, the box contains the thermostat switch and an abundance of wiring and terminal strips. 
However, if the device is left in a tank for extended time periods, it is suggested that the electrical enclosure be checked for presence of combustible gasses prior to energization of electrical equipment.

\subsection{Deployment Device Mast \& Arm}

There are no electrical components besides an inclinometer, inclinometer cabling, and neutron probe cabling that pass through this space. All electrical cabling passing through this space is intrinsically safe, again see Appendix A.

The inclinometer is a simple apparatus, containing a wire wound pot immersed in a silicon oil bath.

\subsection{Neutron Probe}

This device could not be made intrinsically safe, as it contains a high voltage neutron detector bias power supply (650 VDC -- current limited to less than 1 milliamp). However, the cabling to and from the neutron probe has been made intrinsically safe (meeting the intent of NEC Article 504). The intrinsic safety was obtained by placing FM approved intrinsic safety barriers on the probe inlet power wires, and also providing a custom isolation network within the probe itself to prevent backfed power in the event of a fault. See Appendix A for a more detailed discussion.

Therefore, the neutron probe system was encased in an explosion proof housing. The housing was not destructively tested, rather the design was extensively critiqued against UL-1203. The results of this critique is contained in Appendix $\mathrm{C}$.

The neutron probe case (and connector) has been determined to meet the intent of UL-1203, based upon the evidence from Appendix C. The neutron probe case and connector are adequately designed as an explosion proof housing.

\subsection{Miscellaneous Equipment Adjacent to Deployment Device}

This space is considered a non-classified location, once the deployment device is fully installed and the riser bolts have been torqued. Electrical equipment in the immediate vicinity of a riser should not be energized until tank containment is reestablished/sealed.

For reference, SMMS equipment required in this space will include a headset intercom, and a video monitor. 


\subsection{References}

1. SST Hazardous Classification document, Huckfeldt

2. SY-101 Haz. Class.Doc., Huckfeldt

3. Magison, Ernest C., "Electrical Instruments in Hazardous Locations," 3rd Edition, Instrument Society of America.

4. Engineering Work Plan for Surface Moisture Measurement (WHC-SD-WM-WP-300 Rev. 0)

5. Bossert, John A., "Hazardous Locations Guide for Design, Testing, Construction, and Installation of Equipment in Explosive Atmospheres," 1995, Canadian Standards Association.

6. ANSI/NFPA 70, "National Electrical Code - 1993"

7. ANSI/ISA-RP12.6-1987, "Installation of Intrinsically Safe Systems for Hazardous (Classified) Locations."

8. Class Number 3610, "Approval Standard - Intrinsically Safe Apparatus and Associated Apparatus for Use in Class I, II, and III, Division 1 Hazardous (Classified) Locations", October 1988

9. ANSI/UL 1203-1988, "Standard for Explosion-Proof and Dust-Ignition-Proof Electrical Equipment for use in Hazardous (Classified) Locations."

10. SMMS Drawing Tree - H-14-100457

Appendix A: Bussell intrinsic safety circuit write up, inclinometer and probe wiring. barriers regarding neutron probe power in \& zener diode network protected faulted power back from probe.

Appendix B: Bussell catalog cut sheets and test reports submitted to ETL, explosion proof thing, rest of ETL package

Appendix C: Study of Probe housing compliance to UL-1203

Appendix D: SAIC and PNL Explosion Pressure Calculations

Appendix E: SMMS Structural Evaluations for Normal Operating and Handling Conditions 


\section{A.1 Introduction}

Figure Al shows a block diagram of the SMMS and the demarcation between intrinsically safe portion of the system and the non-intrinsically safe portion of the system. The SMMS has two electrical components in a tank, the probe assembly and the inclinometer. The probe will be discussed below in detail. The inclinometer is a wire wound potentiometer and is immersed in silicon oil for dynamic response purposes. Therefore the inclinometer is a simple apparatus and is intrinsically safe with the appropriately chosen intrinsic safety barrier.

Intrinsic safety parameters were selected for the SMMS on the basis of their entity safety parameters. Entity safety parameters are those parameters that define the maximum open circuit voltage, maximum short circuit current, maximum allowed capacitance, and maximum allowed inductance in the intrinsically safe apparatus, e.g. the inclinometer. Manufacturers seek approval for their intrinsic safety barriers using entity approval concept. Listing by entity paramaters allows interchangibility between manufacturers and permits intrinsically safe system to be easily qualified by verifying the correct relationship between entity safety parameters of a intrinsically safe apparatus and a intrinsic safety barrier. Figure A2 the relationship between entity safety parameters between the intrinsically safe apparatus, e.g. inclinometer, and the associated apparatus, i.e. intrinsic safety barrier and attached instrumentaion. Tables Al to A3 shows the figure safety parameters of the intrinsic safety barriers.

\section{A.2 Inclinometer}

The inclinometer is pendulum based inclinometer with potentiometer output. The potentiometer is a wire wound potentiometer and has a inductance of 75 to 80 microhenries (see attached inductance calculations). The inductance of wire wound is insignificant to inductance limits in the entity parameters of its intrinsic safety barrier, 47 millihenries. A piece of modified 0.187 diameter stainless steel well logging cable is used to connect the inclinometer to Elcon Instruments, Inc. model 1072 intrinsic safety barrier. [The outer cable jacket was removed to make 0.187 diameter stainless steel cable more flexible.] The stainless steel wrapped well logging cable was selected because of its abrasion resistance. A sealed jam-nut type bulkhead fitting is used to pass the cable through the bulkhead from the mechanical side of the enclosure to the electrical side of the enclosure.

\section{A.3 SMMS Neutron Probe}

The SMMS neutron probe consists of a probe housing containing four printed circuit boards and three boron-10 neutron detector tubes. Each of the four electronic boards are 2.875 inches in diameter and are described below in order as they are located the probe, bottom to top. The voltage supplied to the probe is provided through two intrinsically safe circuits. One intrinsically safe circuit provides $14 \mathrm{~mA}$ of current at $16 \mathrm{~V}$ for the high voltage power supply. The other intrinsically safe circuit provides $31 \mathrm{~mA}$ of current at $15 \mathrm{~V}$ for the probe amplifier power supplies. 


\begin{tabular}{|c|c|c|c|c|c|c|c|c|c|c|c|}
\hline \multicolumn{12}{|c|}{$\begin{array}{l}\text { Table Al } \\
\text { Entity Safety Parameters for Intrinsic Safety Barriers for Neutron Probe Power Supply } \\
\text { (High Voltage and Low Voltage) } \\
\text { Stahl 9351/10-14-10 }\end{array}$} \\
\hline $\begin{array}{c}\mathrm{V}_{\mathrm{oc}} \\
\text { Maxi- } \\
\text { mum } \\
\text { Open } \\
\text { Circuit } \\
\text { Voltage } \\
\text { from IS } \\
\text { Barrier } \\
\text { (V) }\end{array}$ & $\begin{array}{c}\mathrm{V}_{\max } \\
\text { Intrin- } \\
\text { sically } \\
\text { Safe } \\
\text { Appara- } \\
\text { tus } \\
\text { Maxi- } \\
\text { mum } \\
\text { Al- } \\
\text { lowed } \\
\text { Voltage } \\
\text { (V) }\end{array}$ & $\begin{array}{c}\mathbf{I}_{\mathrm{sc}} \\
\text { Maxi- } \\
\text { mum } \\
\text { Short } \\
\text { Circuit } \\
\text { from IS } \\
\text { Barrier } \\
\text { (mA) }\end{array}$ & $\begin{array}{c}\mathrm{I}_{\max } \\
\text { Intrin- } \\
\text { sically } \\
\text { Safe } \\
\text { Appara- } \\
\text { tus } \\
\text { Maxi- } \\
\text { mum } \\
\text { Al- } \\
\text { lowed } \\
\text { Current } \\
\text { (mA) }\end{array}$ & $\begin{array}{c}\mathrm{C}_{\mathrm{a}} \mathrm{IS} \\
\text { Barrier } \\
\text { Maxi- } \\
\text { mum } \\
\text { AI- } \\
\text { lowed } \\
\text { Circuit } \\
\text { Capaci- } \\
\text { tance } \\
(\mu \mathrm{F})\end{array}$ & $\begin{array}{l}\text { Cital } \\
\text { Circuit } \\
\text { Total } \\
\text { Capaci- } \\
\text { tance } \\
(\mu \mathrm{F})\end{array}$ & $\begin{array}{c}\mathrm{C}_{\text {cable }} \\
\text { Cable } \\
\text { Capaci- } \\
\text { tance } \\
(100 \mathrm{ft} \\
\times 60 \\
\mathrm{pF} / \mathrm{ft}) \\
(\mu \mathrm{F})\end{array}$ & $\begin{array}{c}\mathrm{C}_{\mathrm{i}} \\
\text { Intrin- } \\
\text { sically } \\
\text { Safe } \\
\text { Appara- } \\
\text { tus } \\
\text { Capaci- } \\
\text { tance } \\
(\mu \mathrm{F})\end{array}$ & $\begin{array}{c}\mathrm{L}_{\mathrm{a}} \mathrm{IS} \\
\text { Barrier } \\
\text { Maxi- } \\
\text { mum } \\
\text { Al- } \\
\text { lowed } \\
\text { Circuit } \\
\text { Induc- } \\
\text { tance } \\
\text { (mH) }\end{array}$ & $\begin{array}{l}\text { L total } \\
\text { Circuit } \\
\text { Total } \\
\text { Induc- } \\
\text { tance } \\
\text { (mH) }\end{array}$ & $\begin{array}{c}\mathrm{L}_{\mathrm{c}} \\
\text { Cable } \\
\text { Induc- } \\
\text { tance } \\
(100 \mathrm{ft} \\
\times 0.2 \\
\mu \mathrm{H} / \mathrm{ft}) \\
(\mathrm{mH})\end{array}$ & $\begin{array}{c}\mathrm{L}_{\mathrm{i}} \\
\text { Intrin- } \\
\text { sically } \\
\text { Safe } \\
\text { Appara- } \\
\text { tus } \\
\text { Induc- } \\
\text { tance } \\
(\mathrm{mH})\end{array}$ \\
\hline 19 & 20 & 330 & $<330$ & 0.24 & $<0.026$ & 0.006 & $<0.02$ & 0.18 & 0.02 & 0.02 & 0 \\
\hline \multicolumn{12}{|c|}{$\begin{array}{l}\text { Notes: } \\
\text { 1Inductance and capacitance per foot are assumed to be } 60 \mathrm{pF} / \mathrm{ft} \text { and } 0.2 \mu \mathrm{H} / \mathrm{ft} \text {. } \\
\text { 2The effective inductance presented to the cable from probe is effectively zero because of the three series diodes in series } \\
\text { in the isolation networks for the power supplied. No reverse current will flow through these diodes when the } \\
\text { inductance in the probe current is interrupted. }\end{array}$} \\
\hline
\end{tabular}


Appendix A

WHC-SD-WM-DA-202 REV 0

Page 4 of 19

\begin{tabular}{|c|c|c|c|c|c|c|c|c|c|c|c|}
\hline & & & & & Tab & $A 3$ & & & & & \\
\hline & & En & ty Safety & Parameter & for Intrir & sic Safety & Barrier fo & Inclinom & ter & & \\
\hline & & & & & ELCO & 1072 & & & & & \\
\hline $\begin{array}{c}\mathrm{V}_{\propto} \\
\text { Maxi- } \\
\text { mum } \\
\text { Open } \\
\text { Circuit } \\
\text { Voltage } \\
\text { from IS } \\
\text { Barrier } \\
\text { (V) }\end{array}$ & $\begin{array}{l}\mathrm{V}_{\max } \\
\text { Intrin- } \\
\text { sically } \\
\text { Safe } \\
\text { Appara- } \\
\text { tus } \\
\text { Maxi- } \\
\text { mum } \\
\text { Al- } \\
\text { lowed } \\
\text { Voltage } \\
\text { (V) }\end{array}$ & $\begin{array}{c}\mathrm{I}_{\mathrm{sc}} \\
\text { Maxi- } \\
\text { mum } \\
\text { Short } \\
\text { Circuit } \\
\text { from IS } \\
\text { Barrier } \\
\text { (mA) }\end{array}$ & $\begin{array}{l}I_{\max } \\
\text { Intrin- } \\
\text { sically } \\
\text { Safe } \\
\text { Appara- } \\
\text { tus } \\
\text { Maxi- } \\
\text { mum } \\
\text { Al- } \\
\text { lowed } \\
\text { Current } \\
\text { (mA) }\end{array}$ & $\begin{array}{c}\mathrm{C}_{\mathbf{a}} \text { IS } \\
\text { Barrier } \\
\text { Maxi- } \\
\text { mum } \\
\text { Al- } \\
\text { lowed } \\
\text { Circuit } \\
\text { Capaci- } \\
\text { tance } \\
(\mu \mathrm{F})\end{array}$ & $\begin{array}{l}\mathrm{C}_{\text {total }} \\
\text { Circuit } \\
\text { Total } \\
\text { Capaci- } \\
\text { tance } \\
(\mu \mathrm{F})\end{array}$ & $\begin{array}{c}\mathrm{C}_{\text {cable }} \\
\text { Cable } \\
\text { Capaci- } \\
\text { tance } \\
(100 \mathrm{ft} \\
\times 60 \\
\mathrm{pF} / \mathrm{ft}) \\
(\mu \mathrm{F})\end{array}$ & $\begin{array}{c}\mathbf{C}_{\mathbf{i}} \\
\text { Intrin- } \\
\text { sically } \\
\text { Safe } \\
\text { Appara- } \\
\text { tus } \\
\text { Capaci- } \\
\text { tance } \\
(\mu \mathrm{F})\end{array}$ & $\begin{array}{l}\mathrm{L}_{\mathrm{a}} \mathrm{IS} \\
\text { Barrier } \\
\text { Maxi- } \\
\text { mum } \\
\mathrm{Al-} \\
\text { lowed } \\
\text { Circuit } \\
\text { Induc- } \\
\text { tance } \\
\text { (mH) }\end{array}$ & $\begin{array}{l}\mathrm{L}_{\text {total }} \\
\text { Circuit } \\
\text { Total } \\
\text { Induc- } \\
\text { tance } \\
(\mathrm{mH})\end{array}$ & $\begin{array}{c}\mathbf{L}_{\mathrm{c}} \\
\text { Cable } \\
\text { Induc- } \\
\text { tance } \\
(100 \mathrm{ft} \\
\mathrm{x} 0.2 \\
\mu \mathrm{H} / \mathrm{ft}) \\
(\mathrm{mH})\end{array}$ & $\begin{array}{c}\mathrm{L}_{\mathrm{i}} \\
\text { Intrin- } \\
\text { sically } \\
\text { Safe } \\
\text { Appara- } \\
\text { tus } \\
\text { Induc- } \\
\text { tance } \\
(\mathrm{mH})\end{array}$ \\
\hline 13.1 & $\begin{array}{l}\text { Not } \\
\text { Appli- } \\
\text { cable }\end{array}$ & 26 & $\begin{array}{l}\text { Not } \\
\text { Appli- } \\
\text { cable }\end{array}$ & 1.1 & 0.07 & $<0.06$ & $<0.01$ & 47 & $<0.03$ & 0.02 & $<0.01$ \\
\hline $\begin{array}{l}\text { Notes: } \\
\text { Inducta }\end{array}$ & d & 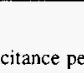 & 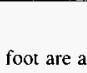 & 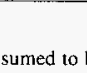 & $\mathrm{C}_{2}$ & $a$ & & & & & \\
\hline
\end{tabular}

\section{A.3.2 Detector Tubes}

The two sizes of boron- 10 lined detectors tubes are used in the probe. The detectors are 0.5 inches in diameter and 2.5 and 2.75 inches long. The detector tubes are hermetically sealed and are filled with a fill gas consisting of Argon and Carbon Dioxide. A internal anode wire runs the length of detector tube and is electrically connected to an anode tube. The detectors in the SMMS probe are polarized with $650 \mathrm{VDC}$. The bottom detector assembly contains a solid state temperature sensor. The temperature sensor is molded plastic package and is embedded in an aluminum block. Wiring to temperature sensor is sleeved with heat shrink tubing to provide additional electrical insulation and to provide protection against abrasion resistance.

\section{A.3.3 Preamplifier Board}

The purpose of the preamplifier board is to convert the current pulses or charge pulses $\left(5 \times 10^{-13}\right.$ coulombs per pulse) to a voltage signal. The preamplifier board has three charge sensitive amplifiers and three high voltage bias resistors, 10 Megohms, for the detectors. A dc blocking capacitor, $3 \mathrm{kV}$ rating, isolates the front end of each charge amplifier from the detector bias voltage. All high voltage components are mounted on insulated terminals which have a voltage rating of $1500 \mathrm{~V}$. Additionally the front end of the charge sensitive amplifiers is clamped to 
ground with back-to-back diodes and a 1 kilohm resistor provides current limiting for the front end field effect transistor. Power is provided to this board from the low voltage power supply on high voltage/low voltage power supply board, via the line driver board. The preamplifier board has a solid internal ground plane. Figure A3 shows the schematic for the preamplifier board. The preamplifier board contains significant energy storage components in the form of high voltage capacitors, a 0.1 microfarad capacitor charged to $650 \mathrm{VDC}$. The discharge path for this capacitor is through the voltage regulator bleeder network on the high voltage/low voltage power supply board, 100 Megohms to ground. Thus the bleed off time constant is 10 seconds or about 60 seconds to dischage to $1 \%$ of initial value.

A 0.060 -inch thick stainless steel plate is located between the preamplifier board and the line driver board. The primary purpose of this plate is to provide electrostatic shielding between the line driver output signals and the charge sensitive amplifier inputs. During prototype testing it was found that the output pulses from the line driver outputs were coupled into the charge sensitive amplifier inputs. The plate is grounded to the case of the probe through metallic contact through metal spacer and mounting screws. The pulse signal from each charge sensitive amplifier is connected to line driver board through RG-174 coaxial cable. The shields of the coaxial cables are terminated to ground on each board. These coaxial cables are well separated from high voltage terminals on the preamplifer board and the high voltage lead wire from the high voltage/low voltage power supply board. The dielectric in the RG-174 coaxial cable is rated for $1100 \mathrm{~V}$. 
Appendix A

WHC-SD-WM-DA-202 REV 0

Page 6 of 19

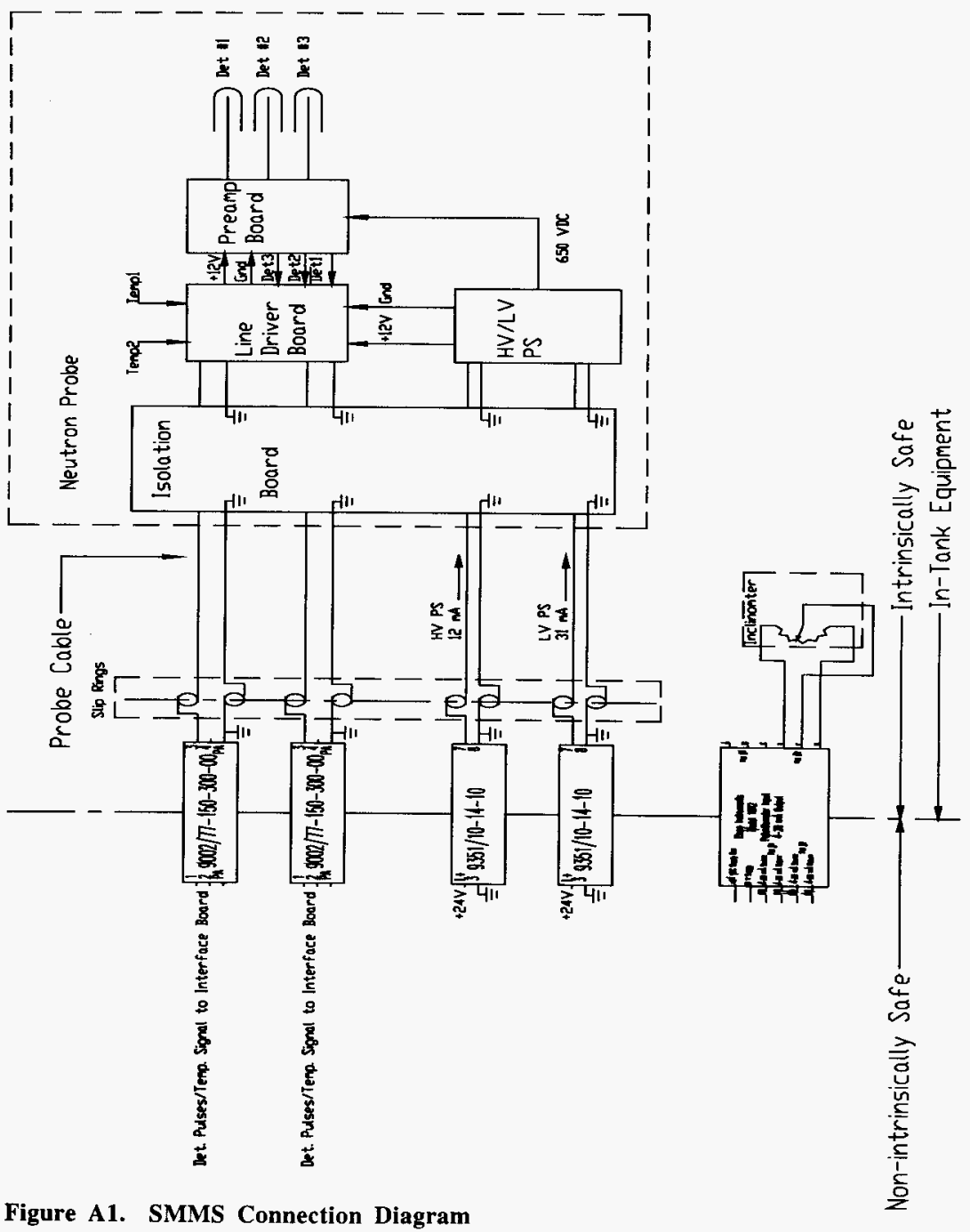



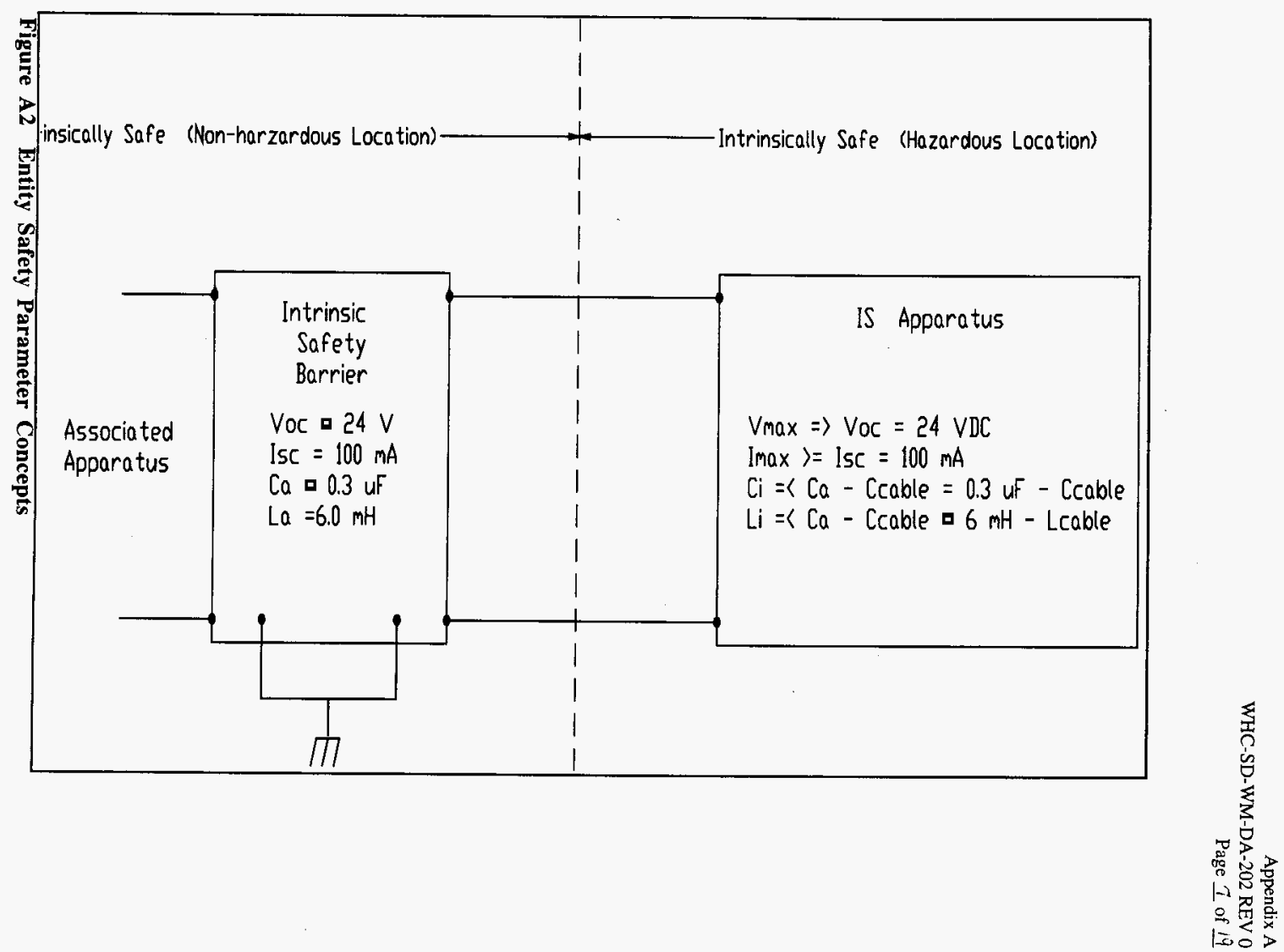
Appendix A

WHC-SD-WM-DA-202 REV 0

Page 8 of 19

\section{A.3.4 Line Driver Board}

The purpose of the line driver board is to provide additional linear amplification for neutron detector counting pulses. The amplification stages combine the pulses from detectors 1 and 2 into positive and negative going pulses to permit tranmission of linear pulses from the two detectors over one coaxial cables. Pulses from detector 3 are inverted and transmitted over on a second coaxial cable. In addition to amplification of the counting pulses, two temperature signals are combined with the counting pulses in the form of a DC voltage level that varies from 4 to $6 \mathrm{~V}$ above ground for a temperature range of -100 to +100 degrees Celsius. The output pulse amplitude of the two line driver amplifiers are set to $1.25 \mathrm{~V}$ (positive and negative going pulses) with a $5 \times 10^{-13}$ coulomb charge input to charge amplifiers ( $100 \mathrm{mV}$ through a 5 picofarad capacitor). Potentiometers are provided to adjust the pulse amplitude for each detector. The line driver board is powered from the 12 VDC power supply located on the high voltage/low voltage power supply. Figure A4 shows the the schematic for the line driver board. The second solid state temperature sensor is located on this board.

Two RG-174 coaxial cables connect the two counting signal outputs of the line driver board to isolation board. The cables is routed up through a slot in the high voltage/low voltage power supply board. High voltage components are well separated from these two cables by spacing and a grounded metal spacer.

\section{A.3.5 High Voltage/Low Voltage Power Supply}

This printed circuit board provides the $650 \mathrm{VDC}$ bias voltage for the three neutron detectors and the 12 VDC power supply voltage for the electronic circuit boards. The high voltage is boosted from the 14 to $15 \mathrm{~V}$ provided to the high voltage power supply from the intrinsic safety barrier located at the top of the mast. A commercial DC-DC converter is used to convert a regulated DC voltage to a high voltage. The DC-DC converter is epoxy potted in a deep-drawn steel housing. A potentiometer mounted on this board to provide an adjustable range from 550 to $725 \mathrm{VDC}$. By changing a resistor (unsoldering and soldering required) the range of output of the high voltage supply can be varied from about 500 to $1500 \mathrm{VDC}$ with approximately $200 \mathrm{~V}$ range of voltage adjustability. High voltage components are mounted on insulated terminals above the printed circuit board. The insulated terminals are rated for 1500 VDC. Figure A5 shows the circuit schematic of the high voltage/low voltage power supply board. High voltage silcone rubber insulated lead wire, rated for $5 \mathrm{kV}$, is used to connect the output of the high voltage power supply to the preamplifier board.

Like the preamplifier board, this board also contains significant energy storage components in the form of high voltage capacitors, a 0.1 microfarad capacitor and a 0.01 microfacrad capacitor charged to 650 VDC. The discharge path for this capacitor is through the voltage regulator bleeder network on the high voltage/low voltage power supply board, $100 \mathrm{Megohms}$ to common. Thus the bleed off time contant is 10 seconds or about 60 seconds to dischage to $1 \%$ of initiial value. Load test on output of high voltage power supply show that the high high voltage power supply is current limited. The maximum steady short current obtained from the high voltage supply is about 600 microamperes while the intrinsic safety barrier provides $90 \mathrm{~mA}$ of current to the high voltage power supply. 
The low voltage power supply, $+12 \mathrm{~V}$, is also located on this printed circuit board. The circuit components are located on the bottom of printed circuit board along with the regulator for the high voltage power supply. The printed circuit board contains a ground plane in the center of board. The insulation of hook-up wire used to distribute the low voltage power to line driver board, and preamplifier board is rated for $600 \mathrm{~V}$ per Mil-W-16878E. This military standard requires high potential testing to $2,000 \mathrm{~V}$. The wiring for the low power supply is very well separated from the high voltage lead wire to the preamplifier board. Power is provided to the high voltage/low voltage power supply from the isolation board via two twisted pairs. The twisted pairs are soldered in two sets of thru holes on the high voltage/low voltate power supply board from the high voltage components. 

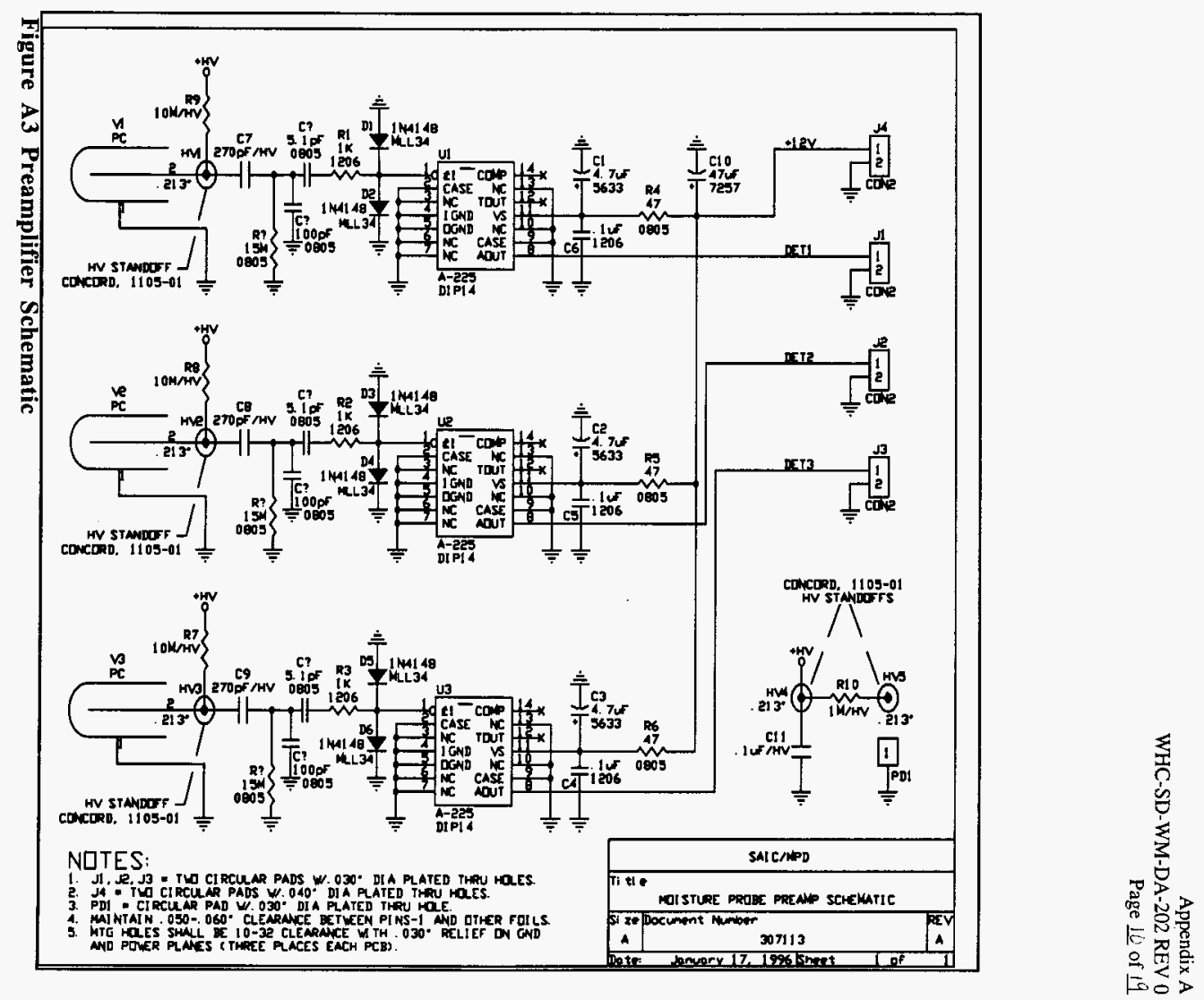


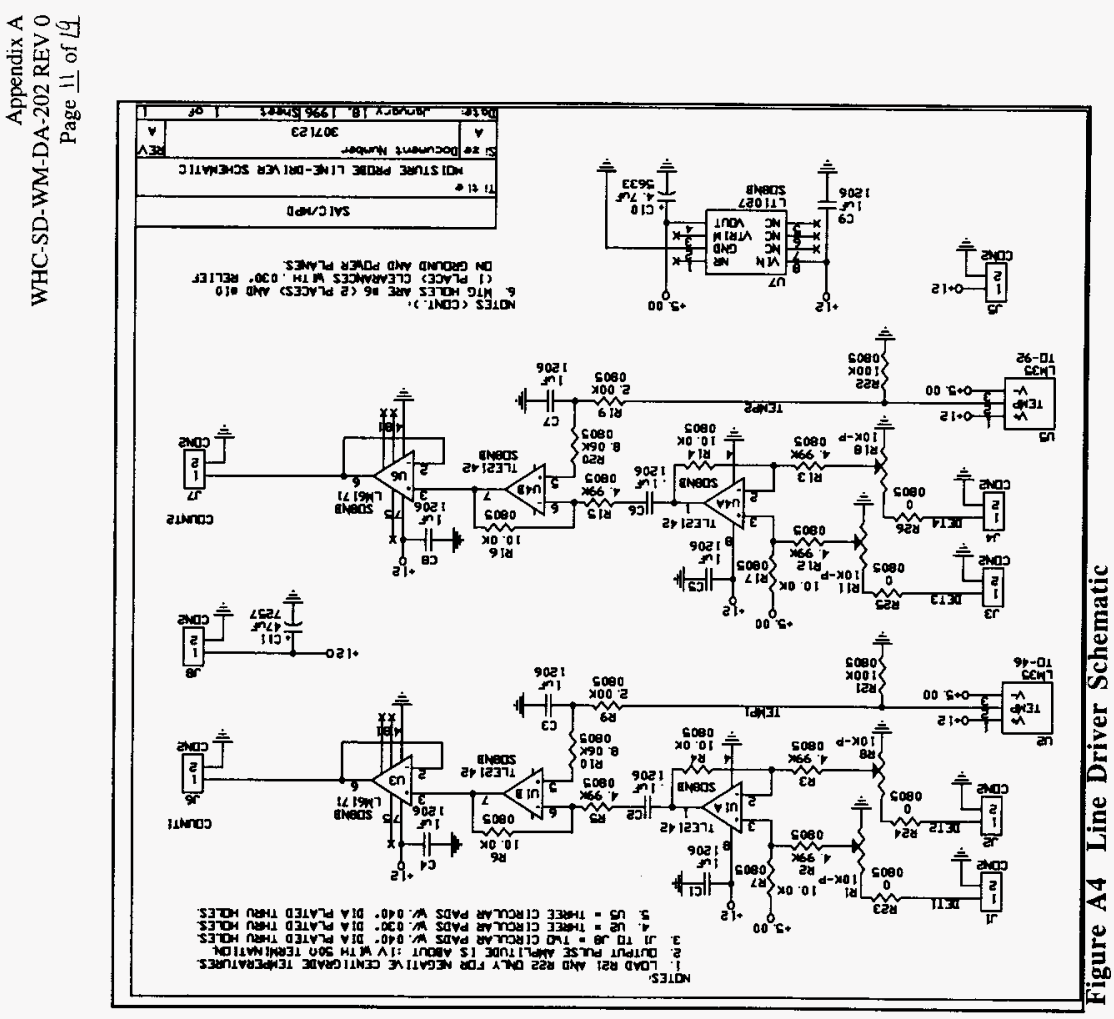


Appendix A

WHC-SD-WM-DA-202 REV 0

Page 12 of 19

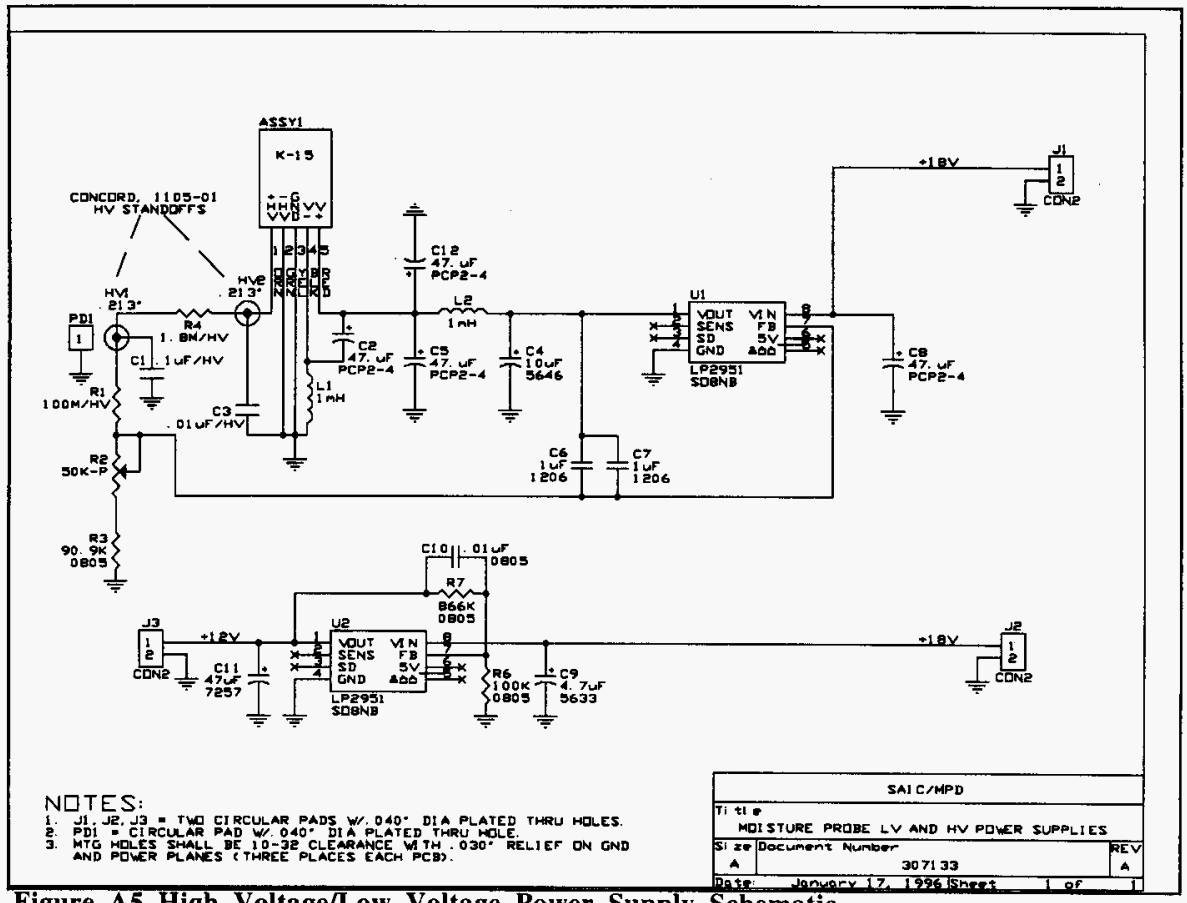

Figure A5 High Voltage/Low Voltage Power Supply Schematic 
Appendix A

WHC-SD-WM-DA-202 REV 0

Page 13 of 19

\section{A.3.6 Isolation Board}

The isolation board is located $1 / 2$ inch above a 0.060 -inch thick metal stainless steel plate. Another 0.060 -inch thick stainless steel metal plate is located $1 / 2$ inch above the isolation board. These two metal plates are grounded through the mounting screw and metal spacers to probe enclosure. Wiring from the probe electronics passes through a hole in the bottom plate and is soldered into four pairs of thru holes on the bottom side of the circuit board. Wiring to probe connector passes through two sets of holes in the top plate and is connected to probe connector. The metal plates have rubber grommets in the holes where wiring passes through. Four isolation neworks are constructed on this printed circuit board. A solid copper ground plane surrounds each of the isolation networks on both sides of the printed circuit board.

\section{A.3.6.1 High Voltage/Low Voltage Power Supply Input Power Isolation Network}

The isolation board contains the isolation networks to limit the amount of energy that can flow into the the coaxial cables and power supply cable if a fault takes place in the SMMS probe. The power supply isolation nework consists of three series connected diodes and redundant voltage limiting $20 \mathrm{~V}$ 1-watt zener diodes. Each of the three series connected diodes has a peak inverse voltage of $1000 \mathrm{~V}$. The basis for this protection scheme is to prevent current flow from probe back into cable and clamp the voltage with redundant zener diodes. These diodes effectively isolate the cable from any inductance in the probe by preventing current flow out of the probe. An additional feature of this configuration is teverse voltage protection of prove electronics. The maximum voltage that can be supplied from the Stahl $9351 / 10-14-10$ barriers is $19 \mathrm{~V}$. The zener diodes will not begin to conduct until the voltage at the probe connector reaches about $22 \mathrm{~V}$ because of voltage drops of three series connected diodes ( 0.6 to $0.8 \mathrm{~V}$ drop per diode)

\section{A.3.6.2 Pulse Output Isolation Network}

The output pulses from the line drivers are isolated from the cable with a 50 ohm 2-watt metal film resistors and two sets of $15 \mathrm{~V}$ zener diodes. The $50 \mathrm{ohm}$ resistors were selected on the basis of an open circuit voltage $15 \mathrm{~V}$. The ignition current for a resistive circuit with cadmium metals is $1 \mathrm{~A}$. After derating by $2 / 3$ (qualification by analysis derating factor) and $1 / 1.5$ (energy derating factor), the current is $444 \mathrm{~mA}$. The minimum tesistance value then is $12 \mathrm{~V} / 444 \mathrm{~mA}$ or $27 \mathrm{ohms}$. The value of $50 \mathrm{ohms}$ was chosen because it matches the impedance of the line driver to the impedance of the coaxial cable. A metal film resistor was chosen for this application because of requirements of intrinsically safe apparatus approval standards such as FM Class 3610 [A2]. Metal film resistor have a high probability of failure in the most desirable mode, open circuit mode ( $95 \%$ fail in open circuit mode and 5\% fail in short circuit mode) [A1]. Redundant $15 \mathrm{~V} 1$-watt zener diodes were chosen to limit the voltage on both ends of the $50 \mathrm{ohm}$ resistor to $15 \mathrm{~V}$. The desirable failure mode for these zener diodes is to fail shorted. Zener diodes fail in the shorted mode half of the time, (50\% fail open) [A1]. The probability that at least one of the one of two zener diodes will fail shorted is 0.75 . It should be noted that the output of the low voitage power supply is $12 \mathrm{~V}$. The voltage at this isolation network will only exceed $12 \mathrm{~V}$ when there is:

(1) failure of low power supply - maximum voltage is limited by the intrinsic safety barrier 19 $\mathrm{V}$ open circuit; and 
(2) a fault from the high voltage power supply to a circuit component - maximum voltage limited by $15 \mathrm{~V}$ zener diodes and other circuit components, capacitors (70\% to $80 \%$ of time fail shorted), and integrated circuits [A1].

The largest peak current through the zener diodes on the cable side of $50 \mathrm{ohm}$ resistor from the probe is about $100 \mathrm{~mA}$. The current through these zener diodes will decay as the voltage as the power supply capacitors decay. This value is based upon $18 \mathrm{~V}$ being applied on probe side of the $50 \mathrm{ohm}$ resistors. The zener diodes on the circuit side of the $50 \mathrm{ohm}$ resistor were placed there to limit the voltage and absorb the initial voltage surge if the $650 \mathrm{~V}$ power supply should fault to the $12 \mathrm{~V}$ power supply. Faults from the intrinsic safety barriers, Stahl $9002 / 77-150-300-00$ are limited to a short circuit current of $138 \mathrm{~mA}$ and a maximum open circuit voltage of 14.5 volts dless for volitage levels upto 250 VRMS applied on the non-intrinsically safe side of the barrier. The maximum voltage available on the non-intrinsically safe side of the barrier is $24 \mathrm{VDC}$. The zener diodes can tolerate this condition indefinitely with no damage.

\section{A.3.6 Probe Connector}

Two power supply pairs and two coaxial cables from the isolation board are connected to the cable head through a military cable connector. The dielectric rating of the connector is $1300 \mathrm{~V}$. The two power supply pair have pin and socket inserts for each conductor and the coaxial cables have coaxial cable inserts.

\section{A.3.7 Grounding and Bonding}

The probe housing is bonded to the shield wires of the two shield wires of the two 18 AWG wires. The shield wires are bonded to the cap of the probe enclosure and to ground bus for the intrinsic safety barrier located in the mast head. The probe housing is not externally grounded other than these shield wires except through the contact through the arm during installation and during interim storage during the tank. When the probe is suspended in the head space of the tanks these ground wires provide only bonding path for the probe. The ground resistance through the waste in the bottom of the tanks can vary greatly from the megohm range to a few ohms depending on the mositure content of the waste. The resistance of the two shield wires is less than $2 \mathrm{ohms}$.

The probe cable jacket is a semiconductive plastic that will drain the electrostatic charge induced as a result of being rolled off of the winch, passing down through the mast, and rolling over the shoe assemblies at the end of the arm. The semiconductive plastic is LNP Engineering Plastics StatKon-ME1. The surface resistivity is $10^{2}$ to $10^{4} \mathrm{ohms} / \mathrm{square}$ and $10^{3}$ to $10^{4} \mathrm{ohms}-\mathrm{cm}$. 
Appendix A

WHC-SD-WM-DA-202 REV 0

Page 15 of 19
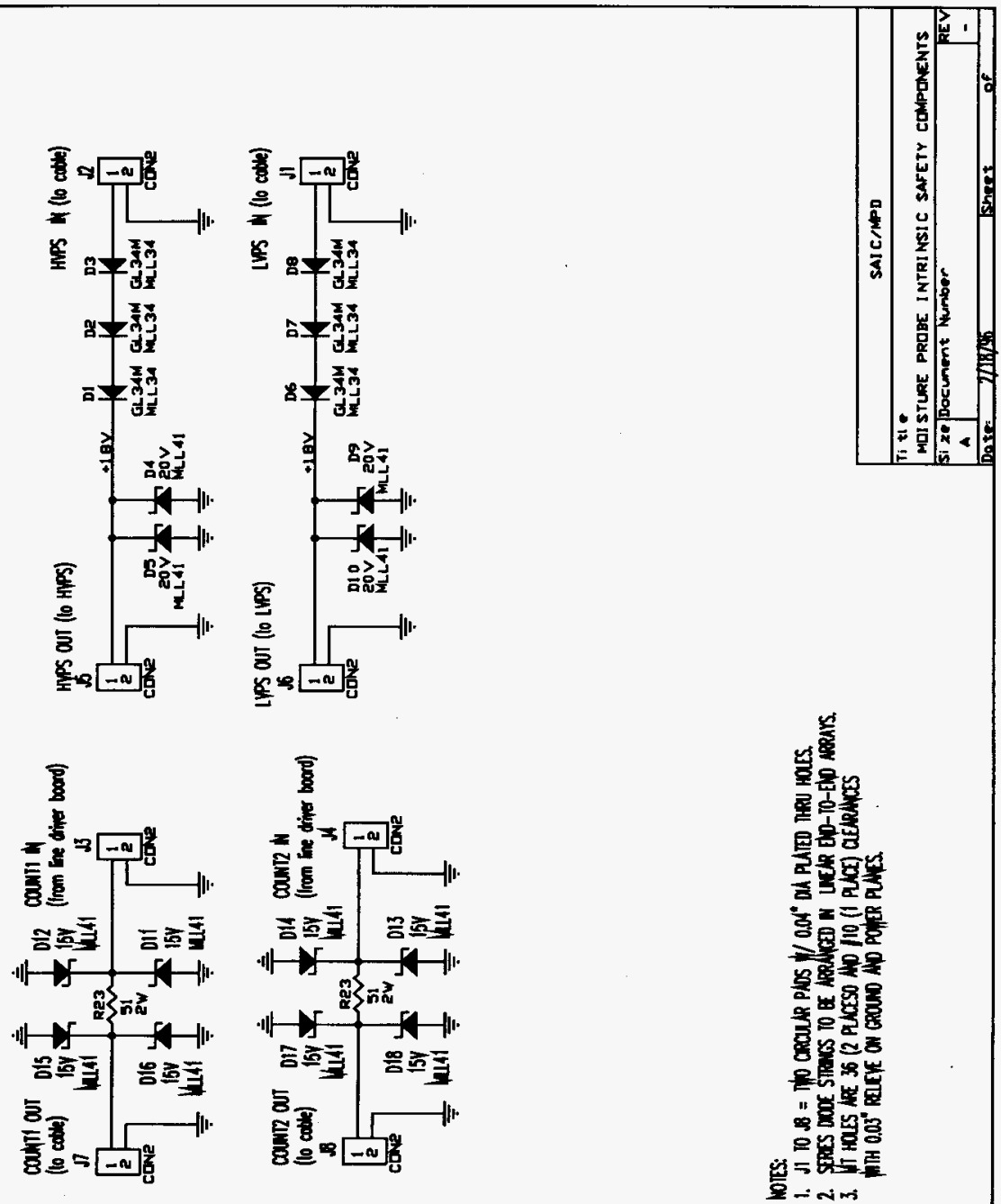

Figure A6 Interface Board Schematic (located in mast assembly in non-classified location). 
DESIGN CALCULATION

WHC-SD-WM-DA-202 REV O

(1) Drawing

(2) Dor. No.

(3) Page

Appendix A

(4) Building

(5) Rev

(6) Job No

of - Page le of $\angle 9$

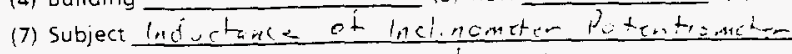

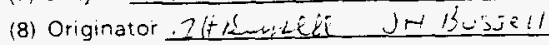
Date $5 / 1 / 4$

(9) Checker Date

(10)

Alternate Metriod of calculatery indotane oi Inclinoweter:

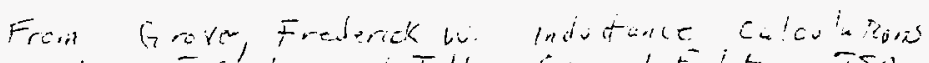

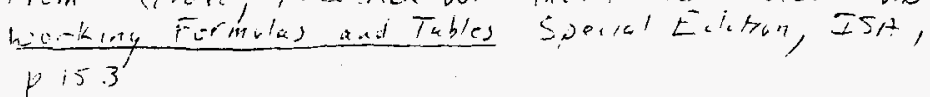

Exartion $122 a$

$$
\begin{aligned}
& L \rightarrow C .00254 F d_{2} \mathrm{~N}^{2} \quad F=\operatorname{tabutatad~loke} \\
& \text { in } t_{a} b l e 4 c \\
& \left.i_{2}=\text { co. }\right) \text { dim anotim } \\
& N=\text { totel number at } \\
& L=\quad \text { indortanceis }
\end{aligned}
$$

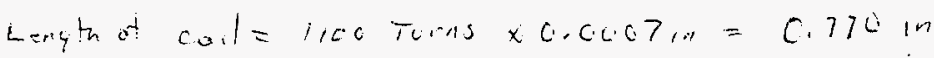

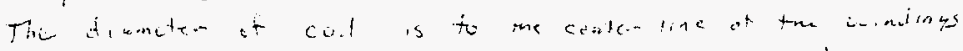

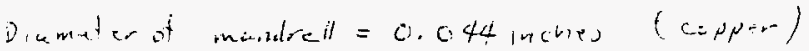

$$
\begin{aligned}
& \text { Dicenter it were }=0.0007 \text { inches } \\
& \text { isencter of } c 0.1=0.6447 \text {, wethes }
\end{aligned}
$$

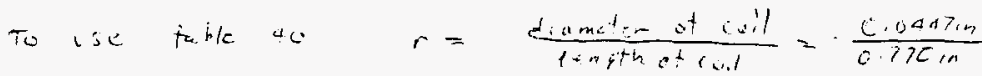

$$
=0 \cdot \cos 0.5
$$

BET MULELE CW

SD $6.2010 .1960 \div(12879$ 
DESIGN CALCULATION

(1) Drawing

(2) Doc. No.

(5) Rev.

(4) Building

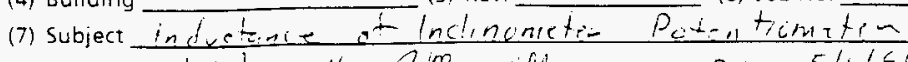

(8) Originator Jn 13-jsell IR valel

(9) Checker

(10)

$$
\begin{aligned}
L & =\frac{(r N)^{2}}{9 r+10 l} \\
& =\frac{(r N)^{2}}{9 r+1 C N d}
\end{aligned}
$$

Formula from

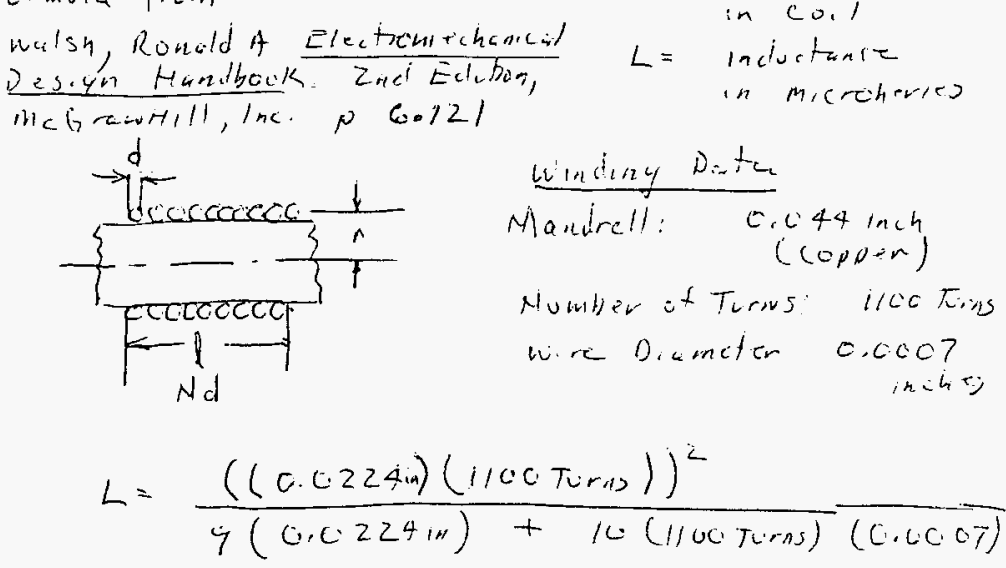

$$
\begin{aligned}
& =\frac{507.1286}{0.2016+7.70} \\
& =76.8 \text { michtranes }
\end{aligned}
$$
Date $5 / 1 / 46$ Date

$$
\begin{aligned}
& r=\sinh \text { reitios ot }
\end{aligned}
$$

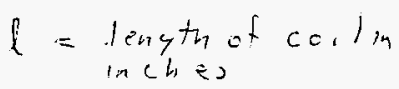

$$
\begin{aligned}
& \mathrm{Nd} \\
& d=\text { wiredeneter } \\
& \text { in inch } 0 \\
& \lambda=\text { nuimbirit toris }
\end{aligned}
$$

Appendix 14A

Page 17 of 19 
(1) Drawing (2) Doc. No (3) Page

Appendix 14

(4) Building (5) Rev of Page 18 of 19

(7) Subject liductame of lactucineter Potentucmetim

(8) Originator jribssell $2 v e$ enell

(9) Checker Date $5 / 1 / 46$ Date

TABLE 40. DESION DATA. SEVOLELLATER CORS

\begin{tabular}{|c|c|c|c|c|c|c|c|c|c|c|}
\hline r & $\boldsymbol{k}$ & $F$ & $\beta$ & $\gamma$ & $r$ & $k$ & $F$ & $B$ & $\gamma$ & \\
\hline 0 & 9.87 & 0 & 0 & $\infty$ & 0.25 & 8.90 & 2.225 & 0.556 & 35.6 & \\
\hline 0.01 & 9.83 & 0.098 & 0.0010 & 983 & .26 & 8.86 & 2.304 & .599 & 34.1 & 13 \\
\hline .02 & 9.79 & .196 & .0039 & 489 & .27 & 8.83 & 2.384 & .644 & 32.7 & 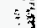 \\
\hline .03 & 9.74 & .292 & .0088 & 325 & .28 & 8.79 & 2.462 & .689 & 31.4 & 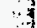 \\
\hline .04 & 9.70 & .388 & .0155 & 243 & .29 & 8.76 & 2.540 & .736 & 30.2 & \\
\hline 0.05 & 9.66 & 0.483 & 0.0242 & 193.2 & 0.30 & 8.72 & 2.617 & 0.785 & 29.1 & \\
\hline .06 & 9.62 & .577 & .0346 & 160.3 & .31 & 8.69 & 2.693 & .835 & 28.0 & \\
\hline .07 & 9.58 & .671 & .0470 & 136.9 & .32 & 8.65 & 2.769 & .886 & 27.0 & \\
\hline .08 & 9.54 & .763 & .0611 & 119.2 & .33 & 8.62 & 2.844 & .939 & 26.1 & \\
\hline .09 & 9.50 & .855 & .0770 & 105.6 & .34 & 8.59 & 2.919 & 0.993 & 25.2 & \\
\hline 0.10 & 9.46 & 0.946 & 0.0946 & 94.6 & 0.35 & 8.55 & 2.993 & 1.048 & 24.4 & \\
\hline .11 & 9.42 & 1.037 & .1140 & 85.7 & .36 & 8.52 & 3.067 & 1. J04 & 23.7 & \\
\hline .12 & 9.38 & 1.126 & .1351 & 78.2 & .37 & 8.49 & 3.140 & 1,162 & 22.9 & \\
\hline .13 & 9.35 & 1.215 & .1580 & 71.9 & .38 & 8.45 & 3.212 & 1.221 & 22.2 & \\
\hline .14 & 9.31 & 1.303 & .1825 & 66.5 & .39 & 8.42 & 3.284 & 1.281 & 21.6 & \\
\hline 0.25 & 9.27 & 1.390 & 0.2086 & 61.8 & 0.40 & 8.39 & 3.355 & 1.342 & 20.97 & \\
\hline .16 & 9.23 & 1.477 & .2363 & 57.7 & .41 & 8.36 & 3.426 & 1,404 & 20.33 & \\
\hline .17 & 9.19 & 1.563 & .2656 & 54.1 & .42 & 8.32 & 3.496 & 1.468 & 19.82 & \\
\hline .18 & 9.16 & 1.648 & .2958 & 50.9 & .43 & 8.29 & 3.565 & 1. 533 & 19.28 & \\
\hline .19 & 9.12 & 1.732 & .3292 & 48.0 & .44 & 8.26 & 3.634 & 1.599 & $18 . \pi 7$ & \\
\hline 0.20 & 9.08 & 1.816 & 0.363 & 45.4 & 0.45 & 8.23 & 3.703 & 1.666 & 18.29 & \\
\hline .21 & 9.04 & 1.899 & .399 & 43.1 & .46 & 8.20 & 3.771 & 1.735 & 17.82 & \\
\hline .22 & 9.01 & 1.982 & .436 & 40.9 & .47 & 8.17 & 3.838 & 1.804 & 17.37 & \\
\hline .23 & 8.97 & 2.063 & .475 & 39.0 & .48 & 8.14 & 3.905 & 1.874 & 16.95 & \\
\hline .24 & 8.94 & 2.144 & .515 & 37.2 & .49 & 8.10 & 3.972 & 1.946 & 16.54 & \\
\hline 0.25 & 8.90 & 2.225 & 0.556 & 35.6 & 0.50 & 8.07 & 4.037 & 2.019 & 16.15 & \\
\hline
\end{tabular}

Sirie the purpise it this calculatern is to bound the metuctane of the enclinometer

$$
\begin{aligned}
F & =0.577 \text { for } \quad r=0.06 \\
L & =0.00254(0.577)(0.0447)(1100 \text { torns })^{2} \\
& =79.3 \text { microhinnie) }
\end{aligned}
$$




\section{A.4 References} A1 $\frac{\text { Engineers, } 1981 .}{\text { Electronic Reliability Data - A Guide to Selected Components," Institute of Electrical }}$

A2 "Class Number 3610, Approval Standard - Intrinsically Safe Apparatus and Associated Apparatus for Use in Class I, II, and III, Division 1 Hazardous (Classified) Locations", October 1988 
Appendix B Bussell catalog cut sheets and test reports submitted to ETL, explosion proof thing, rest of ETL package.

(LOCATED IN PROJECT FILES H5-09, 2920 GEO WASH WAY/55) 
Appendix C

WHC-SD-WM-DA-202 REV 0

Page $\perp$ of 3

\section{APPENDIX C \\ Comparison of Probe Housing to UL-1203 \\ C.1 Probe Enclosure}

The enclosure for the probe is constructed from 3 -inch schedule 40 stainless steel pipe and machined bottom assembly. The machined bottom assembly and the 3 -inch schedule 40 pipe are welded together using a full penetration welding process similar to the welding process used for high pressure piping. The welds were visually inspected and radiographed. Inspection records are available in the $306 \mathrm{E}$ work package, available from D.B. Graves. After the welding was completed the end of the probe was machined down at the bottom 4.23 inches from 0.21 to 0.13 inch sidewall thickness. The transition of between the thicker and thinner wall section is over a 1inch of probe length $\left(5^{\circ}\right.$ taper). Table $\mathrm{C} 1$ shows the surface and volume data for probe enclosure and table $\mathrm{C} 2$ shows a summary of contruction requirements from UL-1203. The requirements in table 6.1 of UL-1203 is satisfied ( 0.067 inches thickness of sheet steel). The housing is designed for 500 psi pressure, five times the peak explosion pressure of hydrogen in a spherical chamber. Calculations performed by Pacific Northwest National Laboratory and SAIC indicate the maximum peak explosion pressure in the housing is about 440 psi Appendix D]. Structual analysis of the probe enclosure concludes that that design of enclosure is acceptable for the 500 psig pressure expected during worst case intemal explosion. [Appendix E, page 5]

The cable strain relief and seal assembly is attached to the probe housing with a nut with two sets of 3.375-16 UNC-2B threads. The two sets of threads allow the cable strain relief and seal assembly to be installed without rotating it more than 1 turn (relative to the probe housing) while the nut is rotated more than 8 turns. The probe cable in the cable strain relief and seal assembly consist of three basic components; a compression cable strain relief nut at the top of the assembly, cap assembly, and cone shaped wedge. The outer jacket of the probe cable is removed exposing the Kevlar2 fiber. After the cable has been threaded through the cap assembly, the cone shaped wedge is slid up under the Kevlar fiber in the tapered through hole in the cap assembly. When the cone shaped wedge is in the proper location, the through hole is filled with Emerson \& Cummings Stycast 1266 epoxy. Pull tests performed on the cable assembly fabricated as described above have breaking strengths greater than 2600 pounds-force. (See pull test report in Appendix B).

More than 8 rotations are required to fully seat the nut. Thus the requirements defined in UL-1203 section 7.28 is satisfied. The clearance between the cable strain relief and seal and the probe housing is 0.002 to 0.003 inches. This clearance is not designed or intended to meet the requirements of UL-1203 in sections 7.25 to 7.34 (0.0015 inches clearance). Equilibrium and temperature tests indicate that the internal components of the housing will operate about $6^{\circ} \mathrm{C}$ above the ambient temperature. (The nominal power dissipation in the housing is 710 milliwatts.) Thus the maximum housing temperature will be less than $100^{\circ} \mathrm{C}$ when the probe is operated in a $90^{\circ} \mathrm{C}$ ambient temperature.

\begin{tabular}{||l|l|}
\hline \multicolumn{2}{|c|}{$\begin{array}{c}\text { Table Cl } \\
\end{array}$} \\
Probe Housing Dimensional Data \\
\hline Internal Volume & 180 cubic inches \\
\hline Total Surface Area & 220 square inches \\
\hline
\end{tabular}

2Kevlar is a trademark of E.I. deMours Dupont Corp. 


\begin{tabular}{||c|l||}
\hline \multicolumn{2}{||c||}{ Summary of Explosion Proof Enclosure Design Requirements } \\
per UL-1203
\end{tabular}




\section{C.1.1 Impact Spark Resistance of Housing}

The housing is fabricated from stainless steel. Stainless steel is one of the better impact spark resistant materials. Tests cited in the literature indicate that stainless steel is spark ignition is difficult to obtain austenitic stainless steel even when grinding specimens on grinding wheel [C2].

\section{C.2 References}

C1 ANSI/UL-1203-1988, "Standardard for Explosion-Proof and Dust-Ignition Proof Electrical Equipment for use in Hazardous Locations."

C2 Letter, RN Johhnson to RE Bauer, "Selection of Spark-Resistance Tube Material for Use in Tank 101-SY," Dated December 20, 1990. 
April 9, 1996

Westinghouse Hanford Company

Richland, WA 99352

Attention: Mr. Jim Bussell

Subject: Overpressure calculations for SMMS probe body

Reference: Task \#25, SW6-SWV-370248

Sir:

Attached are the overpressure calculations performed by Dr. Ali Dabiri. The maximum pressure expected from a hydrogen burn at $1 \mathrm{~atm}$. is $440 \mathrm{psi}$. This is calculated for a Chapman-Jouguet detonation, Figure 7.9, from Shapiro, "Dynamics and Thermodynamics of Compressed Fluid Flow, Vol. 1".

Also attached is a letter from PNL, Mr. Perry Meyer, verifying that this is an upper limit number, with 370 psi being a lower bound value.

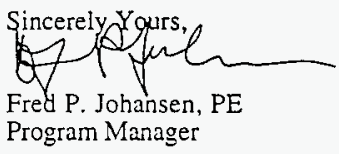


WHC-SD-WM-DA-202 REV 0

$\therefore$ : Max Pressure fuam Neghogen Igritam in 5 MMS

Appendix D

Page $Z$ of $\underline{1}$ probe bady

$$
\begin{aligned}
& \therefore T_{1}=520^{\circ} \mathrm{R}=61^{\circ} \mathrm{F} \\
& \text {.. } \quad \Delta T_{0} / T_{1}=6 \quad \Delta T_{0}=6 \times 520=3120^{\circ} R \\
& =2661^{\circ} \% \\
& =1460^{\circ} \mathrm{C} \\
& \therefore T_{0} / T_{1}=T \\
& \Delta T_{L}= \\
& =3610^{\circ} \mathrm{P} \\
& =3189 \% \\
& =1749^{\circ} \mathrm{C}
\end{aligned}
$$

.. For hodriser $\quad T_{0}=2045^{\circ} \mathrm{C}$

$$
O T_{0}=2045-20=2075^{\circ} \mathrm{C}=3677^{\circ} \mathrm{F}=4136 \mathrm{~K}
$$

$$
\cdots \quad \frac{\Delta T_{b}}{T_{t}}=\frac{4136}{520}=8
$$

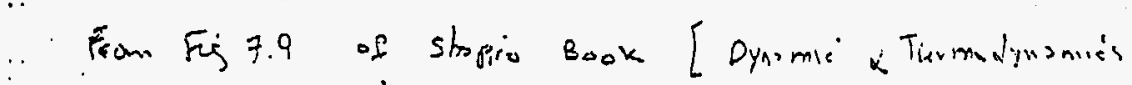
. of corr pleapive. flud flow vol. 1

$$
\begin{array}{ll}
. & \frac{P_{22}}{F_{1}}=30 \\
. & i_{4 i}=4 \% P_{\xi_{1}}
\end{array} \quad, P_{1}=14.7 \mathrm{psi}
$$

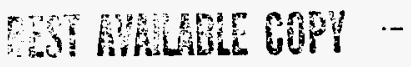



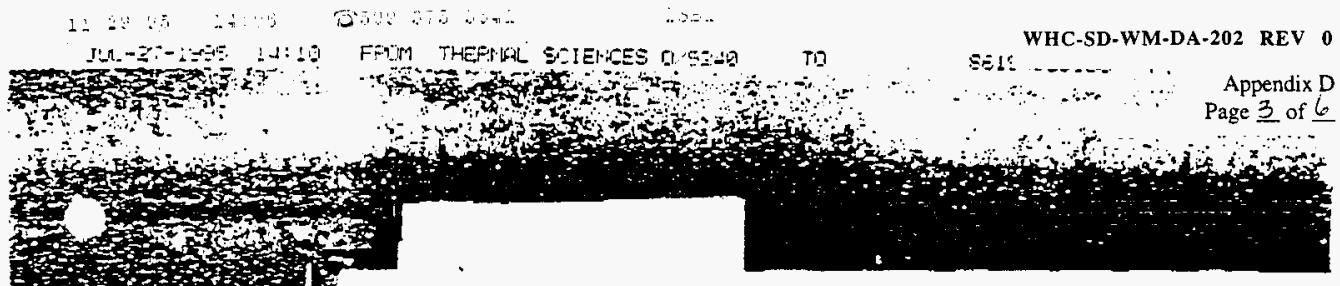

of the cecherisen by which 3 rave starting from reat ulturstrily reaches the stage of tetonation. $=2$ The exormous Baxie prupagation speeds in a detopation wave are possible because the detopation is a combination of an adiabatic compression shock and a subyequent slow buming. To. stwox procencs the hame zont and raise the temperature and pressure of the unburaed gis to such bigh values that the kipeties of the chemical resction are augneated to the point where the flarie $20 n$ e propigates rapidly enough to ken pare with the shock froot.

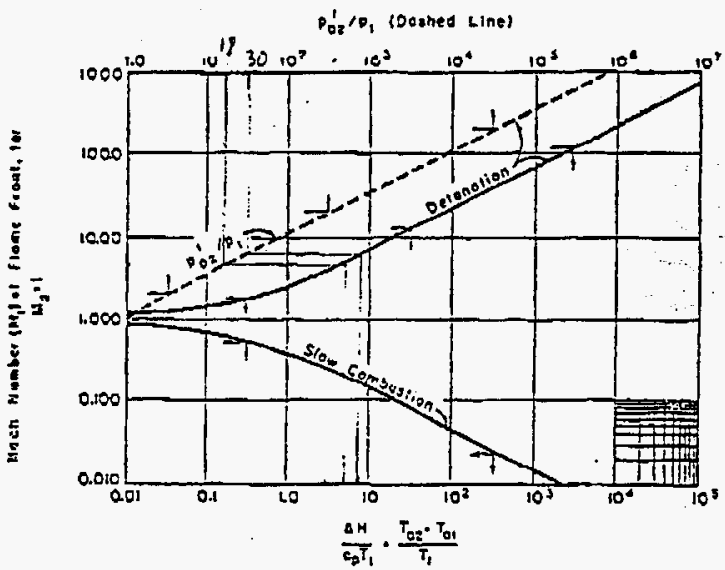

Fic. i.9. Thumally-ghoked wmbestion mave $\left(\mu_{*}=1\right)$ for $l=1.4$ Solid murve

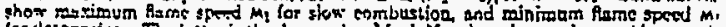

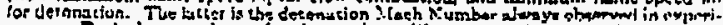

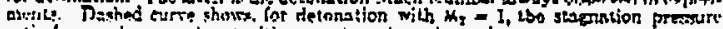

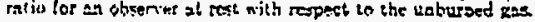

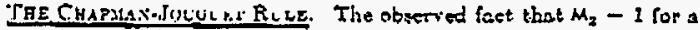
detonation ware is often called the Rule of Chapmen and Jouguet. In order to lind the gurteponding detunation speed $M_{1}$, we set $\left(T_{0} / T_{n}\right)_{2}$

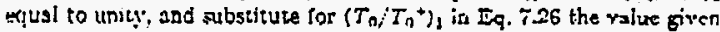
by Eq. T.16. Cartying out these uperations, and simplifying, wo obtain

$$
\left(\frac{T_{M_{2}}-T_{01}}{T_{1}}\right)_{M_{2-1}}=\left(\frac{\Delta H}{c_{p} T_{1}}\right)_{M_{2=-1}}=\frac{\left(1-M_{1}{ }^{2}\right)^{3}}{2\left(l_{E}+1\right) M_{1}^{2}}
$$

The tiro ralues of $M_{l}$ which may be found from this equation corre. spond to the maximum fame-Iront speed for slow combustion and the 


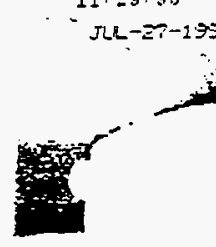

Eirisum soesd for dietonstion. These speeds sre plutted in Fig. 7.9 as 3 function of the creng parameter $\Delta H$ ic $T_{1}$.

One messure of the potentiglitic for dnmsge of a stendy detonstion wave is the rise in stagontion pressure experienesd by an obstrele oves n'bieb the reve pases. Denoting by Pog' the strgoation pressure of the buraed gas in a courdinate system trhen the unburned gas is at rest. it onsy be sboing that

$$
\left(\frac{F_{m 2}}{p_{1}}\right)_{m:-1}=\frac{1+k M_{1}^{2}}{k}\left[1+\frac{k-1}{3}\left(\frac{M_{1}^{2}-1}{1+k M_{1}^{2}}\right)^{z}\right]^{\frac{k}{k-1}}
$$

This atio is also plotted in Fig. 7.9 for a Chapman-jouguet detonation.

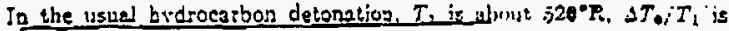
about 6 , and the spend of enund is stout 1000 ftisec. From Fie. 7.9 it may be seen that the flamefront speed is then alogut $3500 \mathrm{ft} / \mathrm{sec}$ and the stagnation pressure increases to sbout 25 atmospheres. The temperature ufter an sdiabstic shock traveling at $3300 \mathrm{ft}$, sete is found from the

liabatic aomal sbock tsbles to be about $3000^{\circ} \mathrm{F}$; thus. as indicated c.eviously, there is ronsiderable preliesting effert availsble for incretsing the Eeme sperd to values nueswry for dotenation

The temperatures in sn stomic explesion are ssid to be messured in millions of destces. If $\lambda T_{0} / T_{1}$ is ascumed to equsl $10^{4}$ for such an explosion, Fje. 7.0 indicates a rare fpeod of the order of mapritude of $200,000 \mathrm{ft} / \mathrm{sec}$ snd a stagnation pressure of the order of mapoitude of $\$ 0,000$ stuospleres!

\subsection{The Recorery Factor}

When a tuid tows through s pipe hsving an insulated mall, the termpersture at the rall (eslled the adisbatic rall tewperature, $T_{a w}$ ) is neither the sucrape stagantion tempersture $T_{0}$ nor the sverage static temperature $T$ of the stream. In 3 gas tor the adiabstic mall herporiture usually lies betwen $T$ and $T_{n}$. The factors infuencisy $T_{\text {as }}$ and theoretical nethods for prodicting its value are disrusered in detsil in Volume II, Chapters $2 \vec{i}$. 23 , ad 29. For the present we shill introduce *ome elementary considerntiocs and sbsll summurize surae exprimental results of value for practical computstiens of pipe fow.

Physical Mechanism of Frictional Beating. The temperature nc

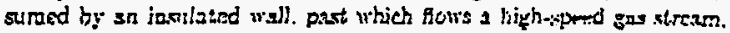
is controlled ly cumplex plitnomens in the buindary layer. Fluid layers far from the wall deliver viscous sheur work to layers nerar the wall. The consectuens iemperature rise of the inser layer is necesuarily ac-

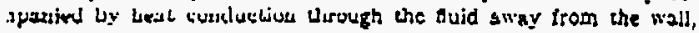


September 5, 1995

Pacific Northwest Laboratories Battelle Boulevard

P.O. Box 999

Richland. Washington 99352

Telephone (509)

$375-6694$

Troy Stokes

WHC

PO Box 1970

MSIN H5-09

Richland, Washington 99352

Dear Troy:

Jim Fort and I have reviewed the hydrogen-air combustion calculation performed by $\mathrm{A}$. Dabiri per your request. We found his calculated combustion pressure of 440 psi to be approximately the theoretical upper limit which is obtained by assuming stoichiometric detonation ( $-30 \% \mathrm{H} 2$ by volume). This represents the highest achievable pressure, and is, therefore, suitable for use as a conservative design pressure.

In addition to reviewing Dabiri's methodology, we performed two separate analyses to verify his result. The first of these utilized an undocumented educational software package which solves the theoretical equations to predict the detonation products. The program, EQLBRM, is an educational PC software written in 1988 by Prof. David Pratt of the University of Washington.

The second method was based on experimental results for $\mathrm{H} 2$-air combustion. The data of Lewis \& Friauf as reported in "Principles of Combustion" by K. K. Kuo, 1986, Wiley \& Son's, page 260 was used, together with the theoretical equations, to determine the detonation stagnation pressure.

For both of the methods, different reactants and buffers were considered which correspond to various stoichiometries. Combustion pressures ranging from $370-410$ psi were computed for stoichiometric conditions. The lower value is from software program and the upper value is based on the experimental data. The resulting pressure from rich or lean detonation is lower.

Please note that $440 \mathrm{psi}$ is an extremely conservative value. If it is found to be difficult to design the canister to handle these pressures, lower, more realistic values could be provided since detonation is very unlikely (experimentally determined lower detonation limit is $18 \%$ $\mathrm{H} 2$ by volume). More realistic pressures would be derived assuming adiabatic buming of pre-mixed $\mathrm{H} 2$-air using realistic values for $\mathrm{H} 2$ concentrations. 
September 5, 1995

Page 2

Please let me know if you have any questions concerning our findings.

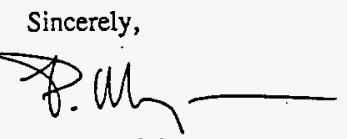

Perry A. Meyer

Research Scientist

$\mathrm{PAM} / \mathrm{kr}$

cc: James M. Bates

James A. Fort

File/LB 
From: $\quad$ Spent Nuclear Fuel Evaluations

Phone: $\quad 376-4193$

Date: April 4, 1996

Subject: SMMS Structural Evaluation for Normal Operating and Handling Conditions

To:

D. B. Graves

L6-0]

cc: $\begin{array}{ll}\text { B. L. Coverdell } & H 5-57 \\ \text { P. R. Deichelbolher } & 57-12 \\ \text { W. G. Farley } & 57-71 \\ \text { S. K. Farnsworth } & H 5-57 \\ \text { C. E. Hanson * } & H 5-09 \\ \text { L. S. Krogsrud } & \mathrm{R3}-08 \\ \text { R. P. Omberg } \star & \mathrm{R} 3-85 \\ \text { G. A. Ritter } & H 0-38 \\ \text { T. I. Stokes } & H 5-09 \\ \text { G. F. Vargo Jr. } & H 5-09 \\ \text { SLH File/LB } & \end{array}$

* without attachment

References: (1) Memo, S. L. Hecht to D. B. Graves, "SMMS Structural Evaluation for Accident Conditions.", November 28, 1995

(2) T. I. Stokes, et al, Handout: $60 \%$ Design Briefing Surface Moisture Measurement System (SMMS), October 4, 1995.

(3) Hanford Plant Standard - SDC-4.1, Standard Arch-Civil Design Criteria - Design Loads for Facilities, Rev 11, September 6, 1989.

(4) ASME BOILER \& PRESSURE VESSEL CODE - SECTION III. RUTES for Construction of NUCLEAR POHER PLANT COMPONENTS,

(5) Hanford Site Hoisting and Rigging Manual, RL-92-36, Rev. 0,1992

The attached analysis addresses the structural integrity and related requirements of the Surface Moisture Measurement System (SMIS) deployment assembly and the Hanford Site high-level waste (HLW) tanks component (s) to which it interfaces with during normal operations and handling. Structural assessment for design basis accident conditions (with the exception of the postulated detector hydrogen explosion, which is addressed, herein) were previously provided in reference 1. In the evaluation of the SMHS for structural integrity, it is required that the calculated stresses/strains for normal conditions comply with required or industry standard limits and safety factors.. Additionaliy, the calculated deformations are required to 
be within Timits as to meet functional requirements of the SMMS and tank systems. This should preclude any damage to the SMMS assembly and interfacing tank components. The results of the attached analysis show that the SMMS assembly and interfacing tank riser will maintain their structural integrity under the normal operating and handling conditions, addressed herein. A summary of these analyses, along with a discussion of loadings, assumptions and acceptance criteria, are given below.

\section{DESIGN LOADINGS/EVENTS AND ASSUMPTIONS}

The SMMS deployment device is classified as a Safety Class 3 component. The interfacing tank riser is classified as a Safety Class 2 component. The natural phenomena design loads, evaluated herein, for these Safety class components is the $80 \mathrm{MPH}$ wind Toads (per HPS-SDC-4.1, Standard Arch-Civil Design Criteria; Design Loads for Facilities - Ref. 3). Normal loadings considered are operational, operational wind, and installation loads. Normal operation arm motion loads are conservatively address by considering a postulated off-normal accident condition the where the arm actuator cable system is overloaded (by roughly a factor of 10) to failure. Each of these loadings, with corresponding stresses and allowable limits, are addressed. The assembly is assumed to be at a uniform constant temperature, with the maximum expected temperature not exceeding $150 \mathrm{~F}$. Analyses are based on description given in Reference 2 and Drawings H-14-100459, $100460,100461$.

\section{ACCEPTANCE CRITERIA}

Allowable values of calculated stresses and or strains used in the evaluation given herein are those given in the American Society of Mechanical Engineers (ASME), Boiler and Pressure Vessel Code - Section III; Nuclear Vessels ${ }^{14]}$. Other criteria are utilized in cases where they are more appropriate than the ASME code. For example, for crane lifting the criteria given in the Hanford Site Hoisting and Rigging Manual ${ }^{5}$ s are employed. These are cited in the particular application. As ductile construction material are used in the design, and the loading is not cycled a significant number of times, peak stress and associated fatigue damage are not generally considered. Deformations are evaluated as to their impact on the functional requirements of the SMMS device and the tank riser system interface requirements. Material properties, upon which allowables are based, are taken as minimum values, unless certified material property data exist for the actual metal or component used. Generally, most components are constructed of 304 or 316 stainless steel (SS), unless otherwise specified.

\section{LOADS, STRESSES AND DESIGN MARGINS (SUMMARY)}

In the attachment, evaluations are made as to the loading, stresses and structural integrity of the SMMS deployment device under various loading conditions. Loads are calculated when necessary for respective conditions. Stresses are determined for the critical Tocations and are compared against a) lowable limits. 


\section{Normal Operation and Handling Conditions}

These loading conditions include those which are expected and are designed to. These include normal operations and normal, expected, handiing loads. Structural integrity evaluation for these conditions is per criteria given in ASME B\&PV Section III, for Design Conditions, unless otherwise stated. The components are to remain intact and totally functional and continue normal operations after these loading conditions are experienced.

\section{Wind Loading (see attachment pages 2-4)}

The design wind load, for safety class 2 and 3 components are those loads associated with 80 and $70 \mathrm{mph}$ winds ${ }^{[3]}$, respectively. The Tank Farms have placed $15 \mathrm{mph}$ wind speed operating limits on crane lifts, so as crane lifts are not allowed during higher wind speeds. It is currently expected, that during SMMS operations, if higher than allowed wind speeds are expected, or experienced, the SMMS device will be lowered and positioned in a parked location. This parked position is expected to be approximately at the appropriate tank riser interface. Hence, two different design conditions were considered. These are: (1) a maximum $80 \mathrm{mph}$ load in the parked position, and (2) an operating wind load, which can be at any crane controlled vertical location. This operating load is assumed to be twice, the crane operating limit (to account for gusts), or $30 \mathrm{mph}$.

\section{0 mph wind at parked position}

While the SMMS device need only be designed for a $70 \mathrm{mph}$ wind (safety class 3 ), the analysis assumed a wind speed of $80 \mathrm{mph}$, as it is the required design conditions for the interfacing riser. Here it is conservatively assumed that the line from the crane does not provide any horizontal resistance.

The maximum (orientation dependent) wind load or drag on the enclosure box was calculated at 242 lbs. This produces a maximum bending stress on the SMMS mast (at the riser system interface) of $4,840 \mathrm{psi}$. This primary bending stress is well below the 30,000 psi ASME Section III allowable limit. For the riser, a maximum stress of $14,900 \mathrm{psi}$ is predicted at tank dome interface. As the allowable stress limit for this condition is 24,000 psi, an acceptable condition exists.

\section{0 mph wind at any operating position}

The SMMS deployment device was assumed to be at the highest elevation which can transmit a bending moment to the riser system. Any horizontal constraint from the crane is conservatively neglected.

The maximum (orientation dependent) wind load or drag on the enclosure box was calculated at 34 lbs. This produces a maximum bending stress on the SMMS mast (at the riser system interface) of 8,600 psi. This primary bending stress is well below the 30,000 psi ASME Section III allowable limit. For the riser, a maximum stress of 4,940 psi is predicted at tank dome interface, well below the allowable stress limit of 24,000 psi. 
Handling Loads - Horizontal-to-Vertical Lift ( see attachment pgs. 5-10)

The SMMS deployment device is transported to and within the tank farm in a horizontal position. This relatively flexible 35-39 ft. long assembly is then lifted to a vertical orientation, so it can be lowered into the waste tank riser. To do this lift requires the use of one or more crane(s).

A finite element analysis (FEA) was used for the analysis of the main structure(s) for the proposed horizontal lift conditions. The FEA model, shown in figure 1 and 2 of the attachment, is comprised of beam elements. The pipe sections are modeled exactly for bending characteristics, whereas the control box regions were modeled primarily to represent the masses at these location only. Hence, stresses at these, non pipe, locations, are erroneous, as they are not expected to be significant. Pseudo areas and densities were used to account for the mass distributions. Loading was induced via gravitational body forces (1 g) and displacement boundary elements were applies to simulate lift conditions $\left(U_{y}=0\right)$.

Four different cases were considered. These were two different proposed lifting configurations for each geometric type, i.e., long and short. Lifting points are assume to be at: 1) just above the slot on the mast, and 2) at the enclosure box. Two cases consider a lift from the lifting arms only, whereas, the other two cases assume an additional lift point at the enclosure box region, at the top of the box. Results of these analyses, showed that the maximum principal stress, $\sigma_{1}$, or the absolute value of the minimum principal stress, $\left|\sigma_{3}\right|$, in the pipe was in the worst cases predicted at 13,850 psi (see fig. 2 in attachment). The allowable principal stress, per the rules given in the Hanford Site Hoisting and Rigging Manual ${ }^{[5]}$, is $S_{x} / 3$. For the $304 \mathrm{~L} S S$ pipe, with $S_{y}=42.8 \mathrm{ksi}$ (from mat' 7 certs), the allowable principal stress is 14,270 psi. As the calculated stresses are less than the allowable value, the proposed $1 \mathrm{ift}$ scenarios are acceptable.

The crane attachment lifting arms were also evaluated. Maximum loads were assumed, i.e., no lift force at the top of the enclosure box. For the horizontal position, the predicted maximum principal stress on the lifting arm is 5,010 psi, well below the allowable limit of 10,000 psi. The attachment bolts have a predicted maximum shear stress of 17,160 psi. This too, is below the allowable shear stress of 20,000 psi for the high strength bolts. For the vertical lift position, the bolts are now in tension, and here $\sigma_{1}=13,100 \mathrm{psi}$, considerably less than the $40,000 \mathrm{psi}$ limit. For bending, the arm is in the weak direction (due to holes) and the predicted $\sigma_{1}=9,740 \mathrm{psi}$, which is below the 10,000 psi limit.

\section{Arm Actuation Loading (see pages 11-24 in attachment)}

For normal operation, the loading, via cable force, is $10 w$ (< $100 \mathrm{lbs}$ ) and not expected to be a problem. However, a potential conservative bounding accident conditions scenario is postulated. Here, upon an operator lifting the arm to the full up position, via cranking on cable winch, the torque limiter/winch system fails and allows the cable system to reach a load of 1100 lbs (for the current torque limit setting, the maximum cable force is less than 1030 lbs) and subsequentiy the cable is assumed to instantaneousiy go slack, which is highly unlikely, and allows the arm to fall. This 
conservative assumption should more than qualify the system for normal operation, provided all components other that the cable shear pin remain intact. This accident is referred to in the report and attachment as ejther the "cable system accident" or "cable accident".

The full load conditions assumes failure (of the cable system), hence the evaluation is made to assure the failed SMMS device can be removed from the HLW tank, intact. Just prior to the postulated cable system failure, the maximum load is reacted by the component in the load path. The arm stop in the up-position reacts the load (via couple) so that the 1 inch 31655 axle develops an average shear stress (double shear) of $8,210 \mathrm{psi}$. The failure strength of the axle in shear is $15,000 \mathrm{psi}$. The bending moment developed at the arm elbow cause a bending stress in the mast pipe of 23,800 psi, which is below the minimum yield strength of the mast material ( $42.7 \mathrm{ksi})$. The cable lift arm on the SMMS arm assembly, in the maximum loaded upposition, will develop a maximum bending stress of 23,900 psi, an acceptable value considering a minimum yield strength of the $3045 S$ material of 30,000 psi.

Once the cable system fails, the arm accelerates downward, due to gravitational potential energy (PE) and stored elastic strain energy in the deflected arm. This available potential energy of 5,600 in-lbs becomes kinetic energy (KE) and impacts the stop on the mast elbow joint. The calculations show that the mast will plastically deform and absorb the KE in plastic work (or strain energy), before the elbow stop system fails (.5 in dia pin shearing). This prediction included an elastic-plastic FEA on the lower mast system (see fig 5 in the attachment). Predictions showed that a permanent set of 0.7 inches, over the lower 57 inches of the mast, would be required to absorb the KE. The calculated plastic deformations occur in the upper 14 inches of the slotted section of the mast. Analys is shows that it would require up to approximately 200 lbs of additional withdrawal force to pult the 0.7 inch bent 3.5 inch mast through a 4 inch riser, which is doable. A maximum effective stress of $44,320 \mathrm{psi}$ and corresponding equivalent plastic strain of $2.5 \%$ were predicted. The failure strain for this material is $46 \%$, hence their is a large margin to failure.

\section{Off-Normal Accident Conditions (Explosion within the Detector Housing) (see page 25 in attachment)}

This postulated accident condition was not addressed in Reference 1, and hence is provided herein. It is postulated that a spark from the detector electrical system ignites entrapped hydrogen gas within the detector housing, causing a peak pressure of $510 \mathrm{psi}$. It is desirable to show that the housing will retain structural integrity, and hence the event will not propagate to the tank environment.

A maximum primary hoop stress of 6,510 psi was calculated to the thinnest cylindrical section. The bottom flat-head (1/8th inch plate) was calculated to have a maximum bending stress (based on fixed boundary conditions) of $57,300 \mathrm{psi}$. As the thickness of the cylindrical section is the same as the end-plate, the maximum discontinuity bending stress in the cylindrical tube should be slightly lower than that predicted for the flat-head. Since these stresses are lower than the minimum ultimate strength of 75,000 psi for the $302 / 304$ SS material, design is acceptable. 
Page 6

\section{CONCLUSION}

The SMMS deployment device and interfacing tank components were shown to be structurally acceptable for design loading (normal and anticipated) conditions. The minimum Safety Factor on allowable stress was determined to be 1.03 (Design Margin $=0.03$ or $3 \%$ over designed). Calculated deformation were found to be acceptable, so as to assure that the SMMS deployment device will function as intended or can safely be removed from a tank.

\section{Computer Runs}

Input and output files of the SUN4 (SPARC) ALGOR FEA runs made for the SMMS analysis are stored on a compressed UNIX TAR file, smms,tar. $Z$. This file can be found on the Hanford Common File System (CFS), in directory /v92527/fem.
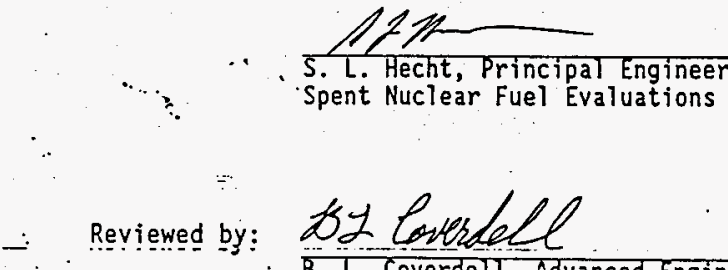

- B. L. CoverdelT, Advanced Engineer Analytical. Services

\section{Attachment}


WHC-SD-WM-DA-202 REV 0

\section{ANALYTICAL CALCULATIONS}

Appendix E

Page 7 of 32

Subject 5 MMS STRUCTURAC ANACYS IS

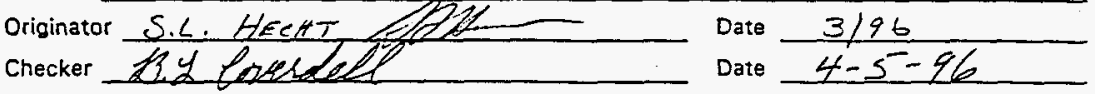

ATTACHMEL

SMMS STRUCTURAL Evaluation FON WORMAL

OpERATING Ano Hariount Conditrous

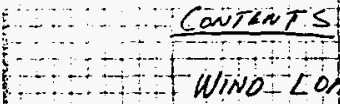

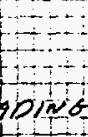

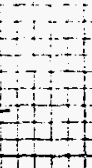

$+\ldots$

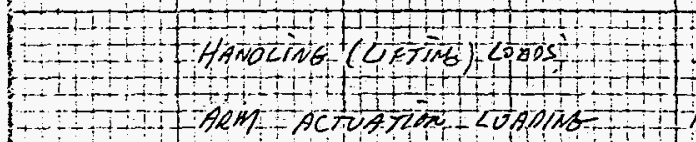

PACES

Page

or $\angle B$ 
DESIGN CALCULATION

WHC-SD-WM-DA-202 REV 0

(1) Drawing (2) Doc. No. (3) Page Appendix E

(4) Building (5) Rev. (6) Job No.

(7) Subject smms

Page 8 of $\underline{32}$

(8) Originator $\frac{5.4 \cdot 4 t / 7}{1.1 \rho}$

(9) Checker Date $3 / 96$ Date $4-5-96$

(10)

WIND LOADS

80 MPH is PADKAD POSITIOD (SARET COASE)

$$
\begin{aligned}
& P \text { (DeAG) }=C_{D} 4 \rho V_{f}^{2} / 2 \text { on Box } 42^{\prime \prime} x+1^{\prime \prime} \text { Crect sect } \\
& c_{0}=f\left(R_{e}\right) \\
& P_{0}=V_{f} d / \\
& j=0.000143 f 7^{2} / s-c, e=00251-15-5 c / t r^{2} \\
& d=\frac{2}{2} / 12=3.5 F T \\
& V_{f}=(80 \mathrm{mi} / \mathrm{hr})(\mathrm{hr} / 3600 \mathrm{f})(5230 \mathrm{fi} / \mathrm{mi})=117 \mathrm{ft} / \mathrm{sec} \\
& R_{2}=0(1 / 2)(3,5) / 000 / 63-2,9 \times 10^{5} \\
& L / d=1, C_{d}=1.18+[1] \\
& \therefore \quad A=(42)(4) / 144=11.96 \mathrm{FT}^{2} \\
& \therefore \quad D=(1.78)(11.96)(1.00251)(117)^{2} / 2=242165
\end{aligned}
$$

THE MAST INTELACTS WITH THS FIRST "eIEID

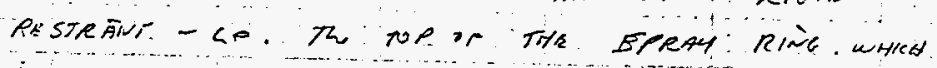

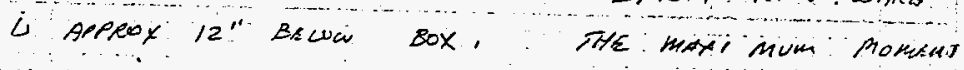
Hex is:

$$
\begin{aligned}
& m=\left(\frac{42}{2}+12\right)(242)=7,99010-16 \\
& \sigma_{b}=\frac{m_{c}}{I}=\frac{(7,990)(1,75)}{2.39}=4,840 \mathrm{psi}
\end{aligned}
$$

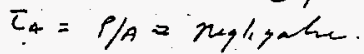

$$
\begin{aligned}
& \sigma_{\text {tane }}=2.5, S_{\text {mix }}=(1,5)(20,000)=30,000\left[{ }_{2}\right], \therefore \text {.k. }
\end{aligned}
$$

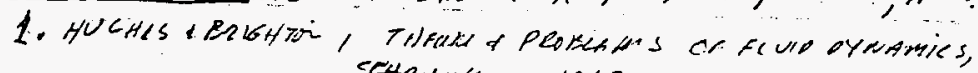
SFHov's, 1967

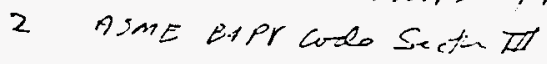

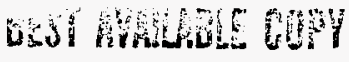

BD 6400.060 , (12.87) 
DESIGN CALCULATION

(1) Drawing

(4) Building

(7) Subject

(8) Originator

(9) Checker
(2) Doc. No.

(5) Rev.

WHC-SD-WM-DA-202 REV 0

Appendix E

(3) Page _ Page 9 of 32 (6) Job No.

Date $\frac{3 / 96}{4-5}$

Date $4-5-46$

(10)

Tith storss on thre 21sEx 4 " SHP' to is

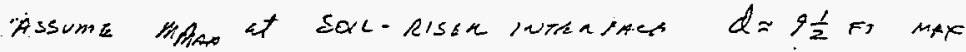

$$
\begin{aligned}
& m_{x o y}=(242)(9,5)(12)=27,600 \mathrm{in} \mathrm{-} \mathrm{16)} \\
& F_{\text {rizen }}=\frac{\pi}{60}\left(P_{0}^{2}-D_{1}^{2}\right)=\frac{\pi}{64}\left(4,5^{ \pm}-4,026^{4}\right)=7,2310^{4} \\
& \vec{\sigma}_{m a x}=\frac{m_{C}}{I}=\frac{(27,600)(2,25)}{7,23}=8 / 590 \text { is }
\end{aligned}
$$

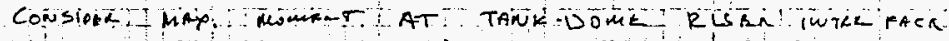

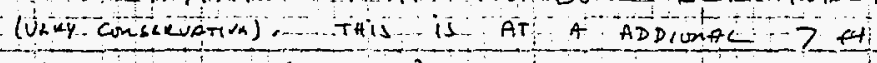

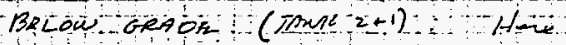

$m_{\text {mex }}=(202)(16,5)(12)=47,900$, INE 15

$$
\sigma_{L}=\frac{m_{L}}{I}=\frac{(47,900)(2,25)}{7,23}=14,900, p s i
$$

ALLAWABCF PLR ASME SE ZII AUI NB 3200

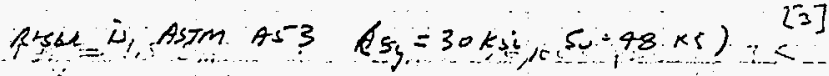

$$
\begin{aligned}
& \operatorname{Sim}=48,000 / 3=16,000 \\
& \text { allo-er }\left(t_{L}+p_{b}\right)=(1,5)\left(s_{m}\right)-24,000 \\
& \left(P_{c}^{\prime}+P_{b}\right)_{\text {RLCO }}>\sigma_{b} \Rightarrow \text { desiblis ok }
\end{aligned}
$$

3. METEL'S HANDBODK, VoL 1 gth Ed. ASM 1975

BEST AVALUBSE COP"

$80.6400 .0601(12 / 87)$ 
DESIGN CALCULATION WHC-SD-WM-DA-202 REV 0

(1) Drawing (2) Doc. No. Appendix E

(4) Building (5) Rev.

(3) Page Page 10 of $\underline{32}$

(7) Subject Sm (6) Job No.

(8) Originator Date $3 / 96$

(9) Checker $\not 1 e$ Date $4-8-96$

(10)

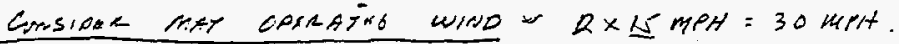

Hew $R_{c}=(30 / 80)\left(2.9 \times 10^{5}\right)=1.09 \times 10^{5}$

Co 5 Amt as te for $=1.18$

tan $D=(30 / 80)^{2}(242)=3416$ $(14 \%)$

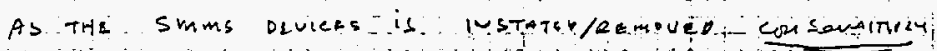
Consicen no houjout support for the crane

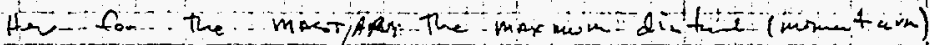

$*$

$$
\begin{aligned}
& \text { is } 33 \text { w }+ \text { loft of mantank }=380 \\
& M_{\text {mus }}=\mathrm{d}=(34)(380)=12,9=0,1 \\
& \sigma_{\text {mex }}=\frac{m_{L}}{I}=\frac{12,920(1,75)}{2.89}=7,820
\end{aligned}
$$

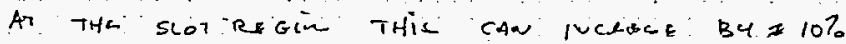
$\therefore$ B...8,6005 Psi.

$R_{A B}$ ALCOA $A=1,5 \operatorname{sm}=(1,5)(20,000)=30,000$ Design is ok.

one $21 \sin I^{-}$

Max Honor ARM $=347+\left(\frac{-3+6+7}{12}\right)(12)=467$ in

$$
H_{\text {max }}=(34)(467)=15,880 \mathrm{i \sim m} / \mathrm{b}
$$

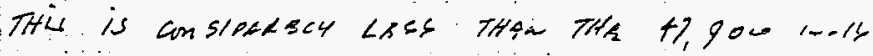

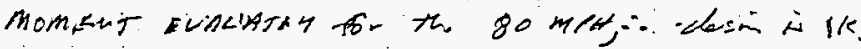

$$
\left(6=\frac{1,8,80}{47,900}\right)(14,900)=4,940
$$

BEST MVRELEEE MI

BD. $6500.0601(12,87)$ 
Subject SmMS

Page $S$ or $\leqslant$

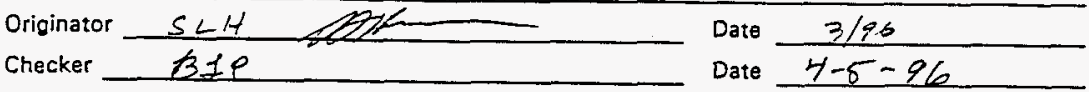

\section{LIFTIR'S cotes}

CONSIDLZ BOTS HOLLZONTA S DAD VERTICAL DOSITADarino crigrt ife

\section{HOnIZENAC}

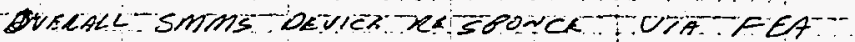

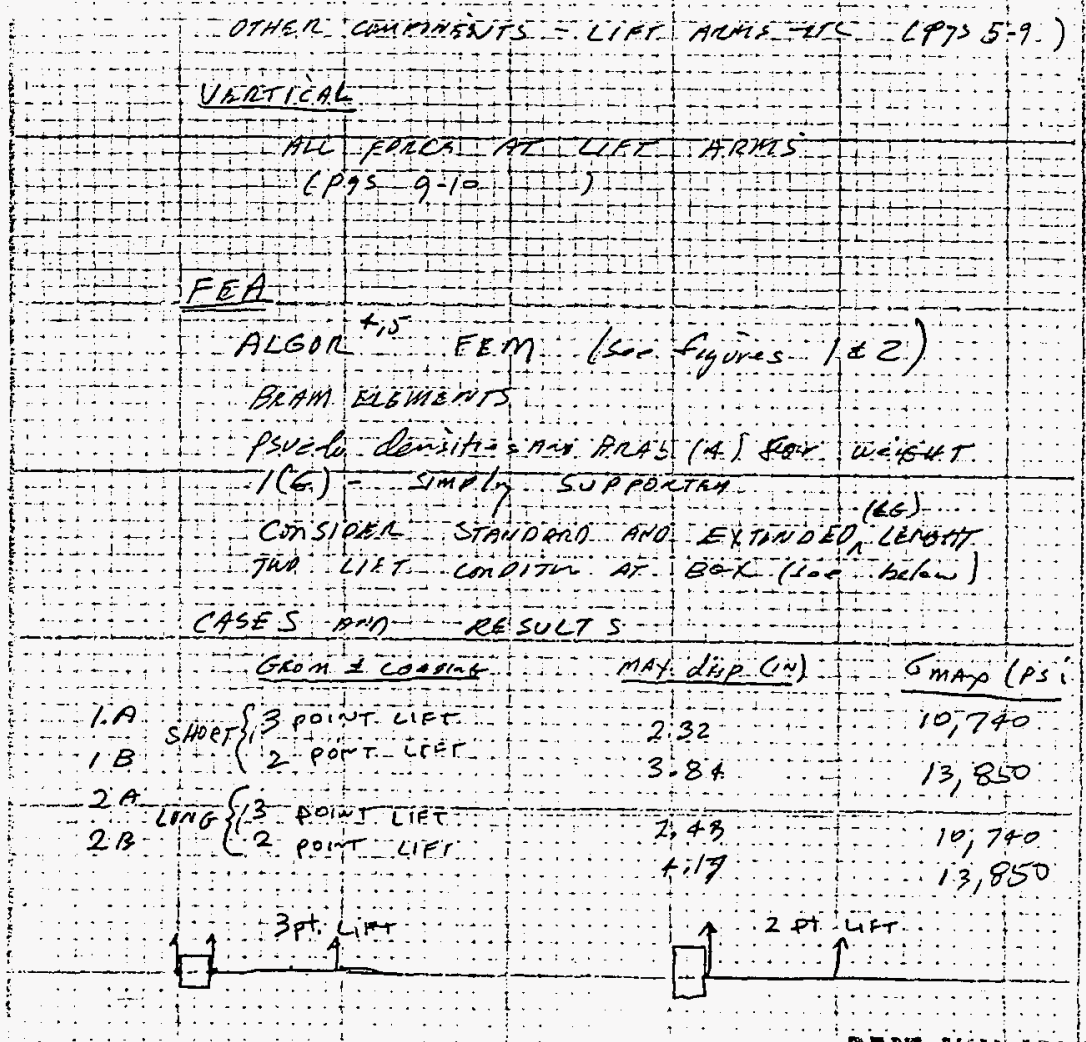


WHC-SD-WM-DA-202 REV 0

Appendix E

ANALYTICAL CALCULATIONS

Page 12 of $\$ 2$

Page 6 of 25

Subject 5

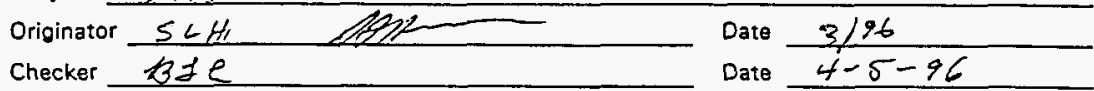

$A C \operatorname{coc} A \cos =S_{4} / 3$

$S_{y}=42,700 .(C \operatorname{ser}(s)$

$S a 1=(42,200 / 3=14,270 \Rightarrow 0 k$,

RASUATS FOR CASE IB is BHOWO II

$F / \epsilon \ldots 2$

(2)

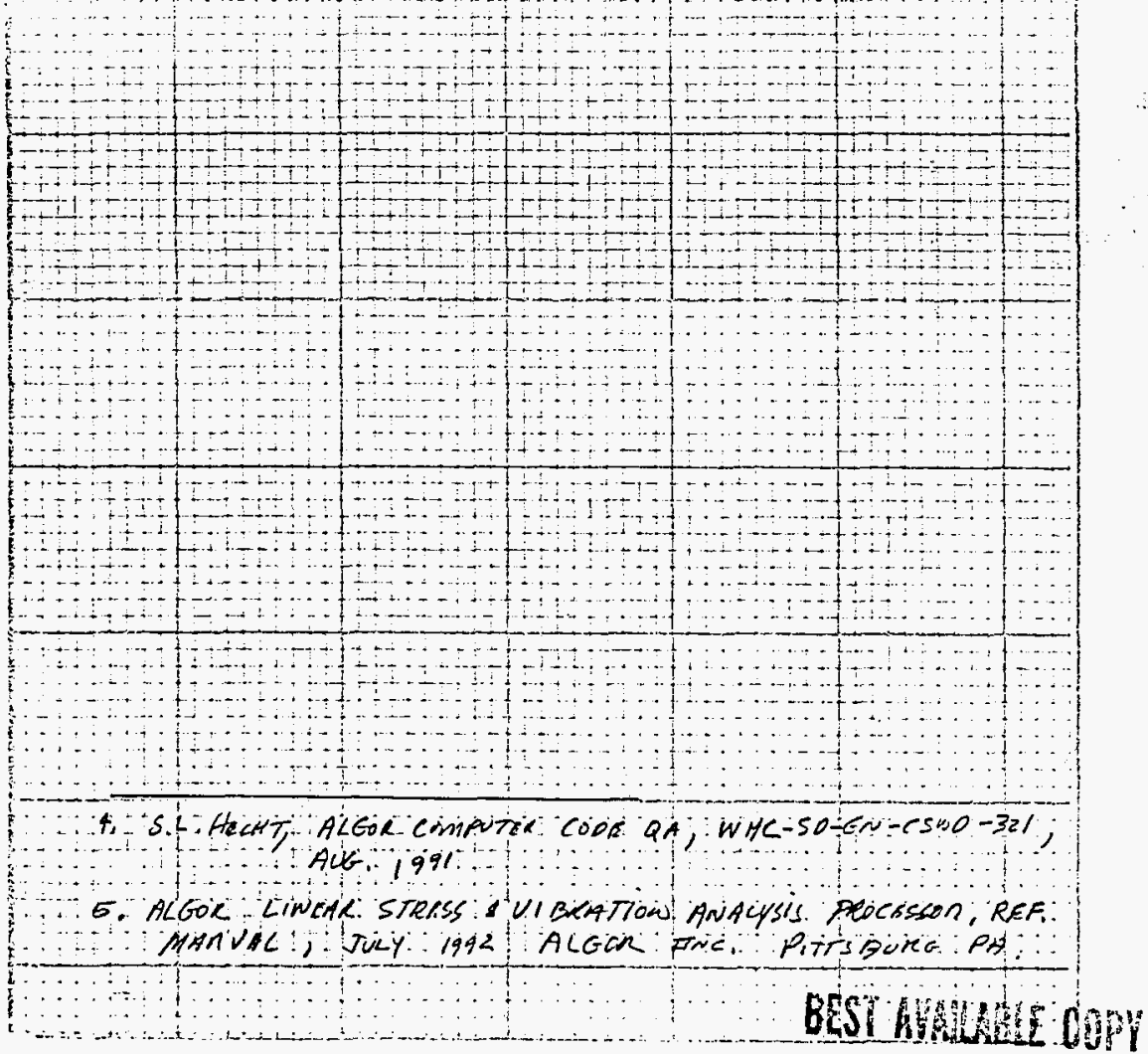




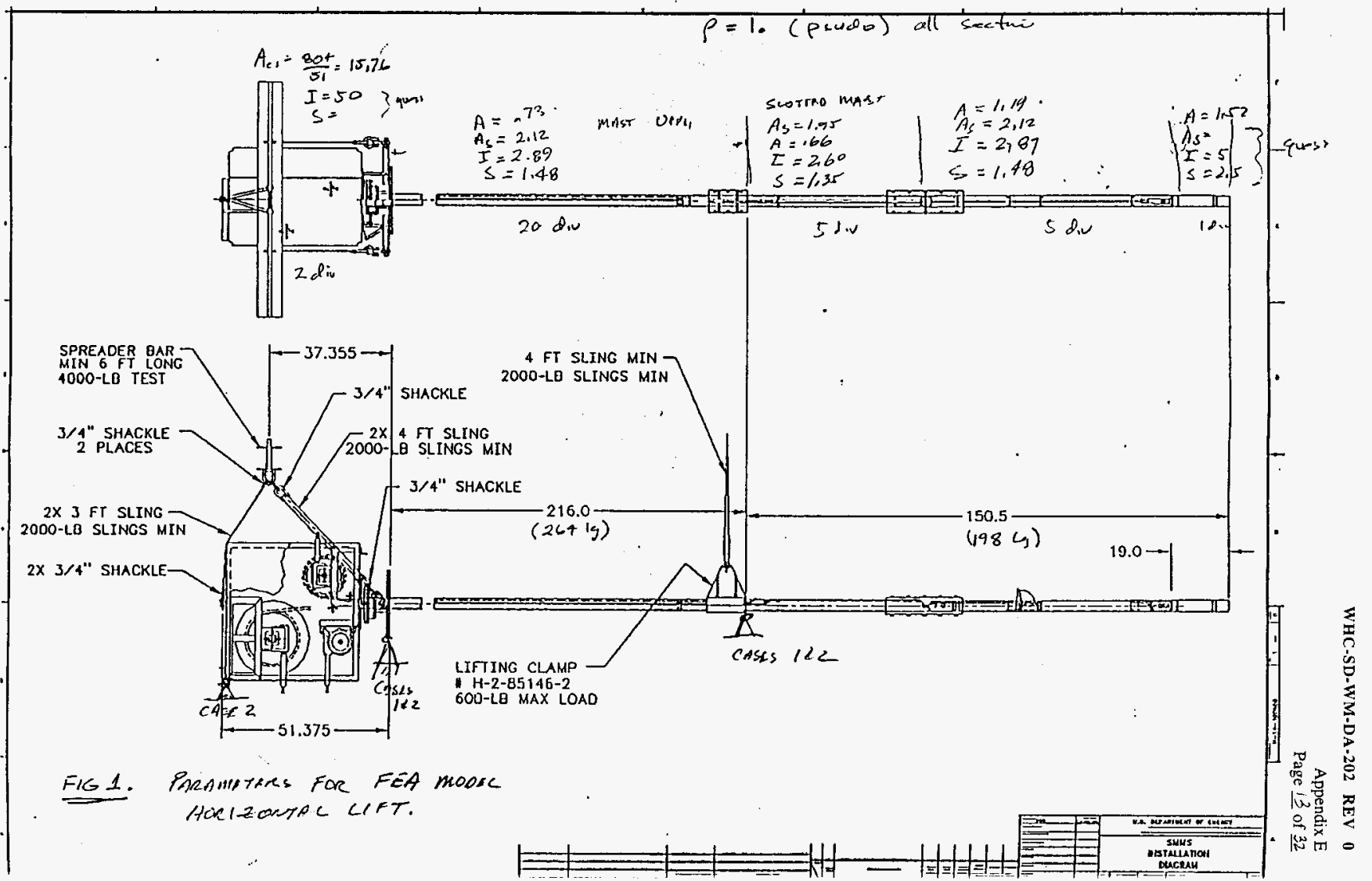




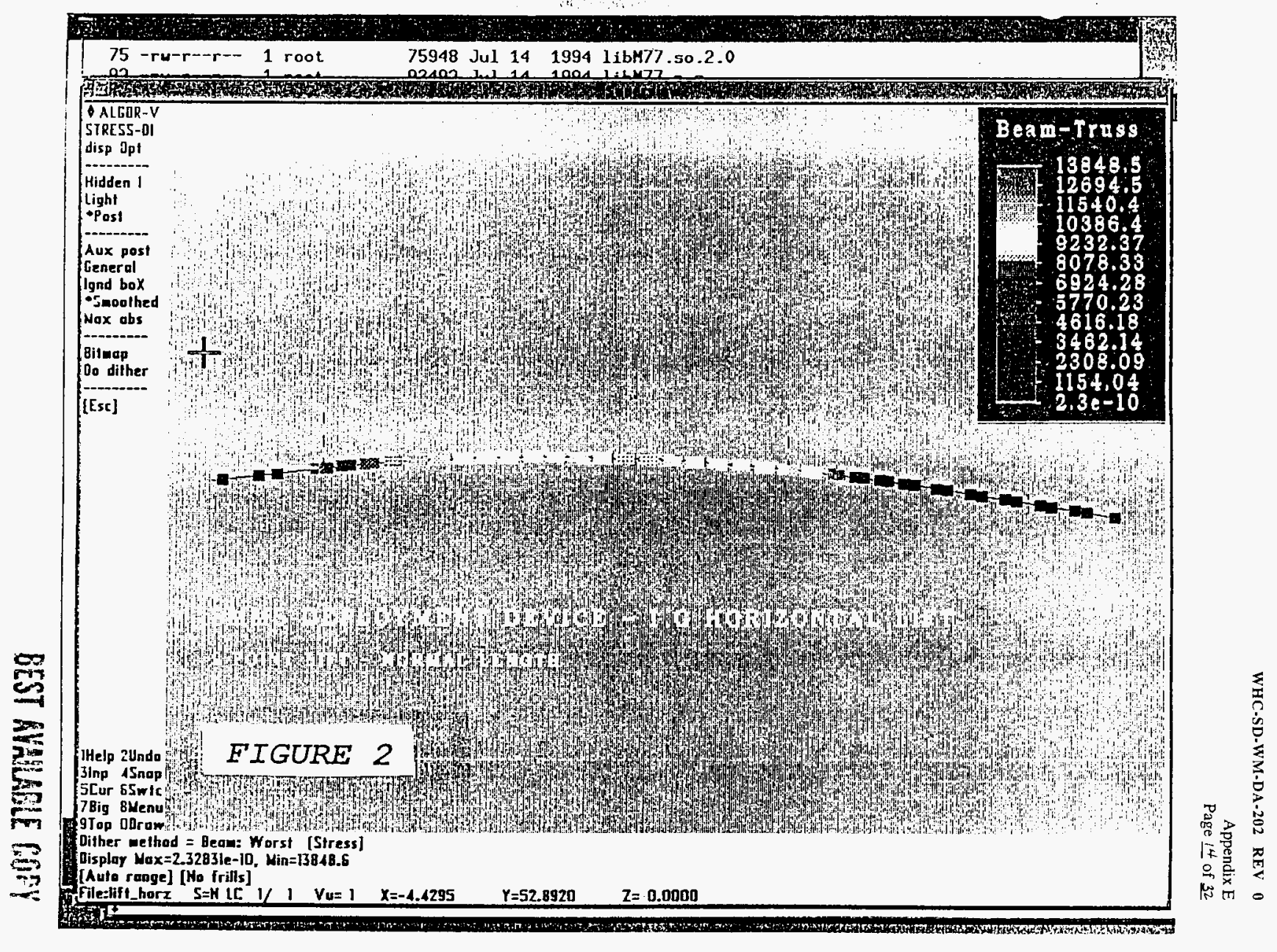


WHC-SD-WM-DA-202 REV 0

Appendix E

ANALYTICAL CALCULATIONS

Page 16 of 32

Page 드

Subject $\frac{5 M m S}{5 L H}$
Originator
Checker

Date $\frac{3 / 96}{4-5-96}$

$\xi m_{A}=0: \quad+84 F_{B}+1,84=(575)(13 ; 2)$

Assum Far it Rigid: :

$F_{2}=\frac{4.34}{1.54} F_{8}$

So $T_{14} \gamma_{184} F_{8}+\left(\frac{4.84}{1.94}\right)(4.84) F_{B}=7,590$

$1=0=520-0 . F=\left(\frac{4.84}{1.54}\right)(520)=1390$

$\xi_{1} F=0 \quad f f_{a}=575-521 \% 1390=-385$

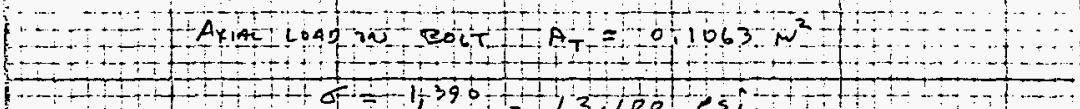

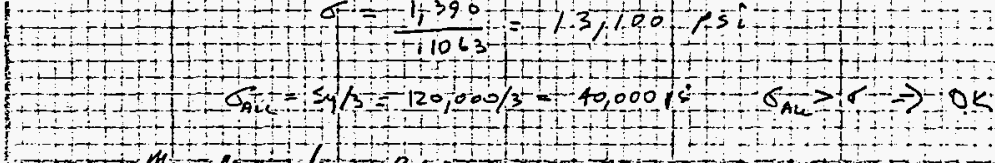

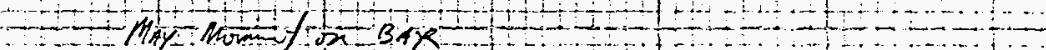

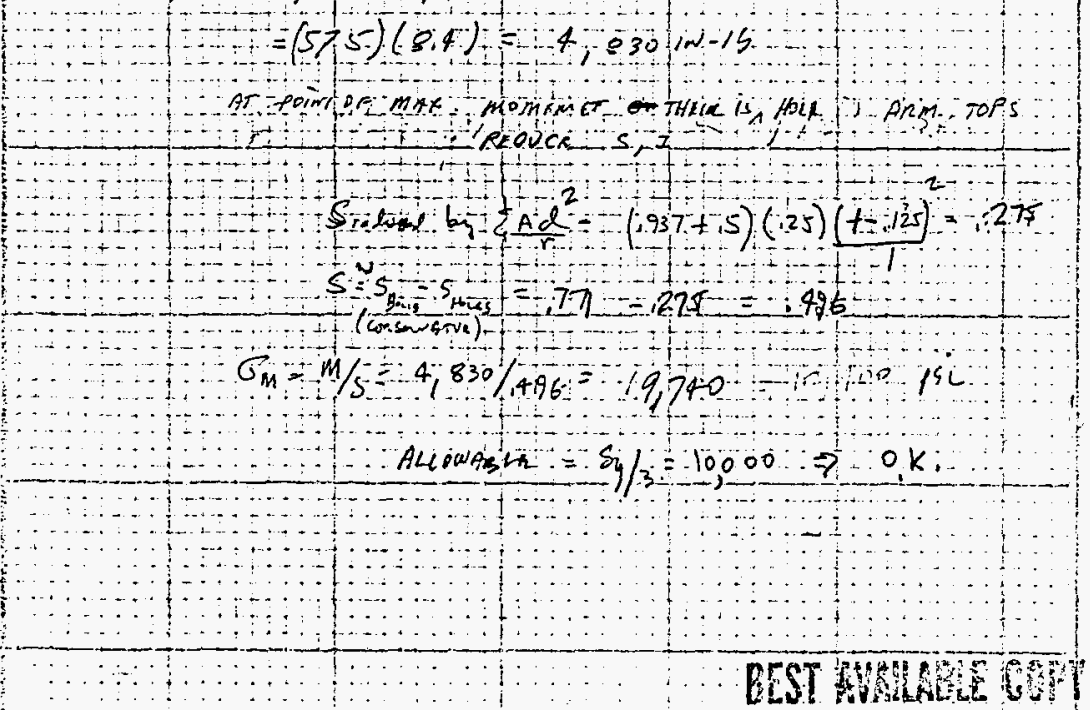




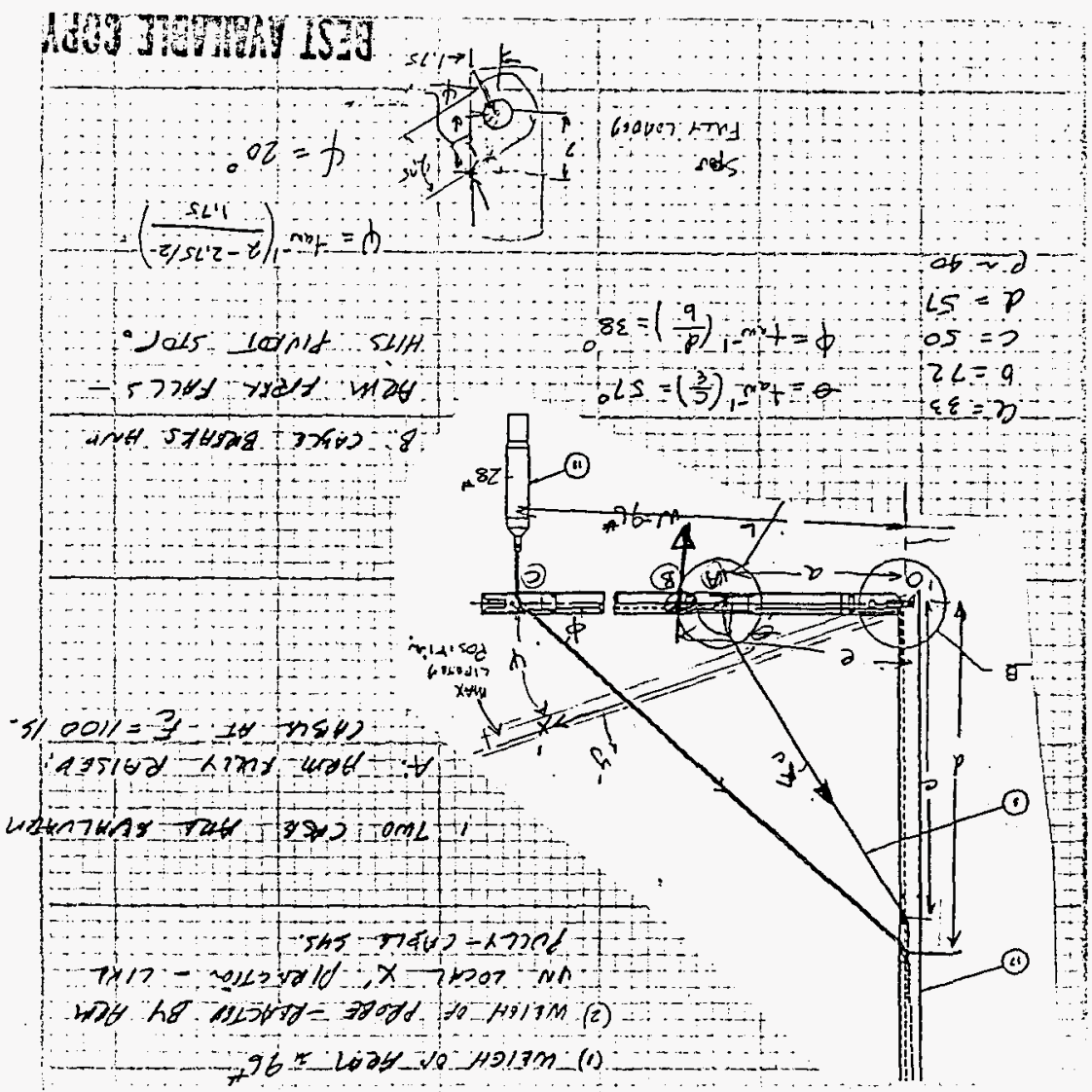

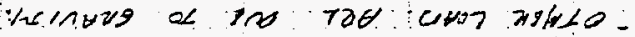

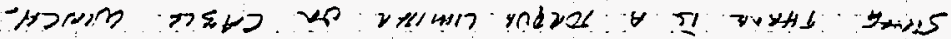

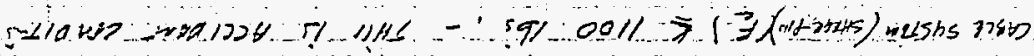

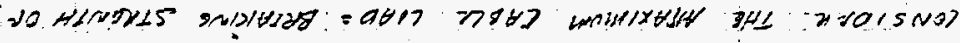

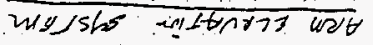

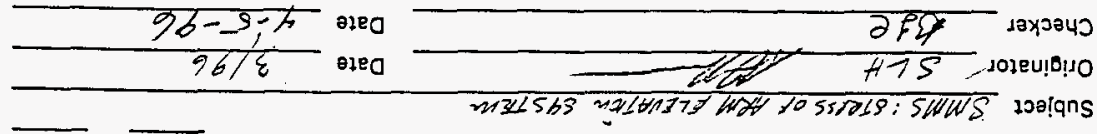

2 ;0 11 abed

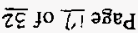

$\exists$ xipuaddV

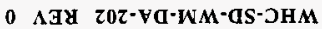

SNOII $\forall า ก ว า \forall ว ~ 7 \forall ว เ \perp \Lambda า \forall N \forall$ 
Subject Smas

Page 12 of 25

Originator $\frac{s+y}{13 y e}$

Date $\frac{3 / 96}{4-5-96}$

$\stackrel{0}{\rightarrow 0}$

d $A \quad F_{x}^{a}=F_{e} \cos (\theta+4)=1100 \cos (57+20)=-24716$ $F^{\prime}=\cdots 1 t 00 \sin \left(77^{\circ}\right)=107016$

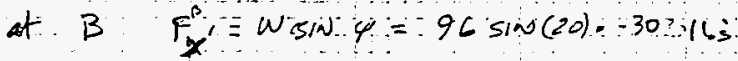

$F^{b}=-96(0) 1(20)=-90$

(a)

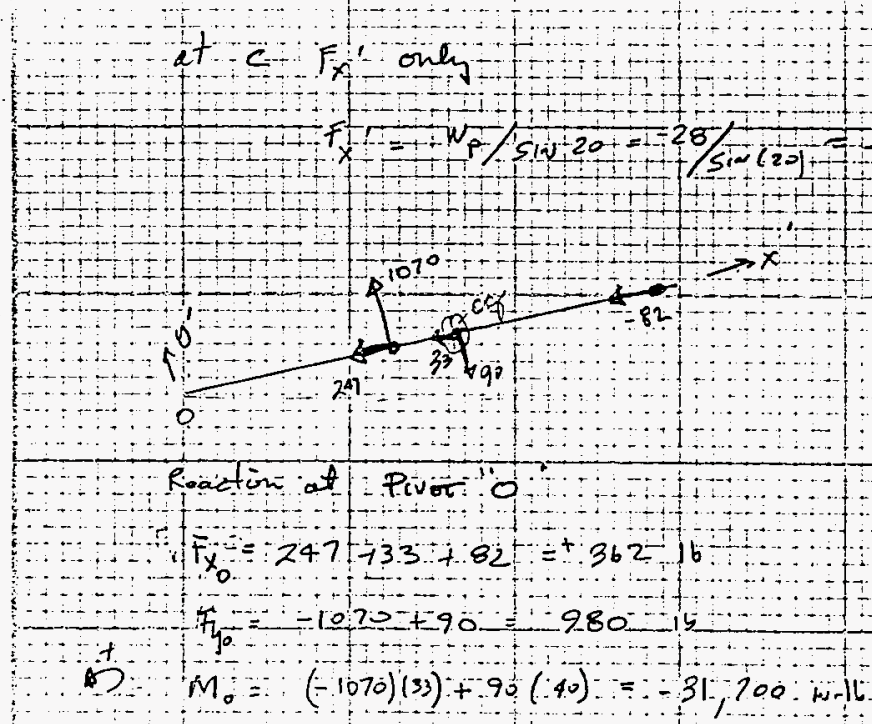

couple enslt de

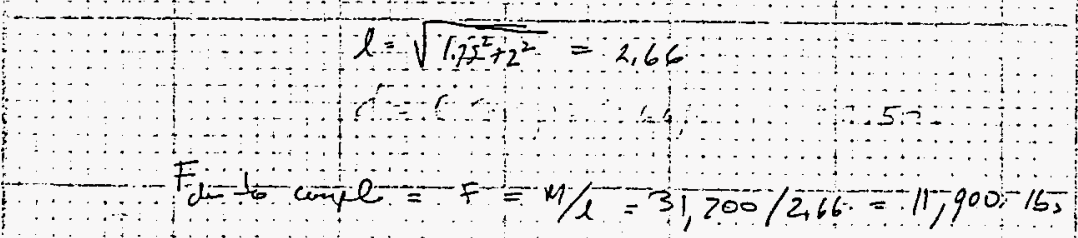


WHC-SD-WM-DA-202 REV 0

Appendix $E$

ANALYTICAL CALCULATIONS

Page 19 of 32

Page 13 of 25

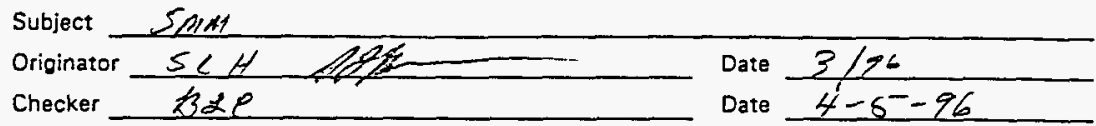

Momoir on IMMS PIft (So4), $S_{j}=427 \mathrm{ksi}$

$$
\begin{gathered}
T=(2.89)(09)-26 \text { (sepp) } \\
\sigma_{6}=\frac{m c}{I}=\frac{(31,700)(1.95)}{2,6}=23,800 \text { <sy ol }
\end{gathered}
$$

CADLR LIFEAQMISATEM

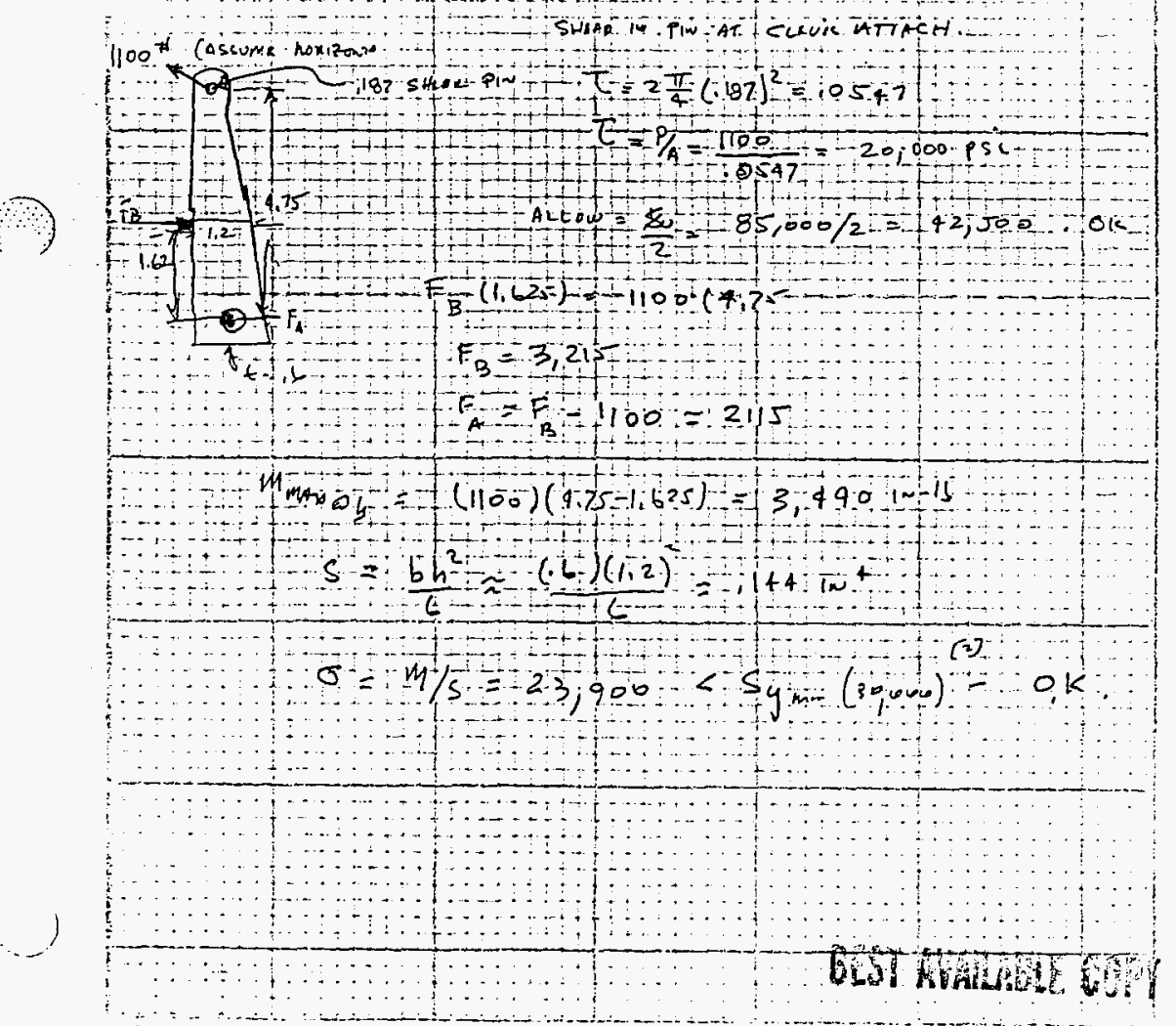

$80-6400-060.1107 / 931$ 
WHC-SD-WM-DA-202 REV 0

Appendix E

ANALYTICAL CALCULATIONS

Page $\underline{20}$ of $\underline{32}$

Page

Subject SoM

Originator $S(f)$

Date $3 / 96$

Checker

Date $4-5-96$

SHLAK in $4 \times 14 E$ E

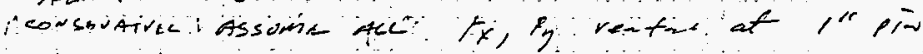

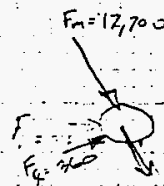

$$
F_{\text {max }}=\sqrt{(11,900+980)^{2}+360^{2}}=12,900165
$$

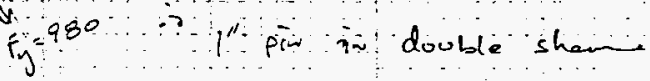

$$
T_{A v g}=P / A=-\frac{12900}{(2)(\pi / 4)(1)^{2}}=8,2103 \text { psi }
$$

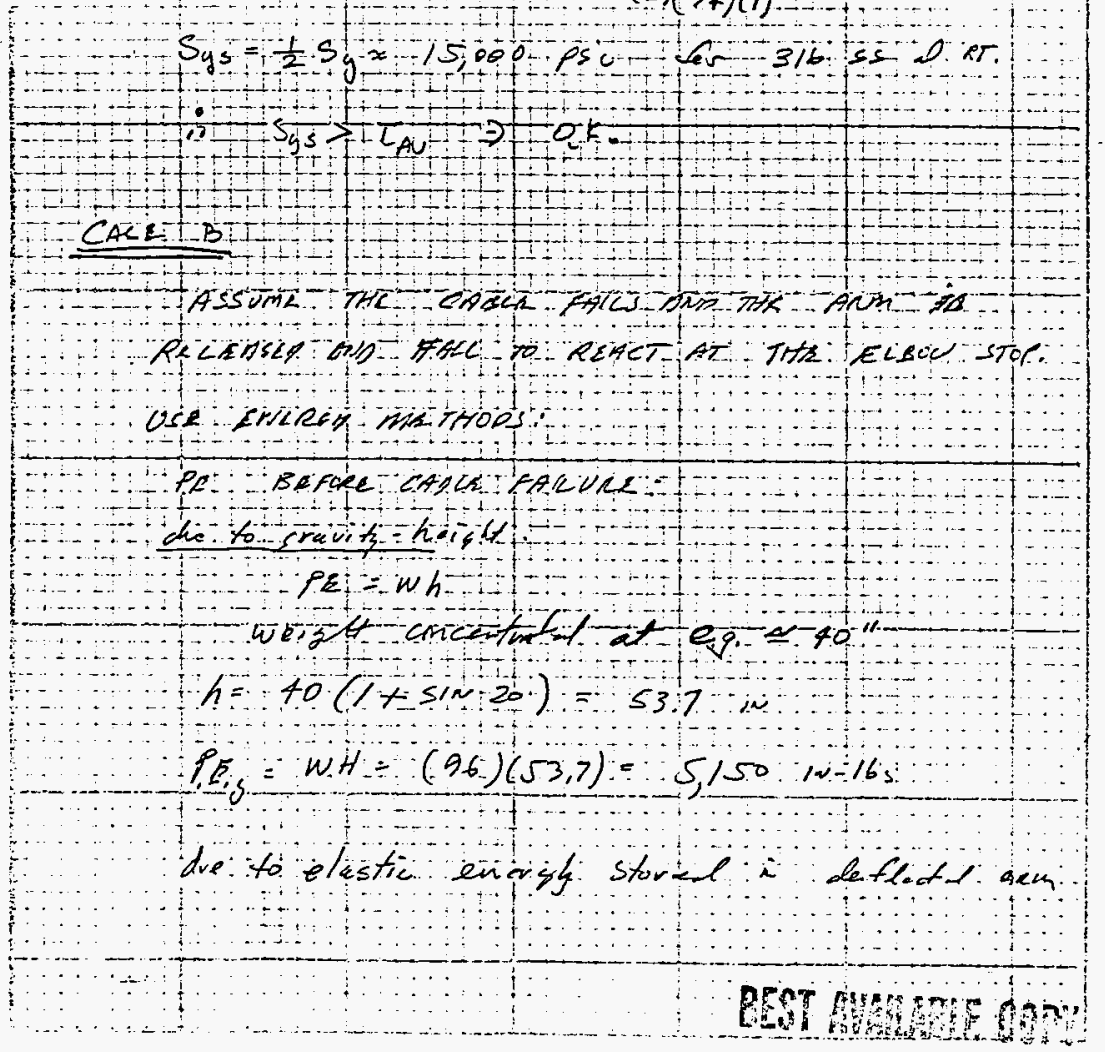

BD. $6400-060.1(07 / 93)$ 
WHC-SD-WM-DA-202 REV 0

ANALYTICAL CALCULATIONS
Appendix E

Page $\underline{21}$ of $3 z$

Page 15

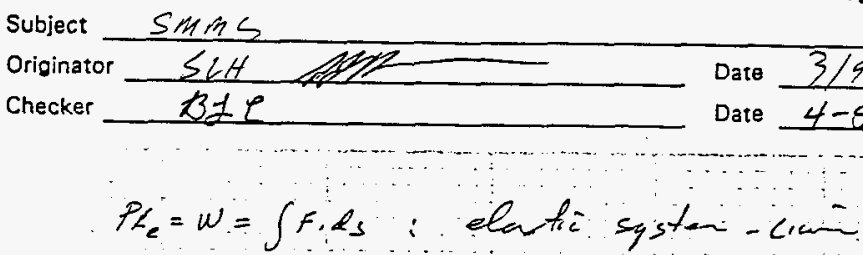

$$
\begin{aligned}
& \therefore p=F \delta \sin / 2 ; \delta=F / z,-\infty w=F^{2} / 2 k
\end{aligned}
$$

CANTILIVAR BBAR:

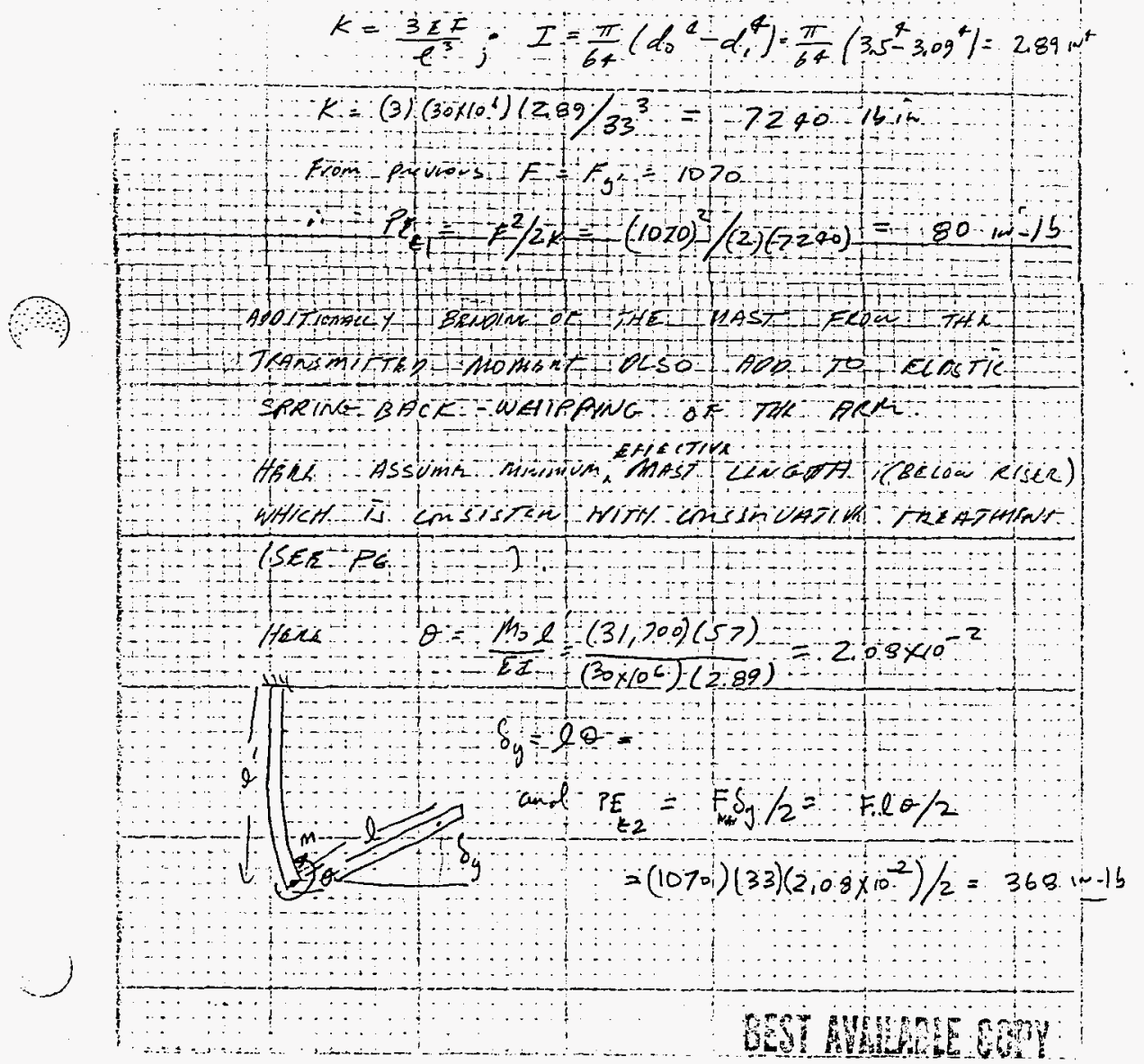

BD.6400-060.1 (07/93) 
Subject SHAy

Originator $\frac{S L H}{131 e}$ Date $\frac{3 / 96}{4-6 r-96}$

$$
\begin{aligned}
& \text { PE port }=P E_{\text {grevt }} P_{2,1} P_{2} \\
& =5,150+80+370=5,600 \text { 11 }
\end{aligned}
$$

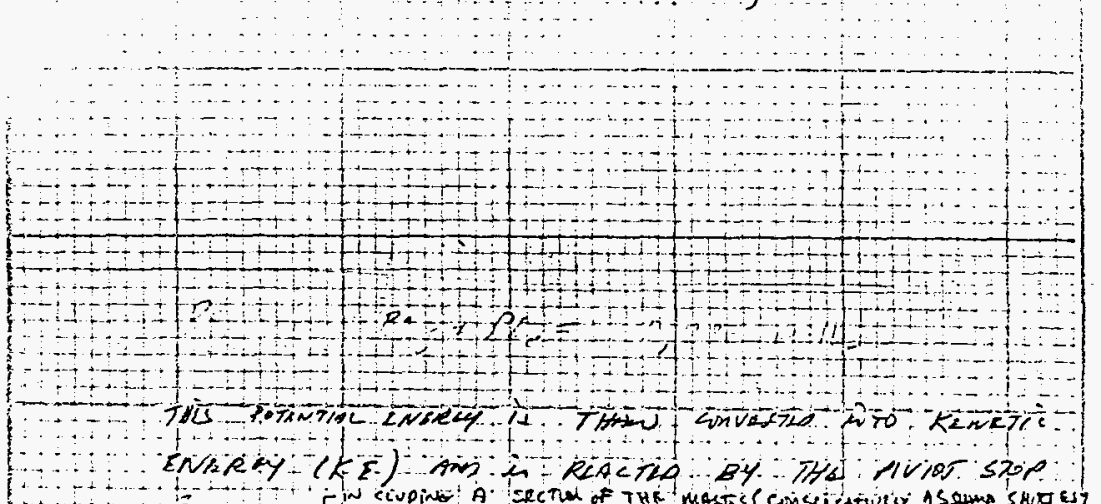
ENAREY (kE) Añ A RLACIAD BY THS PVIOS sTo

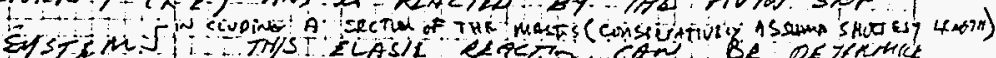

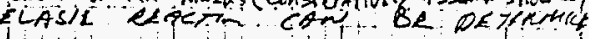
:

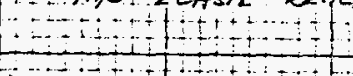 F: : 
WHC-SD-WM-DA-202 REV 0

ANALYTICAL CALCULATIONS

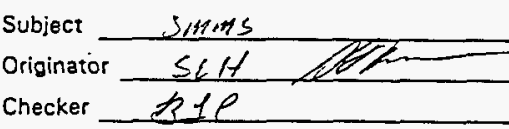

Appendix E

Page $1^{-}$Page 23 of 32

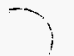

Date $3 / 96$

Date $4-5-96$

THIS IS RESTED BY A COUPLE D. AXML-STOP ON

$$
\begin{aligned}
2 & =\sqrt{3^{2}+925^{2}}=3.14 \\
\therefore F & =m / d=22,800
\end{aligned}
$$

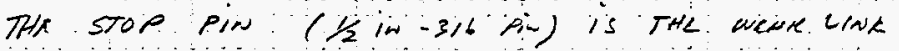

$$
\text { A }
$$

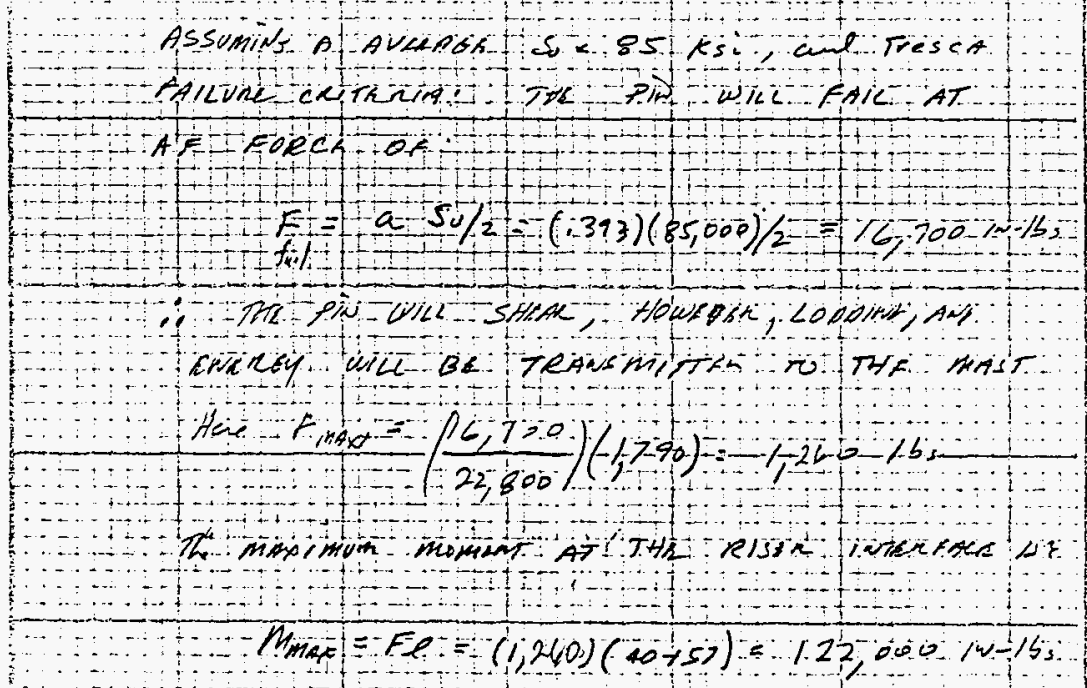

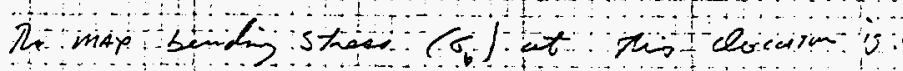

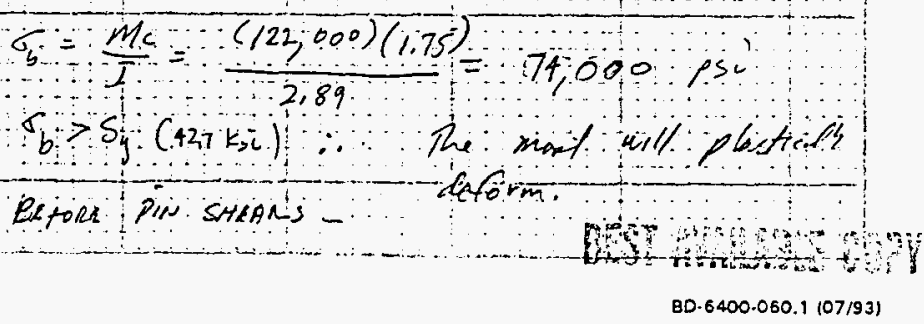


WHC-SD-WM-DA-202 REV 0

Appendix E

ANALYTICAL CALCULATIONS

Page 24 of 32

Page 10 of 25

Subject Sm mS

Originator SCH

Date $3 / 26$

Checker the

Date $4-5-96$

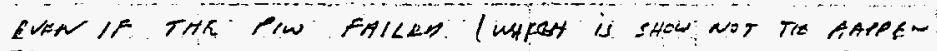

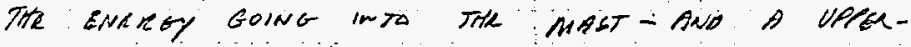

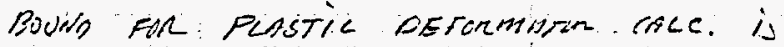

$$
E=\left(\frac{16,700}{22,800}\right)^{2}(-5,600)=3,0001016 \mathrm{~s}
$$

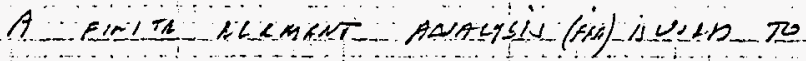

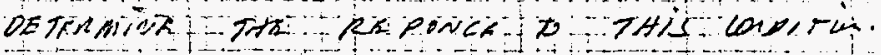

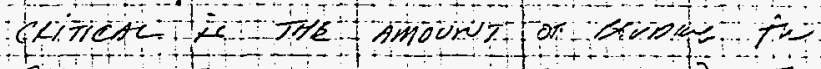

(6)

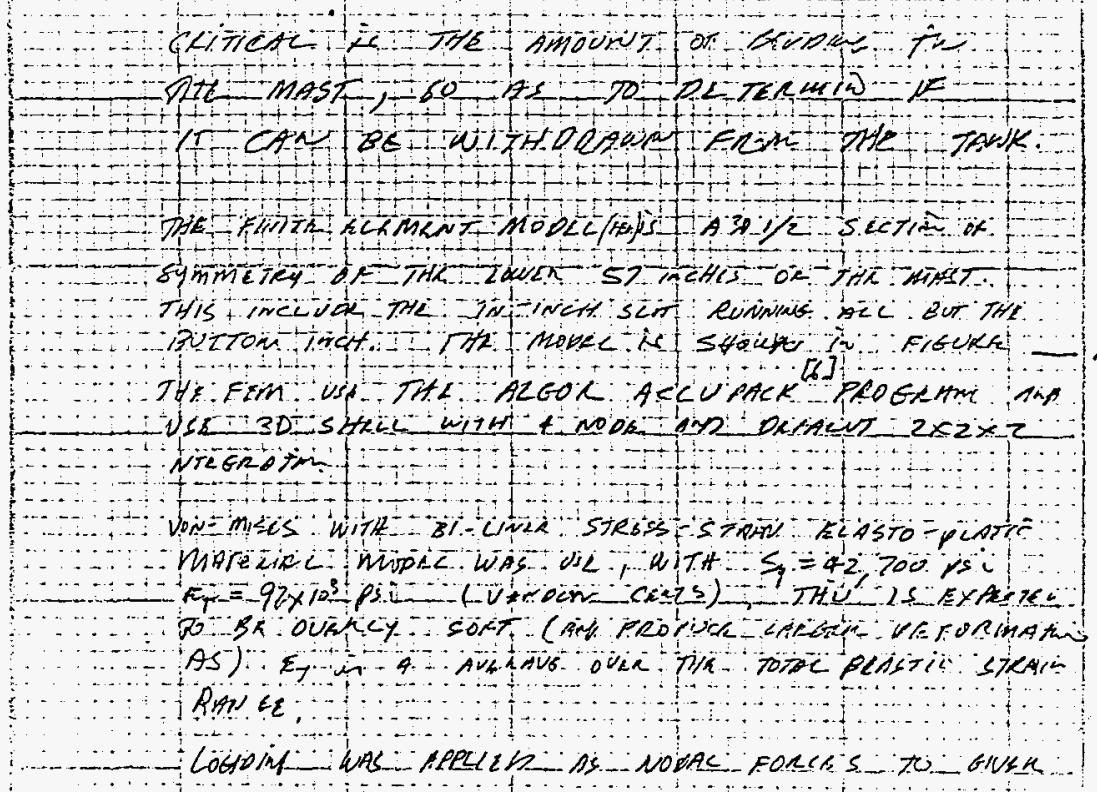

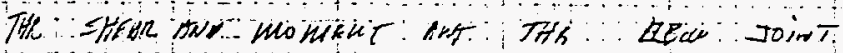

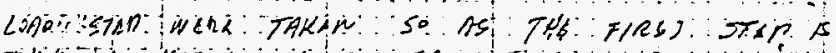

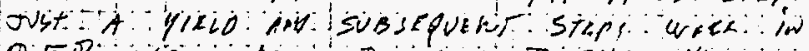

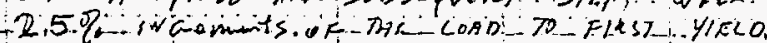

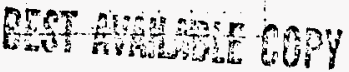

BD. 6400-060.1 107/93) 
WHC-SD-WM-DA-202 REV 0

ANALYTICAL CALCULATIONS

Originator SLH

Checker $z \neq e$

Subject S Mm S

Appendix $E$

Page

Page 25 of 22

Date $3 / 96$

Date $4-5-96$

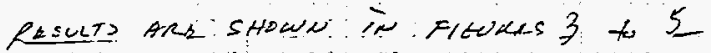

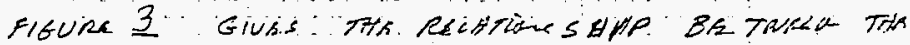

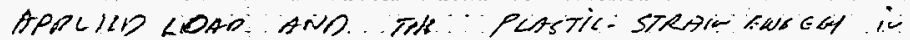

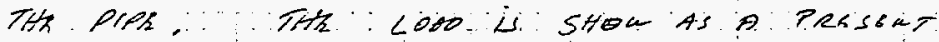

CF THE FULL LOAD CALCULATE ON ? ELASTIC BASIN

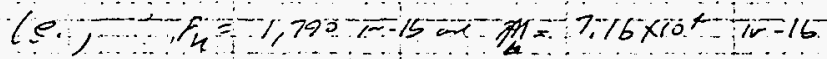

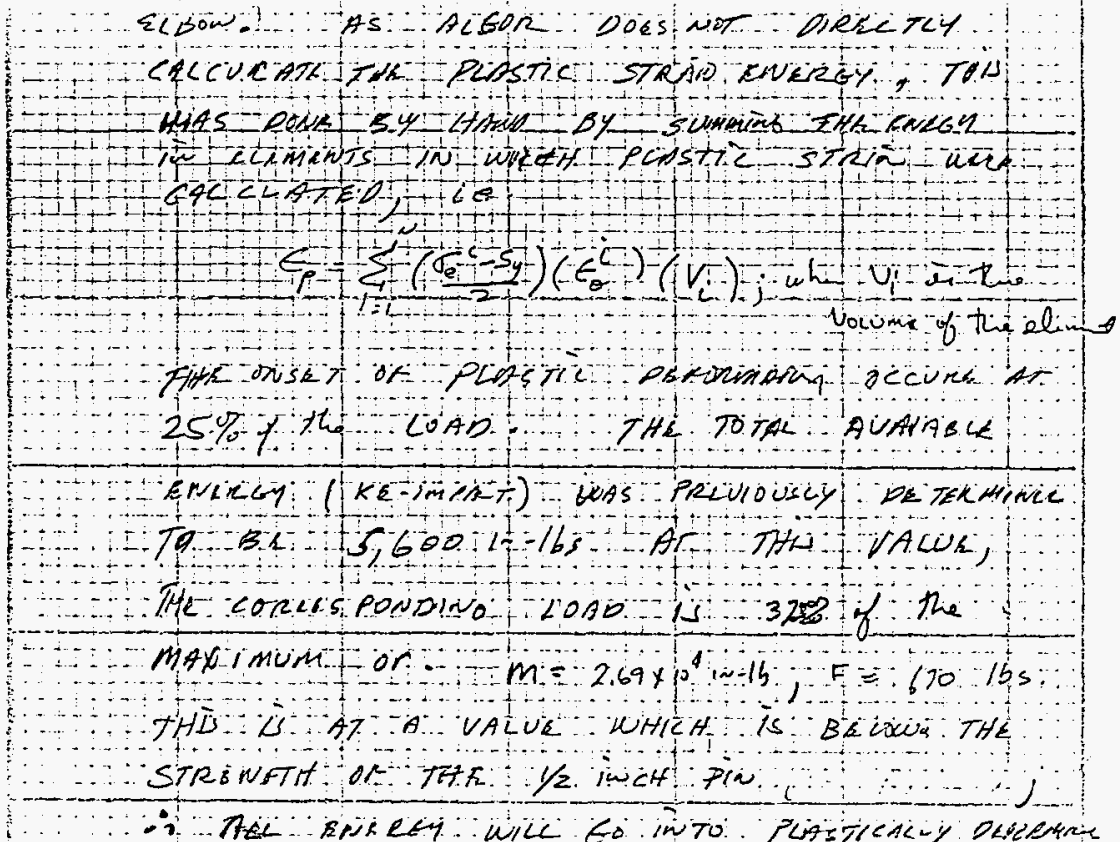

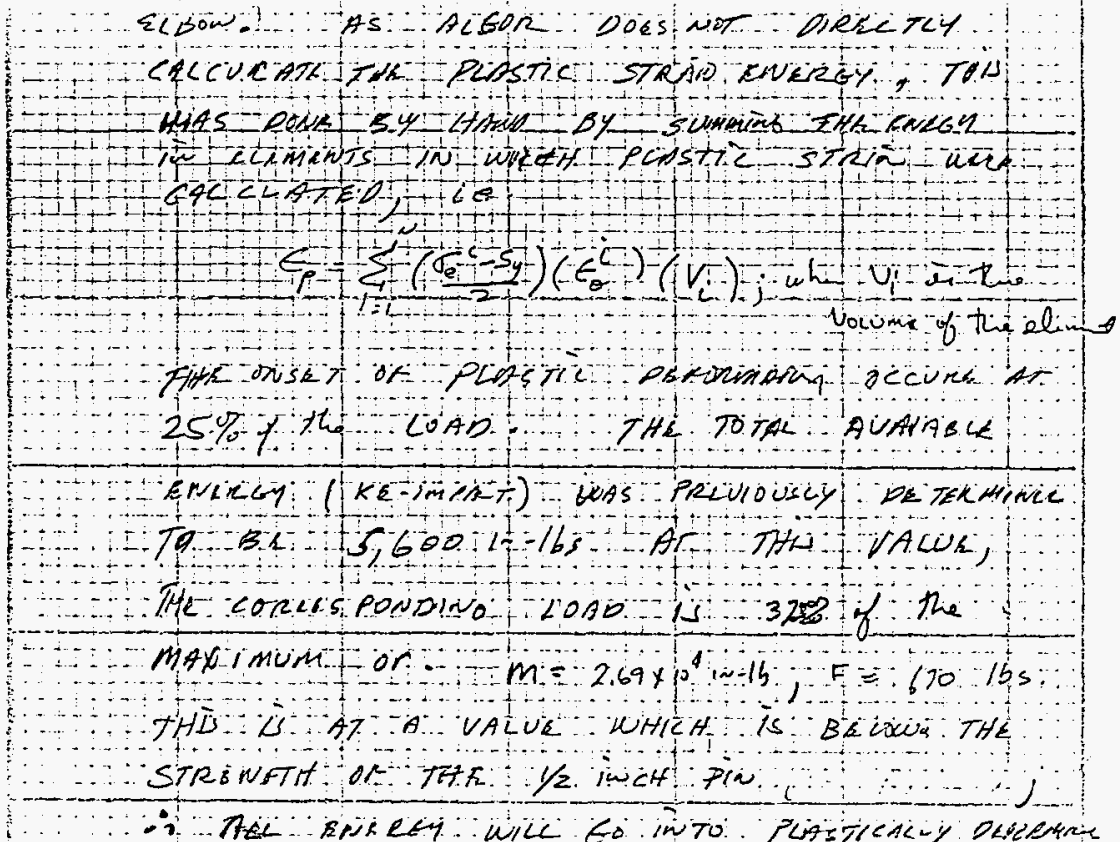

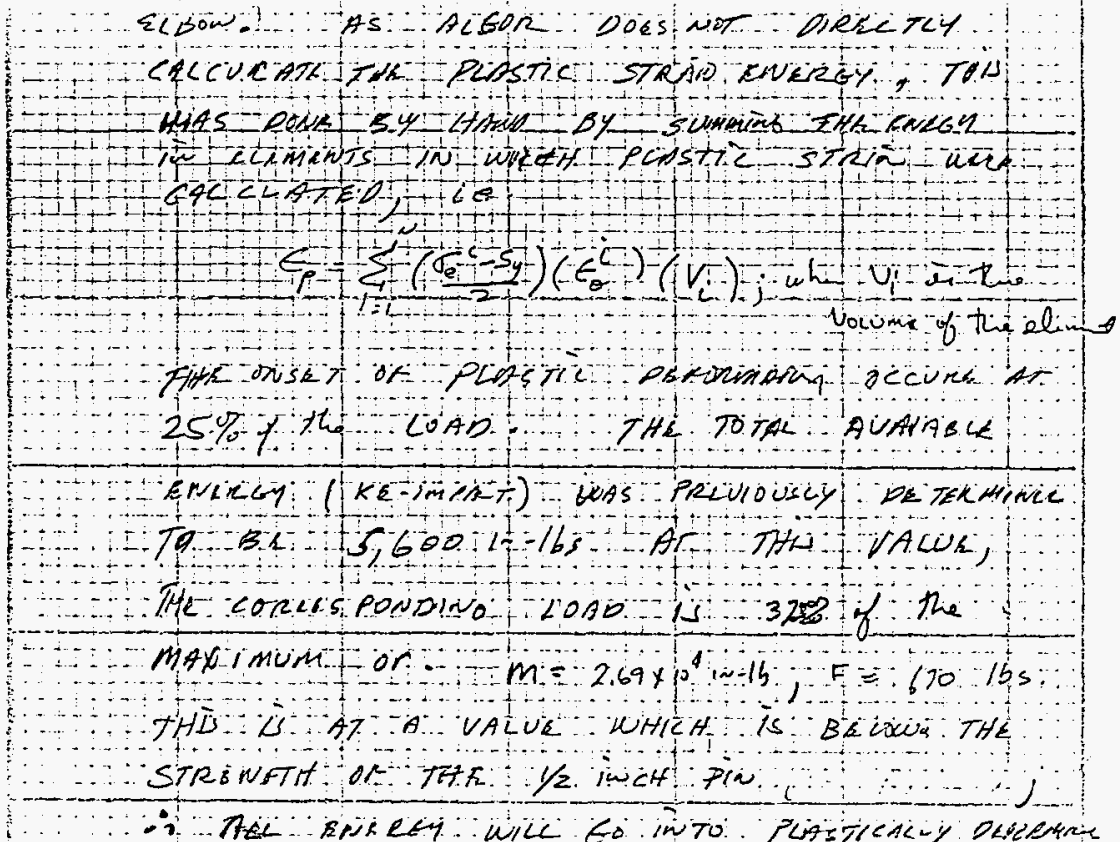

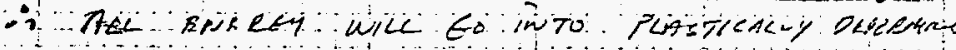

THE MAST

$\checkmark$

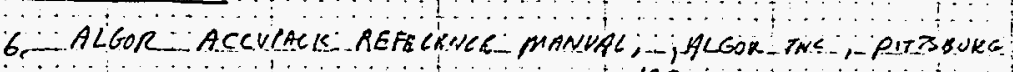

BD .6400.060.1 (07/93) 
WHC-SD-WM-DA-202 REV O

Appendix E

Page $\underline{\underline{L}}$ of $\underline{\underline{2}}$

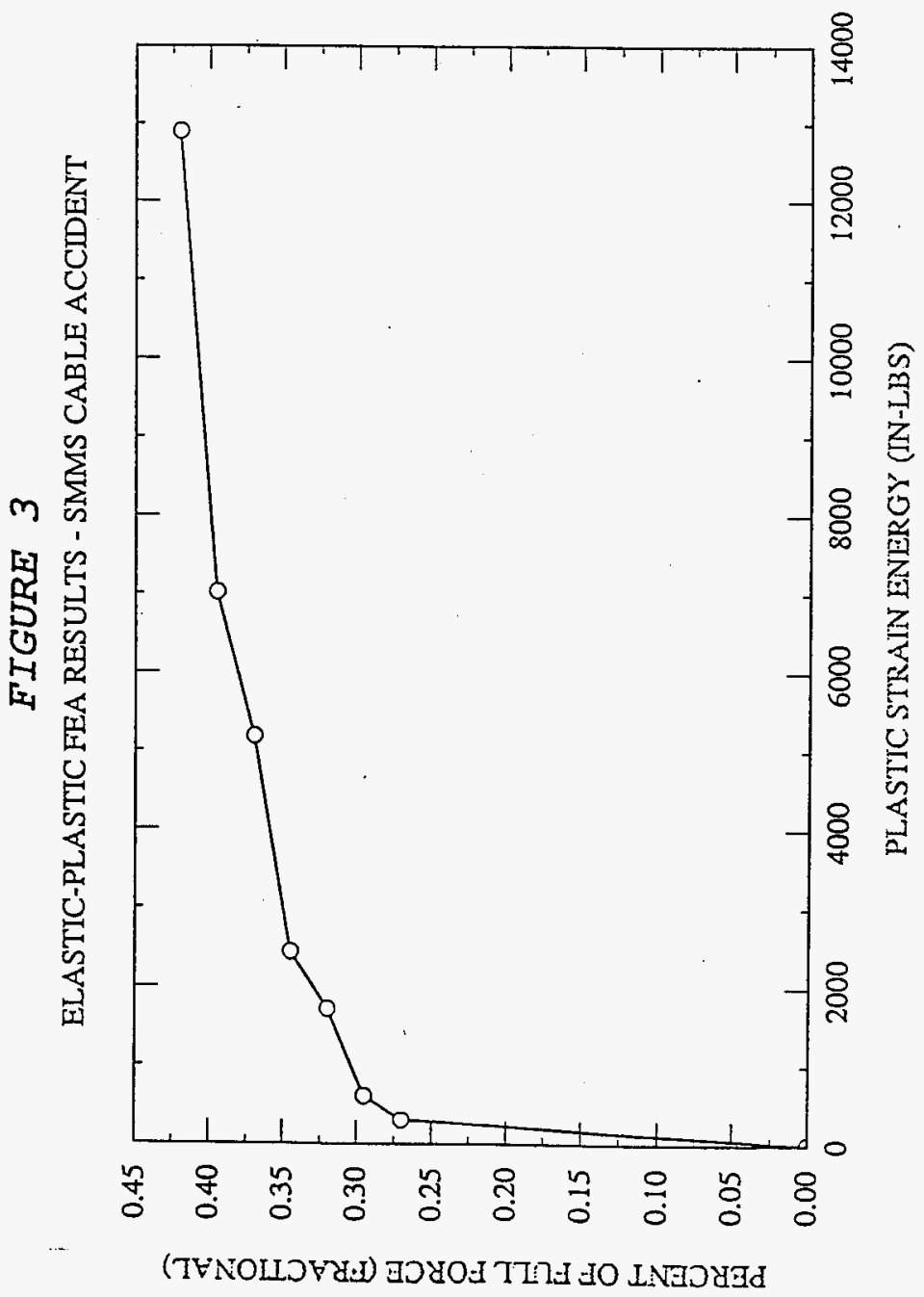




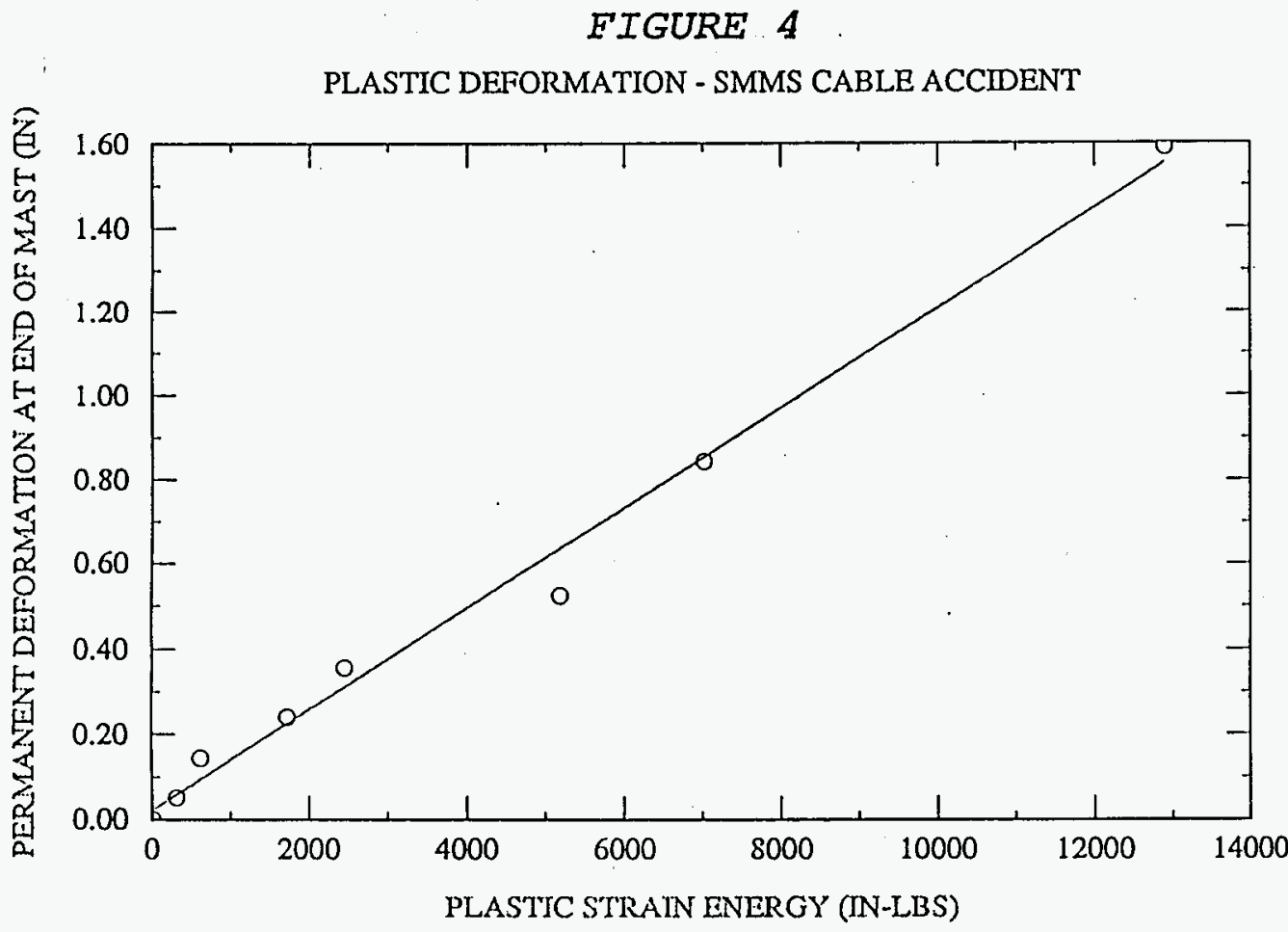




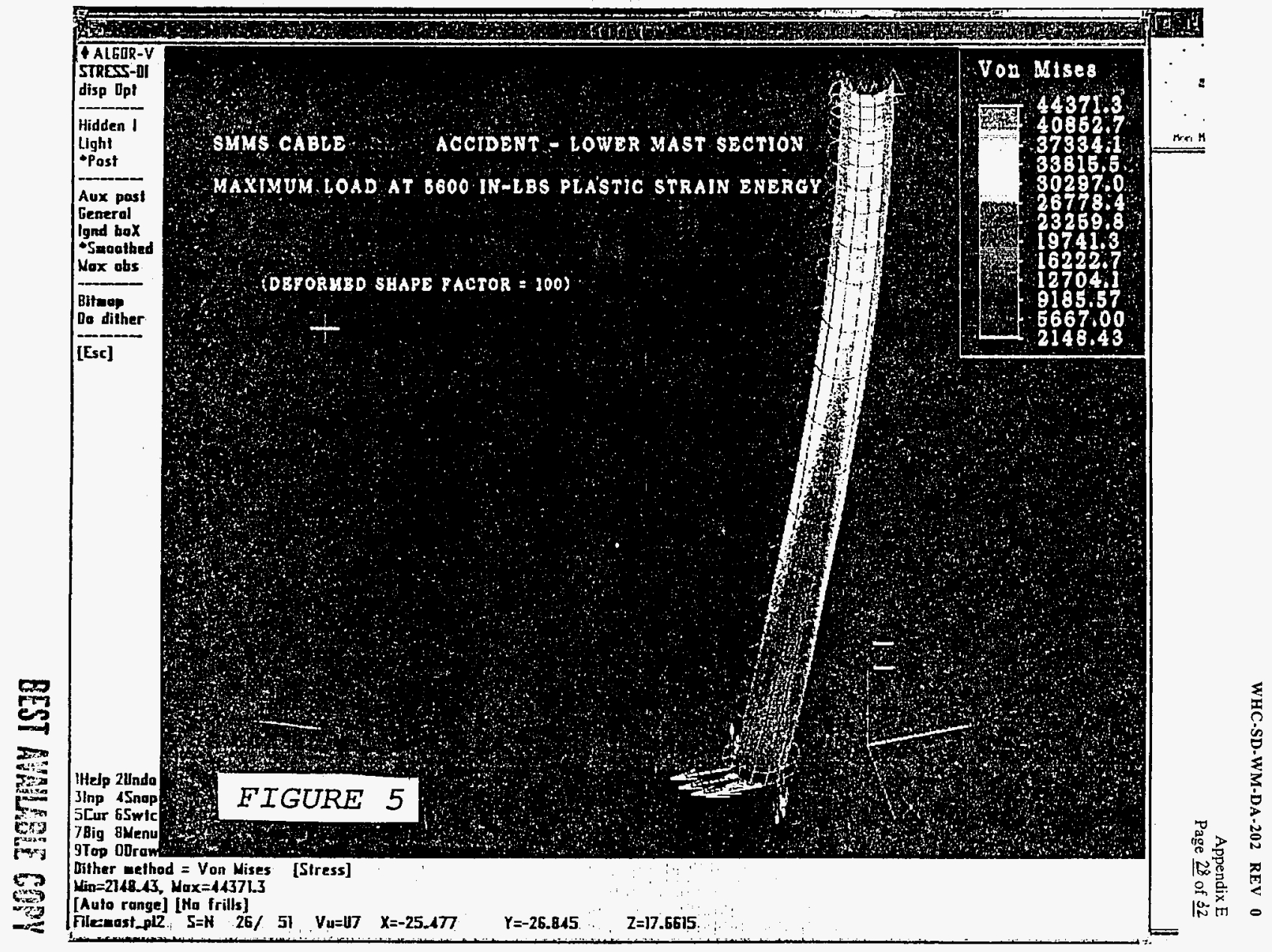


WHC-SD-WM-DA-202 REV 0

ANALYTICAL CALCULATIONS

Appendix $\mathrm{E}$

Page $\%$ Page 29 of 32

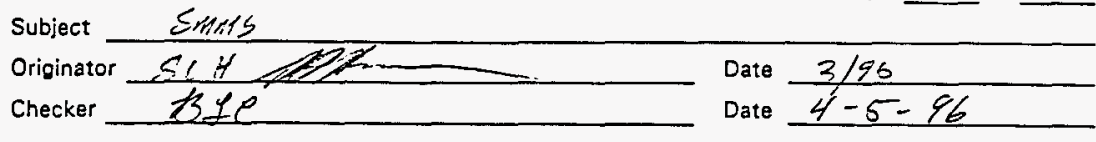

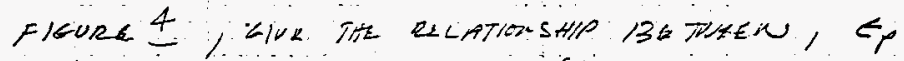

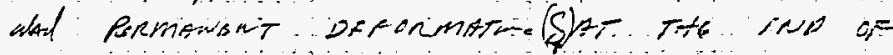
TITR nEST FOC $E_{r}=5600$ TH $d_{p}=0.7$ licks as most of tits PLASTIC

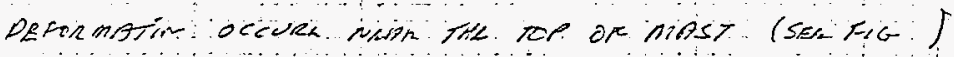

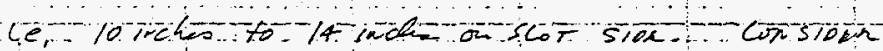

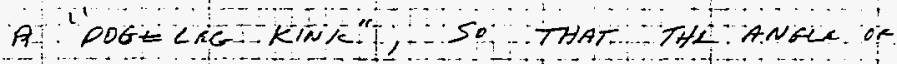

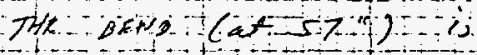

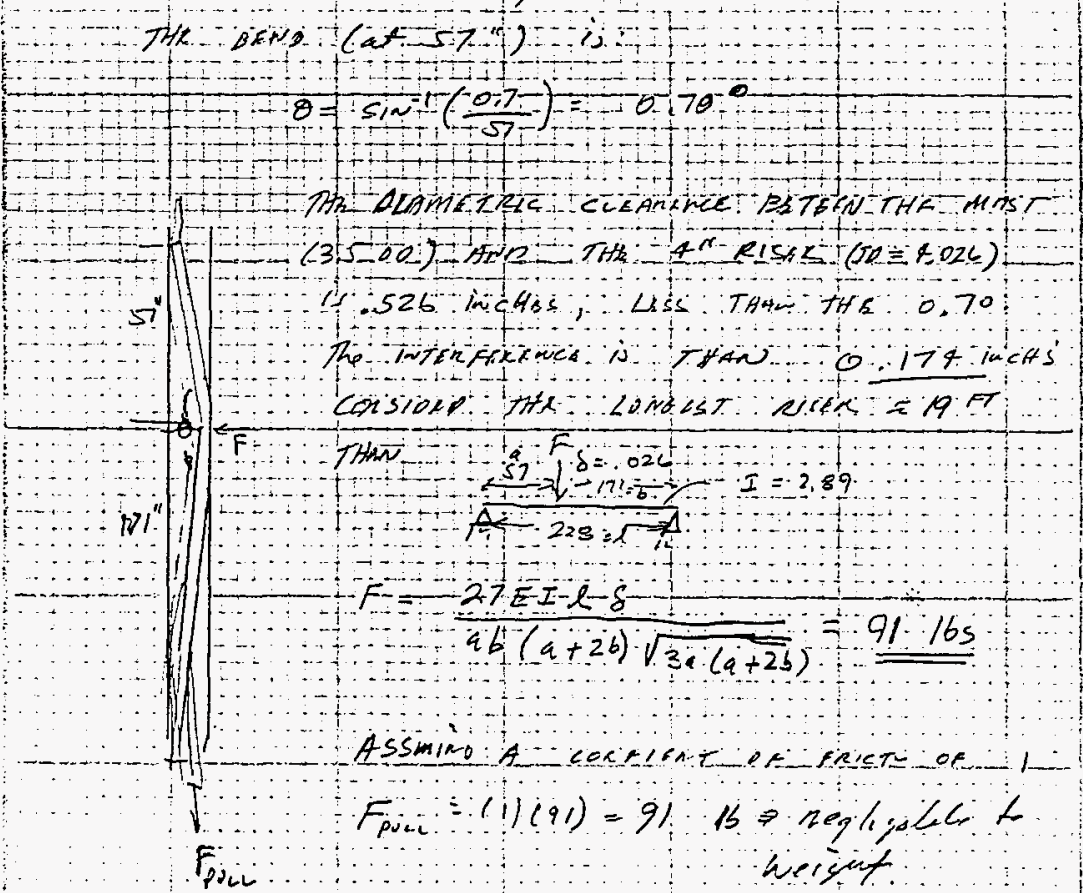

)

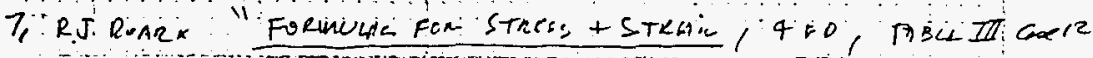

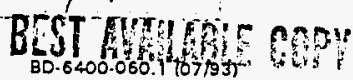


WHC-SD-WM-DA-202 REV O

ANALYTICAL CALCULATIONS

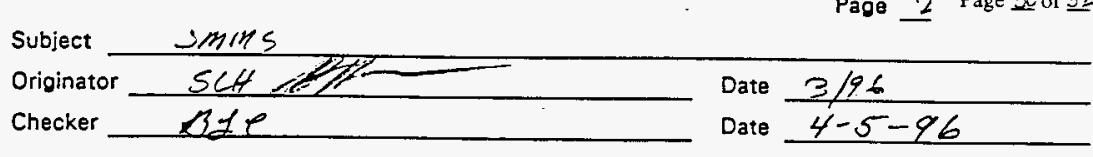

Conston stow Risei $: \quad U=2$ mond coum secti $=(54)(2)=114$ in.

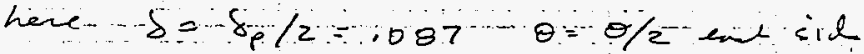

from Retre Thes III Cine 11 .

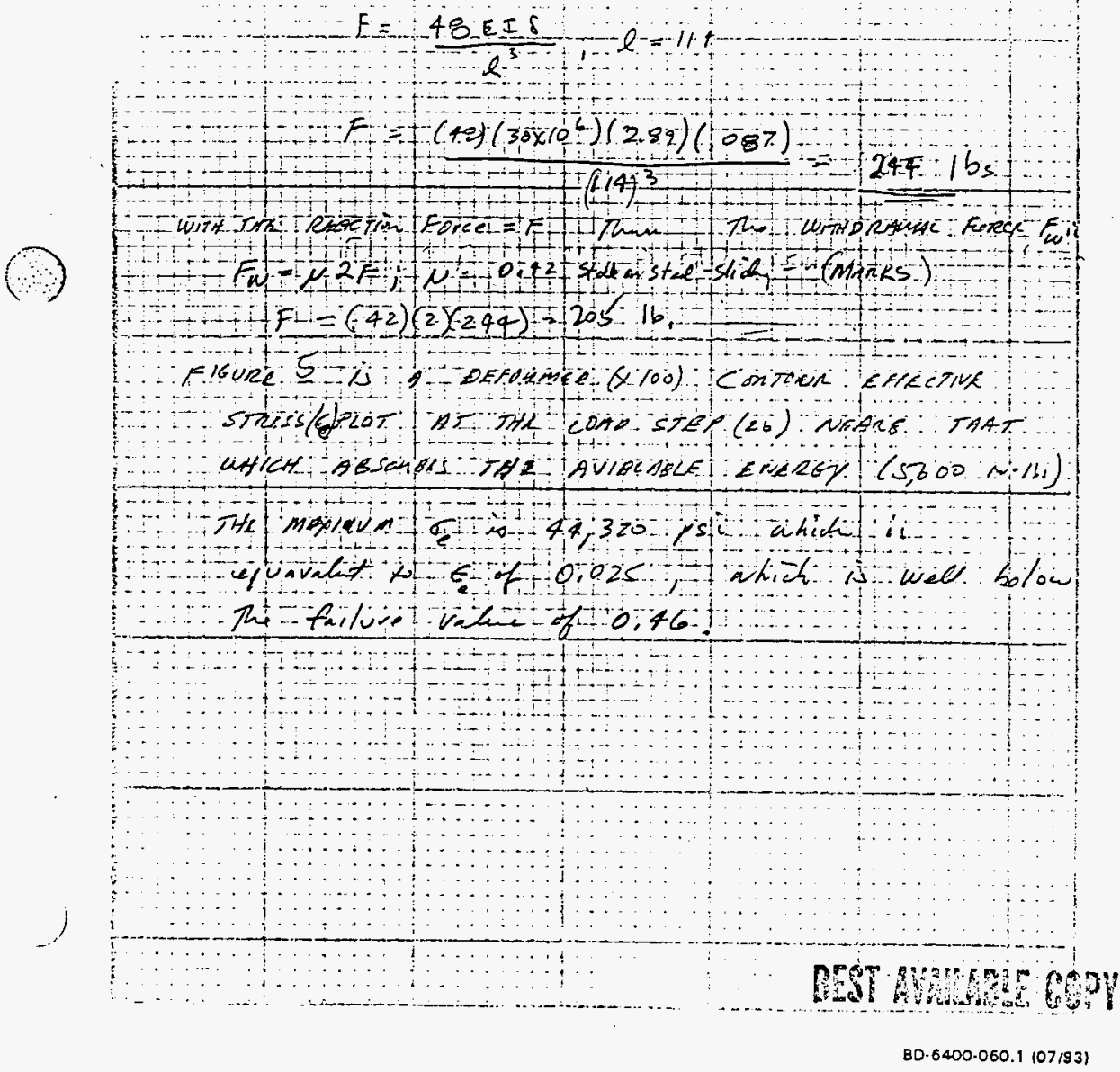


WHC-SD-WM-DA-202 REV O

ANALYTICAL CALCULATIONS

Appendix $\mathrm{E}$

Page 25 Page 31 of 32

Subject ISms - Acerosint

Originator SL HAEHT

Date $3 / 96$

Checker

site

Date $4-5-96$

Accident

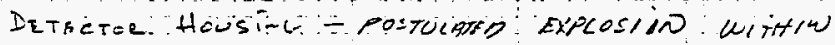

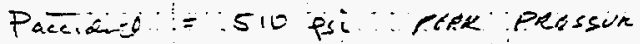

thin section of cyl now

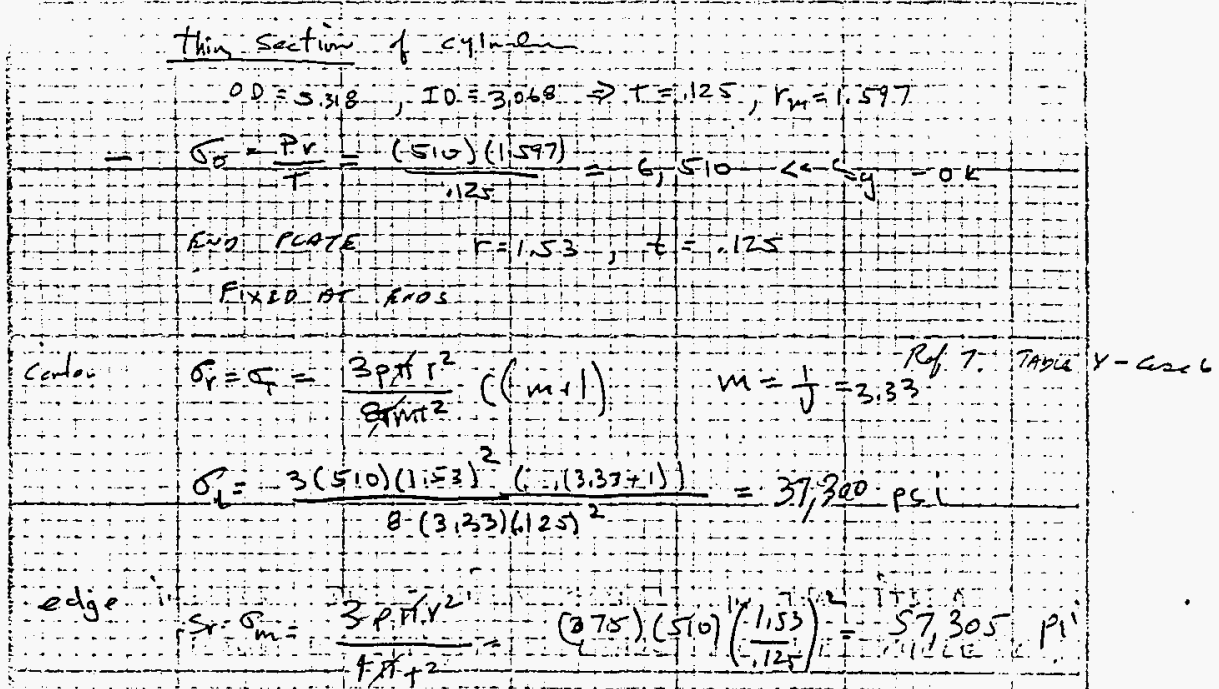

()

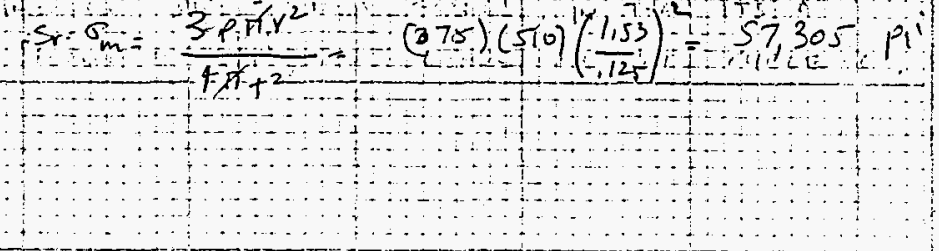

BEST AMMISTE GOV

B0.6400-060.1 (07/93) 


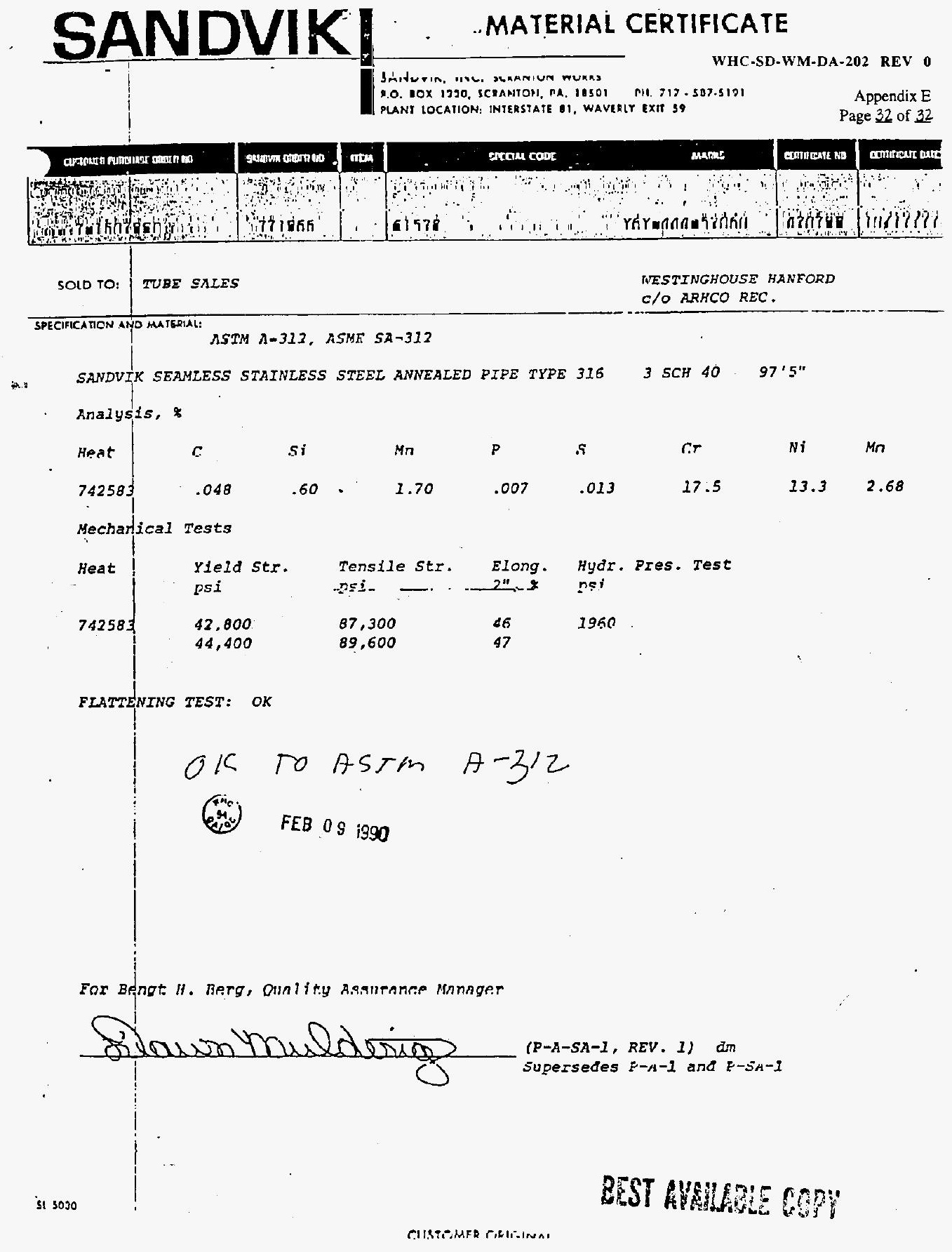

